Supporting Information

\title{
The Synthetic Utility of Tetrabutylammonium Salts in Uranium Metallocene Chemistry
}

Christopher L. Webster, Ryan R. Langeslay, Joseph W. Ziller, and William J. Evans*

Department of Chemistry, University of California, Irvine, California 92697-2025

Email: wevans@uci.edu 


\section{Table of Contents}

Page S3 - Figure S1. NMR spectra of 3.

Page S4 - Figure S2. NMR spectra of 4.

Pages S5-S15 - X-ray Data Collection, Structure Solution and Refinement for 1.

Pages S15-S23 - X-ray Data Collection, Structure Solution and Refinement for 2.

Pages S24-S32 - X-ray Data Collection, Structure Solution and Refinement for 3.

Pages S32-S40 - X-ray Data Collection, Structure Solution and Refinement for 5.

Pages S40-S53 - X-ray Data Collection, Structure Solution and Refinement for 8.

Pages S53-S59 - X-ray Data Collection, Structure Solution and Refinement for 9.

Page 60 - References 


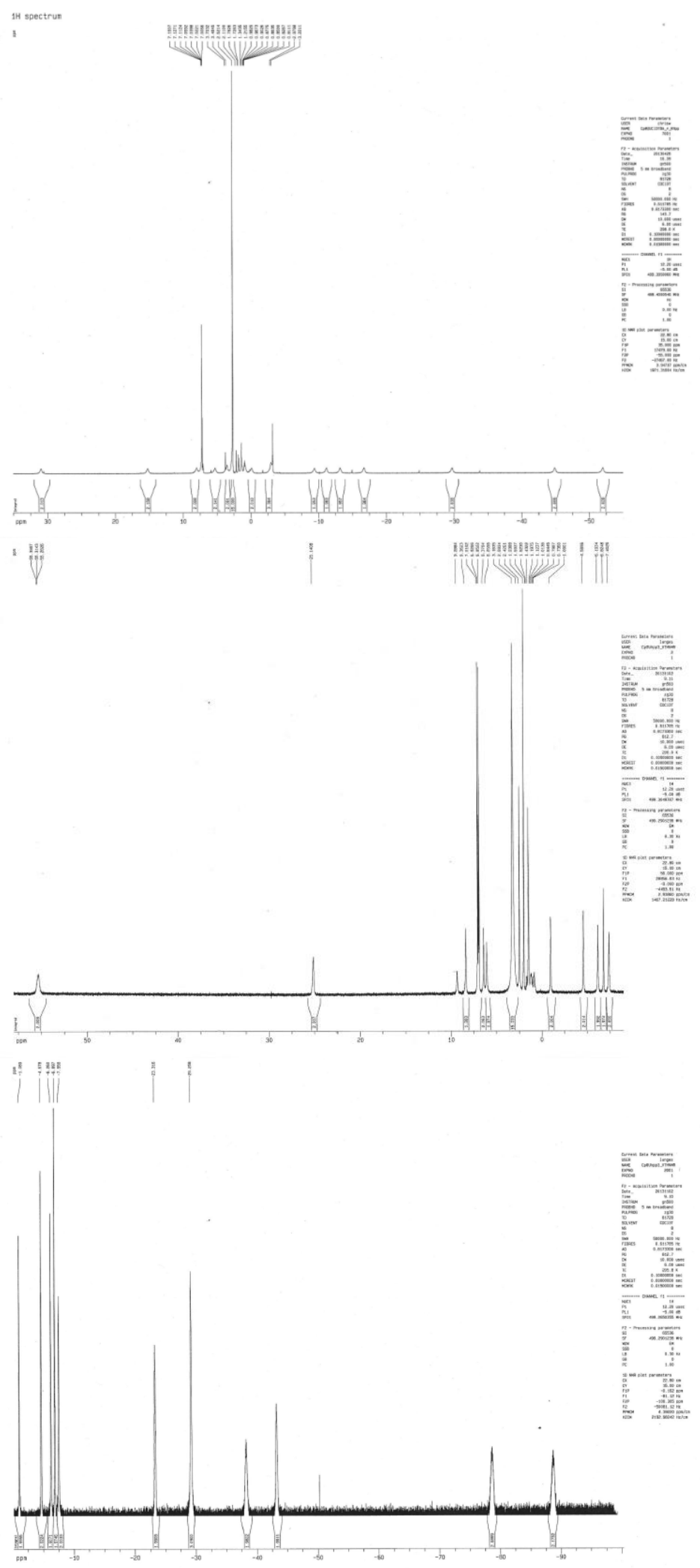

Figure S1. NMR spectra of 3 at room temperature (top) and at $206 \mathrm{~K}$ (middle and bottom, showing two field ranges). 


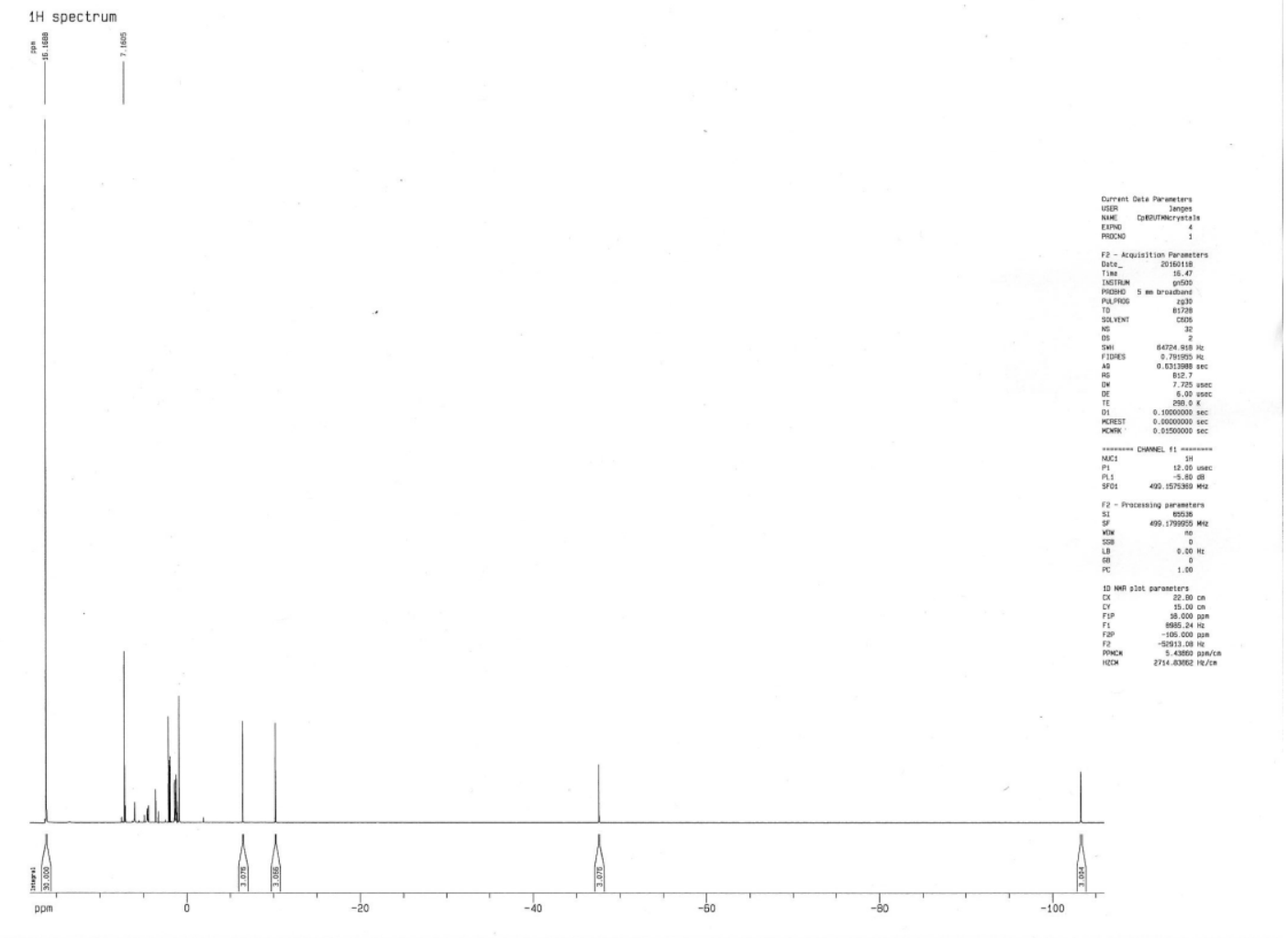

Figure S2. NMR spectra of 4 . 


\section{X-ray Data Collection, Structure Solution and Refinement for 1.}

An orange crystal of approximate dimensions $0.074 \times 0.111 \times 0.310 \mathrm{~mm}$ was mounted on a glass fiber and transferred to a Bruker SMART APEX II diffractometer. The APEX2 ${ }^{1}$ program package was used to determine the unit-cell parameters and for data collection (20 sec/frame scan time for a sphere of diffraction data). The raw frame data was processed using $\mathrm{SAINT}^{2}$ and $\mathrm{SADABS}^{3}$ to yield the reflection data file. Subsequent calculations were carried out using the SHELXTL ${ }^{4}$ program. There were no systematic absences nor any diffraction symmetry other than the Friedel condition. The centrosymmetric triclinic space group $P \overline{1}$ was assigned and later determined to be correct.

The structure was solved by direct methods and refined on $\mathrm{F}^{2}$ by full-matrix least-squares techniques ${ }^{5}$. The analytical scattering factors ${ }^{6}$ for neutral atoms were used throughout the analysis. Hydrogen atoms were included using a riding model. There was one-half molecule of toluene solvent present per formula-unit. The toluene was located about an inversion center resulting in disorder of the methyl group.

At convergence, $w R 2=0.0486$ and Goof $=1.048$ for 448 variables refined against 9915 data $(0.74 \AA), \mathrm{R} 1=0.0202$ for those 9183 data with $\mathrm{I}>2.0 \sigma(\mathrm{I})$.

\section{Definitions:}

$$
\begin{aligned}
& \mathrm{wR} 2=\left[\Sigma\left[\mathrm{w}\left(\mathrm{F}_{\mathrm{o}}^{2}-\mathrm{F}_{\mathrm{c}}{ }^{2}\right)^{2}\right] / \Sigma\left[\mathrm{w}\left(\mathrm{F}_{\mathrm{o}}^{2}\right)^{2}\right]\right]^{1 / 2} \\
& \mathrm{R} 1=\Sigma|| \mathrm{F}_{\mathrm{o}}|-| \mathrm{F}_{\mathrm{c}} \| / \Sigma\left|\mathrm{F}_{\mathrm{o}}\right|
\end{aligned}
$$

Goof $=\mathrm{S}=\left[\Sigma\left[\mathrm{w}\left(\mathrm{F}_{\mathrm{o}}{ }^{2}-\mathrm{F}_{\mathrm{c}}{ }^{2}\right)^{2}\right] /(\mathrm{n}-\mathrm{p})\right]^{1 / 2}$ where $\mathrm{n}$ is the number of reflections and $\mathrm{p}$ is the total number of parameters refined. 


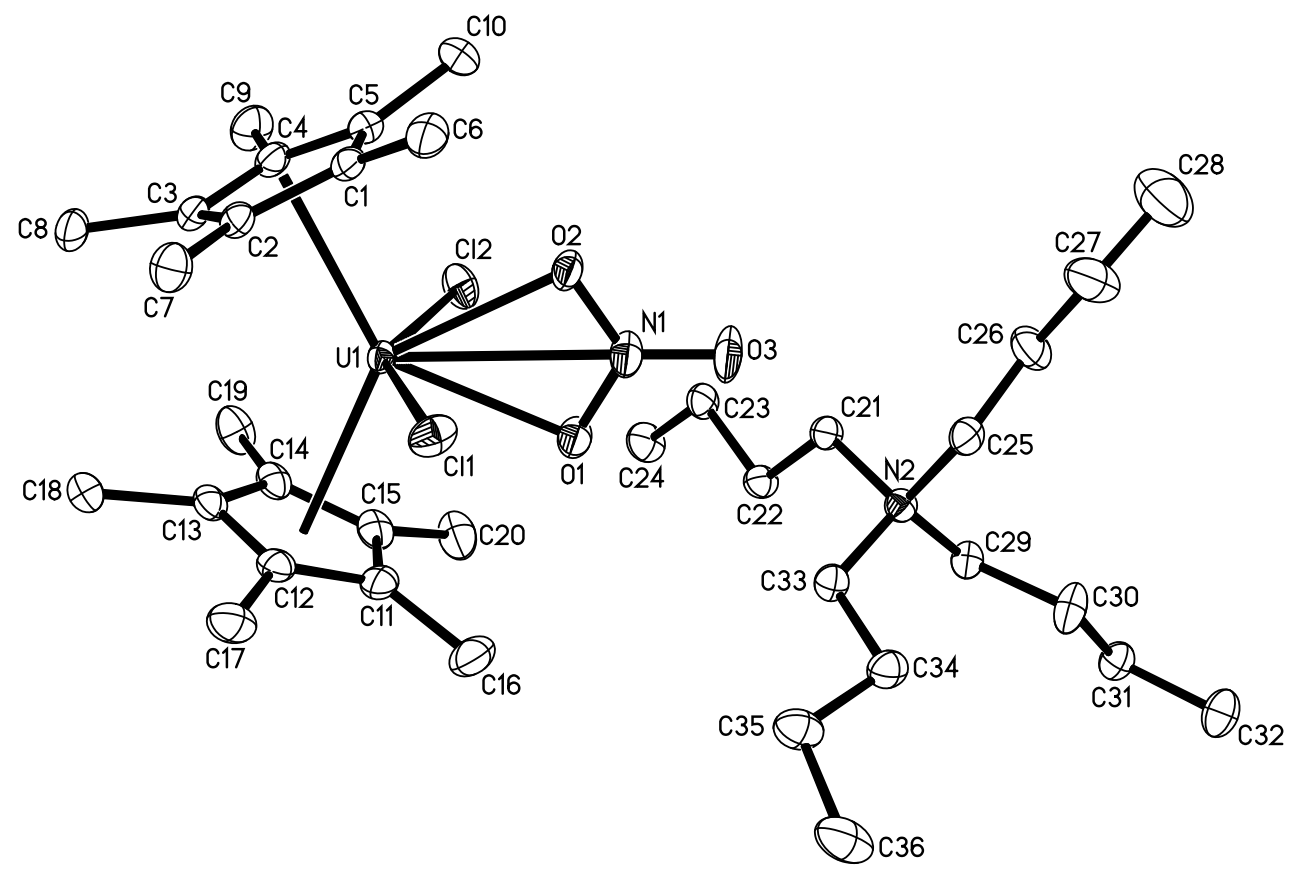

Figure S3. Thermal ellipsoid plot of $\left[\mathrm{NBu}_{4}\right]\left[\left(\mathrm{C}_{5} \mathrm{Me}_{5}\right)_{2} \mathrm{UCl}_{2}\left(\mathrm{NO}_{3}\right)\right], \mathbf{1}$, shown at the $50 \%$ probability level with hydrogen atoms removed for clarity.

Table S1. Crystal data and structure refinement for $\mathbf{1 .}$

Identification code

Empirical formula

Formula weight

Temperature

Wavelength

Crystal system

Space group

Unit cell dimensions

Volume clw8 (Chris Webster)

$\mathrm{C}_{36} \mathrm{H}_{66} \mathrm{Cl}_{2} \mathrm{~N}_{2} \mathrm{O}_{3} \mathrm{U} \cdot 1 / 2\left(\mathrm{C}_{7} \mathrm{H}_{8}\right)$

929.90

$88(2) \mathrm{K}$

$0.71073 \AA$

Triclinic

$P \overline{1}$

$\mathrm{a}=11.2214(5) \AA \quad \alpha=77.9253(5)^{\circ}$.

$\mathrm{b}=11.7908(5) \AA \quad \beta=88.4904(5)^{\circ}$.

$\mathrm{c}=17.7903(8) \AA \quad \gamma=65.5842(5)^{\circ}$.

2091.12(16) $\AA^{3}$ 
Z

Density (calculated)

Absorption coefficient

$\mathrm{F}(000)$

Crystal color

Crystal size

Theta range for data collection

Index ranges

Reflections collected

Independent reflections

Completeness to theta $=25.500^{\circ}$

Absorption correction

Max. and min. transmission

Refinement method

Data / restraints / parameters

Goodness-of-fit on $\mathrm{F}^{2}$
2

$1.477 \mathrm{Mg} / \mathrm{m}^{3}$

$4.045 \mathrm{~mm}^{-1}$

942

orange

$0.310 \times 0.111 \times 0.074 \mathrm{~mm}^{3}$

1.943 to $28.722^{\circ}$

$-15 \leq h \leq 15,-15 \leq k \leq 15,-23 \leq l \leq 23$

24838

$9915[\mathrm{R}($ int $)=0.0201]$

$99.7 \%$

Numerical

0.8126 and 0.4514

Full-matrix least-squares on $\mathrm{F}^{2}$

9915 / 0 / 448

1.048

Final $\mathrm{R}$ indices $[\mathrm{I}>2 \operatorname{sigma}(\mathrm{I})=9183$ data $]$

$\mathrm{R}$ indices (all data, $0.74 \AA$ )

$\mathrm{R} 1=0.0202, \mathrm{wR} 2=0.0474$

$\mathrm{R} 1=0.0237, \mathrm{wR} 2=0.0486$

Largest diff. peak and hole

1.584 and -1.165 e. $\AA^{-3}$

Table S2. Bond lengths $[\AA]$ and angles $\left[{ }^{\circ}\right]$ for $\mathbf{1}$.

\begin{tabular}{ll}
\hline $\mathrm{U}(1)-\mathrm{Cnt} 1$ & 2.503 \\
$\mathrm{U}(1)-\mathrm{Cnt} 2$ & 2.510 \\
$\mathrm{U}(1)-\mathrm{O}(2)$ & $2.5096(16)$ \\
$\mathrm{U}(1)-\mathrm{O}(1)$ & $2.5399(16)$ \\
$\mathrm{U}(1)-\mathrm{Cl}(1)$ & $2.6993(6)$ \\
$\mathrm{U}(1)-\mathrm{Cl}(2)$ & $2.6996(6)$ \\
$\mathrm{U}(1)-\mathrm{C}(1)$ & $2.752(2)$ \\
$\mathrm{U}(1)-\mathrm{C}(15)$ & $2.754(2)$ \\
$\mathrm{U}(1)-\mathrm{C}(5)$ & $2.762(2)$ \\
$\mathrm{U}(1)-\mathrm{C}(14)$ & $2.775(2)$
\end{tabular}




\begin{tabular}{|c|c|}
\hline $\mathrm{U}(1)-\mathrm{C}(11)$ & $2.777(2)$ \\
\hline $\mathrm{U}(1)-\mathrm{C}(2)$ & $2.779(2)$ \\
\hline $\mathrm{U}(1)-\mathrm{C}(4)$ & $2.783(2)$ \\
\hline $\mathrm{U}(1)-\mathrm{C}(12)$ & $2.801(2)$ \\
\hline $\mathrm{U}(1)-\mathrm{C}(3)$ & $2.815(2)$ \\
\hline $\mathrm{U}(1)-\mathrm{C}(13)$ & $2.817(2)$ \\
\hline $\mathrm{U}(1)-\mathrm{N}(1)$ & $2.951(2)$ \\
\hline $\mathrm{O}(1)-\mathrm{N}(1)$ & $1.277(3)$ \\
\hline $\mathrm{O}(2)-\mathrm{N}(1)$ & $1.265(3)$ \\
\hline $\mathrm{O}(3)-\mathrm{N}(1)$ & $1.226(3)$ \\
\hline $\mathrm{C}(1)-\mathrm{C}(5)$ & $1.419(3)$ \\
\hline $\mathrm{C}(1)-\mathrm{C}(2)$ & $1.423(3)$ \\
\hline$C(1)-C(6)$ & $1.501(3)$ \\
\hline $\mathrm{C}(2)-\mathrm{C}(3)$ & $1.417(3)$ \\
\hline $\mathrm{C}(2)-\mathrm{C}(7)$ & $1.505(3)$ \\
\hline C(3)-C(4) & $1.412(3)$ \\
\hline $\mathrm{C}(3)-\mathrm{C}(8)$ & $1.511(3)$ \\
\hline $\mathrm{C}(4)-\mathrm{C}(5)$ & $1.416(3)$ \\
\hline $\mathrm{C}(4)-\mathrm{C}(9)$ & $1.506(3)$ \\
\hline $\mathrm{C}(5)-\mathrm{C}(10)$ & $1.504(3)$ \\
\hline $\mathrm{C}(11)-\mathrm{C}(12)$ & $1.409(3)$ \\
\hline $\mathrm{C}(11)-\mathrm{C}(15)$ & $1.416(4)$ \\
\hline$C(11)-C(16)$ & $1.509(3)$ \\
\hline $\mathrm{C}(12)-\mathrm{C}(13)$ & $1.417(3)$ \\
\hline $\mathrm{C}(12)-\mathrm{C}(17)$ & $1.505(3)$ \\
\hline $\mathrm{C}(13)-\mathrm{C}(14)$ & $1.421(3)$ \\
\hline $\mathrm{C}(13)-\mathrm{C}(18)$ & $1.501(3)$ \\
\hline $\mathrm{C}(14)-\mathrm{C}(15)$ & $1.425(3)$ \\
\hline $\mathrm{C}(14)-\mathrm{C}(19)$ & $1.508(3)$ \\
\hline$C(15)-C(20)$ & $1.508(3)$ \\
\hline $\mathrm{N}(2)-\mathrm{C}(29)$ & $1.519(3)$ \\
\hline $\mathrm{N}(2)-\mathrm{C}(25)$ & $1.528(3)$ \\
\hline $\mathrm{N}(2)-\mathrm{C}(33)$ & $1.528(3)$ \\
\hline $\mathrm{N}(2)-\mathrm{C}(21)$ & $1.532(3)$ \\
\hline$C(21)-C(22)$ & $1.524(3)$ \\
\hline $\mathrm{C}(22)-\mathrm{C}(23)$ & $1.523(3)$ \\
\hline
\end{tabular}




\begin{tabular}{|c|c|}
\hline$C(23)-C(24)$ & $1.524(3)$ \\
\hline$C(25)-C(26)$ & $1.518(4)$ \\
\hline$C(26)-C(27)$ & $1.542(4)$ \\
\hline $\mathrm{C}(27)-\mathrm{C}(28)$ & $1.469(5)$ \\
\hline $\mathrm{C}(29)-\mathrm{C}(30)$ & $1.516(3)$ \\
\hline$C(30)-C(31)$ & $1.516(3)$ \\
\hline$C(31)-C(32)$ & $1.516(3)$ \\
\hline $\mathrm{C}(33)-\mathrm{C}(34)$ & $1.517(3)$ \\
\hline$C(34)-C(35)$ & $1.525(4)$ \\
\hline$C(35)-C(36)$ & $1.526(4)$ \\
\hline $\mathrm{C}(37)-\mathrm{C}(38)$ & $1.379(5)$ \\
\hline $\mathrm{C}(37)-\mathrm{C}(39) \# 1$ & $1.391(4)$ \\
\hline $\mathrm{C}(38)-\mathrm{C}(39)$ & $1.385(5)$ \\
\hline $\mathrm{C}(39)-\mathrm{C}(37) \# 1$ & $1.391(4)$ \\
\hline$C(39)-C(40)$ & $1.470(8)$ \\
\hline Cnt1-U(1)-O(1) & 139.9 \\
\hline Cnt1-U(1)-O(2) & 89.3 \\
\hline Cnt1-U(1)-N(1) & 114.5 \\
\hline Cnt1-U(1)-Cl(1) & 97.9 \\
\hline Cnt1-U(1)-Cl(2) & 96.3 \\
\hline Cnt2-U(1)-O(1) & 90.1 \\
\hline Cnt2-U(1)-O(2) & 140.7 \\
\hline Cnt2-U(1)-N(1) & 115.5 \\
\hline Cnt2-U(1)-Cl(1) & 96.7 \\
\hline Cnt2-U(1)-Cl(2) & 97.8 \\
\hline Cnt1-U(1)-Cnt2 & 130.0 \\
\hline $\mathrm{O}(2)-\mathrm{U}(1)-\mathrm{O}(1)$ & $50.64(5)$ \\
\hline $\mathrm{O}(2)-\mathrm{U}(1)-\mathrm{Cl}(1)$ & 73.97(4) \\
\hline $\mathrm{O}(1)-\mathrm{U}(1)-\mathrm{Cl}(1)$ & $74.69(4)$ \\
\hline $\mathrm{O}(2)-\mathrm{U}(1)-\mathrm{Cl}(2)$ & $75.17(4)$ \\
\hline $\mathrm{O}(1)-\mathrm{U}(1)-\mathrm{Cl}(2)$ & $74.35(4)$ \\
\hline $\mathrm{Cl}(1)-\mathrm{U}(1)-\mathrm{Cl}(2)$ & $145.716(19)$ \\
\hline $\mathrm{O}(2)-\mathrm{U}(1)-\mathrm{C}(1)$ & $69.34(6)$ \\
\hline $\mathrm{O}(1)-\mathrm{U}(1)-\mathrm{C}(1)$ & $118.25(6)$ \\
\hline $\mathrm{Cl}(1)-\mathrm{U}(1)-\mathrm{C}(1)$ & $76.55(5)$ \\
\hline
\end{tabular}




\begin{tabular}{|c|c|}
\hline $\mathrm{Cl}(2)-\mathrm{U}(1)-\mathrm{C}(1)$ & $105.92(5)$ \\
\hline $\mathrm{O}(2)-\mathrm{U}(1)-\mathrm{C}(15)$ & $120.07(6)$ \\
\hline $\mathrm{O}(1)-\mathrm{U}(1)-\mathrm{C}(15)$ & $71.57(6)$ \\
\hline $\mathrm{Cl}(1)-\mathrm{U}(1)-\mathrm{C}(15)$ & 107.97(6) \\
\hline $\mathrm{Cl}(2)-\mathrm{U}(1)-\mathrm{C}(15)$ & $75.48(5)$ \\
\hline $\mathrm{C}(1)-\mathrm{U}(1)-\mathrm{C}(15)$ & $170.17(7)$ \\
\hline $\mathrm{O}(2)-\mathrm{U}(1)-\mathrm{C}(5)$ & $67.94(6)$ \\
\hline $\mathrm{O}(1)-\mathrm{U}(1)-\mathrm{C}(5)$ & $116.67(6)$ \\
\hline $\mathrm{Cl}(1)-\mathrm{U}(1)-\mathrm{C}(5)$ & $104.48(5)$ \\
\hline $\mathrm{Cl}(2)-\mathrm{U}(1)-\mathrm{C}(5)$ & $77.00(5)$ \\
\hline$C(1)-U(1)-C(5)$ & $29.82(7)$ \\
\hline $\mathrm{C}(15)-\mathrm{U}(1)-\mathrm{C}(5)$ & $147.52(7)$ \\
\hline $\mathrm{O}(2)-\mathrm{U}(1)-\mathrm{C}(14)$ & $145.47(6)$ \\
\hline $\mathrm{O}(1)-\mathrm{U}(1)-\mathrm{C}(14)$ & $101.00(6)$ \\
\hline $\mathrm{Cl}(1)-\mathrm{U}(1)-\mathrm{C}(14)$ & $122.12(5)$ \\
\hline $\mathrm{Cl}(2)-\mathrm{U}(1)-\mathrm{C}(14)$ & $78.28(5)$ \\
\hline $\mathrm{C}(1)-\mathrm{U}(1)-\mathrm{C}(14)$ & $140.37(7)$ \\
\hline $\mathrm{C}(15)-\mathrm{U}(1)-\mathrm{C}(14)$ & $29.87(7)$ \\
\hline $\mathrm{C}(5)-\mathrm{U}(1)-\mathrm{C}(14)$ & $126.36(7)$ \\
\hline $\mathrm{O}(2)-\mathrm{U}(1)-\mathrm{C}(11)$ & 116.87(6) \\
\hline $\mathrm{O}(1)-\mathrm{U}(1)-\mathrm{C}(11)$ & $67.69(6)$ \\
\hline $\mathrm{Cl}(1)-\mathrm{U}(1)-\mathrm{C}(11)$ & $78.79(5)$ \\
\hline $\mathrm{Cl}(2)-\mathrm{U}(1)-\mathrm{C}(11)$ & $102.51(6)$ \\
\hline $\mathrm{C}(1)-\mathrm{U}(1)-\mathrm{C}(11)$ & $151.48(7)$ \\
\hline $\mathrm{C}(15)-\mathrm{U}(1)-\mathrm{C}(11)$ & $29.66(7)$ \\
\hline $\mathrm{C}(5)-\mathrm{U}(1)-\mathrm{C}(11)$ & $174.99(7)$ \\
\hline $\mathrm{C}(14)-\mathrm{U}(1)-\mathrm{C}(11)$ & $48.97(7)$ \\
\hline $\mathrm{O}(2)-\mathrm{U}(1)-\mathrm{C}(2)$ & $98.31(6)$ \\
\hline $\mathrm{O}(1)-\mathrm{U}(1)-\mathrm{C}(2)$ & 142.91(6) \\
\hline $\mathrm{Cl}(1)-\mathrm{U}(1)-\mathrm{C}(2)$ & $77.35(5)$ \\
\hline $\mathrm{Cl}(2)-\mathrm{U}(1)-\mathrm{C}(2)$ & $121.91(5)$ \\
\hline $\mathrm{C}(1)-\mathrm{U}(1)-\mathrm{C}(2)$ & $29.81(6)$ \\
\hline $\mathrm{C}(15)-\mathrm{U}(1)-\mathrm{C}(2)$ & $141.43(7)$ \\
\hline $\mathrm{C}(5)-\mathrm{U}(1)-\mathrm{C}(2)$ & $48.97(7)$ \\
\hline $\mathrm{C}(14)-\mathrm{U}(1)-\mathrm{C}(2)$ & $114.45(7)$ \\
\hline $\mathrm{C}(11)-\mathrm{U}(1)-\mathrm{C}(2)$ & $129.31(7)$ \\
\hline
\end{tabular}




\begin{tabular}{|c|c|}
\hline $\mathrm{O}(2)-\mathrm{U}(1)-\mathrm{C}(4)$ & $95.90(6)$ \\
\hline $\mathrm{O}(1)-\mathrm{U}(1)-\mathrm{C}(4)$ & $138.94(6)$ \\
\hline $\mathrm{Cl}(1)-\mathrm{U}(1)-\mathrm{C}(4)$ & $123.57(5)$ \\
\hline $\mathrm{Cl}(2)-\mathrm{U}(1)-\mathrm{C}(4)$ & $74.15(5)$ \\
\hline $\mathrm{C}(1)-\mathrm{U}(1)-\mathrm{C}(4)$ & $48.99(7)$ \\
\hline $\mathrm{C}(15)-\mathrm{U}(1)-\mathrm{C}(4)$ & $123.80(7)$ \\
\hline$C(5)-U(1)-C(4)$ & $29.59(7)$ \\
\hline $\mathrm{C}(14)-\mathrm{U}(1)-\mathrm{C}(4)$ & $97.67(7)$ \\
\hline $\mathrm{C}(11)-\mathrm{U}(1)-\mathrm{C}(4)$ & $145.41(7)$ \\
\hline $\mathrm{C}(2)-\mathrm{U}(1)-\mathrm{C}(4)$ & $48.73(7)$ \\
\hline $\mathrm{O}(2)-\mathrm{U}(1)-\mathrm{C}(12)$ & $137.56(6)$ \\
\hline $\mathrm{O}(1)-\mathrm{U}(1)-\mathrm{C}(12)$ & $94.42(6)$ \\
\hline $\mathrm{Cl}(1)-\mathrm{U}(1)-\mathrm{C}(12)$ & $73.70(5)$ \\
\hline $\mathrm{Cl}(2)-\mathrm{U}(1)-\mathrm{C}(12)$ & $123.09(5)$ \\
\hline $\mathrm{C}(1)-\mathrm{U}(1)-\mathrm{C}(12)$ & $127.20(7)$ \\
\hline $\mathrm{C}(15)-\mathrm{U}(1)-\mathrm{C}(12)$ & $48.65(7)$ \\
\hline $\mathrm{C}(5)-\mathrm{U}(1)-\mathrm{C}(12)$ & $147.60(7)$ \\
\hline $\mathrm{C}(14)-\mathrm{U}(1)-\mathrm{C}(12)$ & $48.74(7)$ \\
\hline $\mathrm{C}(11)-\mathrm{U}(1)-\mathrm{C}(12)$ & $29.26(7)$ \\
\hline $\mathrm{C}(2)-\mathrm{U}(1)-\mathrm{C}(12)$ & $100.65(7)$ \\
\hline $\mathrm{C}(4)-\mathrm{U}(1)-\mathrm{C}(12)$ & $124.91(7)$ \\
\hline $\mathrm{O}(2)-\mathrm{U}(1)-\mathrm{C}(3)$ & $114.51(6)$ \\
\hline $\mathrm{O}(1)-\mathrm{U}(1)-\mathrm{C}(3)$ & $164.95(6)$ \\
\hline $\mathrm{Cl}(1)-\mathrm{U}(1)-\mathrm{C}(3)$ & $105.29(5)$ \\
\hline $\mathrm{Cl}(2)-\mathrm{U}(1)-\mathrm{C}(3)$ & $100.81(5)$ \\
\hline $\mathrm{C}(1)-\mathrm{U}(1)-\mathrm{C}(3)$ & 48.61(7) \\
\hline $\mathrm{C}(15)-\mathrm{U}(1)-\mathrm{C}(3)$ & $121.61(7)$ \\
\hline$C(5)-U(1)-C(3)$ & $48.40(7)$ \\
\hline $\mathrm{C}(14)-\mathrm{U}(1)-\mathrm{C}(3)$ & $91.76(7)$ \\
\hline $\mathrm{C}(11)-\mathrm{U}(1)-\mathrm{C}(3)$ & $127.32(7)$ \\
\hline $\mathrm{C}(2)-\mathrm{U}(1)-\mathrm{C}(3)$ & $29.33(7)$ \\
\hline $\mathrm{C}(4)-\mathrm{U}(1)-\mathrm{C}(3)$ & $29.20(7)$ \\
\hline $\mathrm{C}(12)-\mathrm{U}(1)-\mathrm{C}(3)$ & $100.04(7)$ \\
\hline $\mathrm{O}(2)-\mathrm{U}(1)-\mathrm{C}(13)$ & $165.08(6)$ \\
\hline $\mathrm{O}(1)-\mathrm{U}(1)-\mathrm{C}(13)$ & $115.07(6)$ \\
\hline $\mathrm{Cl}(1)-\mathrm{U}(1)-\mathrm{C}(13)$ & $99.30(5)$ \\
\hline
\end{tabular}




\begin{tabular}{|c|c|}
\hline $\mathrm{Cl}(2)-\mathrm{U}(1)-\mathrm{C}(13)$ & $106.89(5)$ \\
\hline $\mathrm{C}(1)-\mathrm{U}(1)-\mathrm{C}(13)$ & $122.77(7)$ \\
\hline $\mathrm{C}(15)-\mathrm{U}(1)-\mathrm{C}(13)$ & $48.53(7)$ \\
\hline $\mathrm{C}(5)-\mathrm{U}(1)-\mathrm{C}(13)$ & $126.97(7)$ \\
\hline $\mathrm{C}(14)-\mathrm{U}(1)-\mathrm{C}(13)$ & $29.42(7)$ \\
\hline $\mathrm{C}(11)-\mathrm{U}(1)-\mathrm{C}(13)$ & $48.24(7)$ \\
\hline $\mathrm{C}(2)-\mathrm{U}(1)-\mathrm{C}(13)$ & $93.03(7)$ \\
\hline $\mathrm{C}(4)-\mathrm{U}(1)-\mathrm{C}(13)$ & $98.87(7)$ \\
\hline $\mathrm{C}(12)-\mathrm{U}(1)-\mathrm{C}(13)$ & $29.21(7)$ \\
\hline $\mathrm{C}(3)-\mathrm{U}(1)-\mathrm{C}(13)$ & $79.93(7)$ \\
\hline $\mathrm{O}(2)-\mathrm{U}(1)-\mathrm{N}(1)$ & $25.17(5)$ \\
\hline $\mathrm{O}(1)-\mathrm{U}(1)-\mathrm{N}(1)$ & $25.51(5)$ \\
\hline $\mathrm{Cl}(1)-\mathrm{U}(1)-\mathrm{N}(1)$ & $71.64(4)$ \\
\hline $\mathrm{Cl}(2)-\mathrm{U}(1)-\mathrm{N}(1)$ & $74.08(4)$ \\
\hline $\mathrm{C}(1)-\mathrm{U}(1)-\mathrm{N}(1)$ & $93.41(6)$ \\
\hline $\mathrm{C}(15)-\mathrm{U}(1)-\mathrm{N}(1)$ & $96.31(6)$ \\
\hline $\mathrm{C}(5)-\mathrm{U}(1)-\mathrm{N}(1)$ & $92.42(6)$ \\
\hline $\mathrm{C}(14)-\mathrm{U}(1)-\mathrm{N}(1)$ & $124.73(6)$ \\
\hline $\mathrm{C}(11)-\mathrm{U}(1)-\mathrm{N}(1)$ & $92.23(7)$ \\
\hline $\mathrm{C}(2)-\mathrm{U}(1)-\mathrm{N}(1)$ & $120.82(6)$ \\
\hline $\mathrm{C}(4)-\mathrm{U}(1)-\mathrm{N}(1)$ & $118.63(7)$ \\
\hline $\mathrm{C}(12)-\mathrm{U}(1)-\mathrm{N}(1)$ & $116.45(7)$ \\
\hline $\mathrm{C}(3)-\mathrm{U}(1)-\mathrm{N}(1)$ & $139.68(6)$ \\
\hline $\mathrm{C}(13)-\mathrm{U}(1)-\mathrm{N}(1)$ & $140.29(6)$ \\
\hline $\mathrm{N}(1)-\mathrm{O}(1)-\mathrm{U}(1)$ & $95.53(13)$ \\
\hline $\mathrm{N}(1)-\mathrm{O}(2)-\mathrm{U}(1)$ & $97.30(13)$ \\
\hline $\mathrm{O}(3)-\mathrm{N}(1)-\mathrm{O}(2)$ & $121.8(2)$ \\
\hline $\mathrm{O}(3)-\mathrm{N}(1)-\mathrm{O}(1)$ & $121.8(2)$ \\
\hline $\mathrm{O}(2)-\mathrm{N}(1)-\mathrm{O}(1)$ & $116.37(18)$ \\
\hline $\mathrm{O}(3)-\mathrm{N}(1)-\mathrm{U}(1)$ & $176.30(18)$ \\
\hline $\mathrm{O}(2)-\mathrm{N}(1)-\mathrm{U}(1)$ & $57.53(11)$ \\
\hline $\mathrm{O}(1)-\mathrm{N}(1)-\mathrm{U}(1)$ & $58.96(11)$ \\
\hline $\mathrm{C}(5)-\mathrm{C}(1)-\mathrm{C}(2)$ & $107.8(2)$ \\
\hline$C(5)-C(1)-C(6)$ & $125.7(2)$ \\
\hline$C(2)-C(1)-C(6)$ & $126.1(2)$ \\
\hline $\mathrm{C}(5)-\mathrm{C}(1)-\mathrm{U}(1)$ & $75.48(13)$ \\
\hline
\end{tabular}




\begin{tabular}{|c|c|}
\hline$C(2)-C(1)-U(1)$ & $76.14(13)$ \\
\hline$C(6)-C(1)-U(1)$ & $120.14(15)$ \\
\hline$C(3)-C(2)-C(1)$ & $107.7(2)$ \\
\hline$C(3)-C(2)-C(7)$ & $126.2(2)$ \\
\hline$C(1)-C(2)-C(7)$ & $125.8(2)$ \\
\hline$C(3)-C(2)-U(1)$ & $76.77(13)$ \\
\hline$C(1)-C(2)-U(1)$ & $74.05(12)$ \\
\hline $\mathrm{C}(7)-\mathrm{C}(2)-\mathrm{U}(1)$ & $120.61(15)$ \\
\hline$C(4)-C(3)-C(2)$ & $108.4(2)$ \\
\hline $\mathrm{C}(4)-\mathrm{C}(3)-\mathrm{C}(8)$ & $122.5(2)$ \\
\hline $\mathrm{C}(2)-\mathrm{C}(3)-\mathrm{C}(8)$ & $127.0(2)$ \\
\hline $\mathrm{C}(4)-\mathrm{C}(3)-\mathrm{U}(1)$ & $74.12(13)$ \\
\hline $\mathrm{C}(2)-\mathrm{C}(3)-\mathrm{U}(1)$ & $73.90(12)$ \\
\hline $\mathrm{C}(8)-\mathrm{C}(3)-\mathrm{U}(1)$ & $130.97(16)$ \\
\hline$C(3)-C(4)-C(5)$ & $107.9(2)$ \\
\hline $\mathrm{C}(3)-\mathrm{C}(4)-\mathrm{C}(9)$ & $124.6(2)$ \\
\hline $\mathrm{C}(5)-\mathrm{C}(4)-\mathrm{C}(9)$ & $126.7(2)$ \\
\hline $\mathrm{C}(3)-\mathrm{C}(4)-\mathrm{U}(1)$ & $76.68(13)$ \\
\hline $\mathrm{C}(5)-\mathrm{C}(4)-\mathrm{U}(1)$ & $74.38(13)$ \\
\hline $\mathrm{C}(9)-\mathrm{C}(4)-\mathrm{U}(1)$ & $123.03(16)$ \\
\hline$C(4)-C(5)-C(1)$ & 108.1(2) \\
\hline $\mathrm{C}(4)-\mathrm{C}(5)-\mathrm{C}(10)$ & $125.3(2)$ \\
\hline $\mathrm{C}(1)-\mathrm{C}(5)-\mathrm{C}(10)$ & $126.2(2)$ \\
\hline $\mathrm{C}(4)-\mathrm{C}(5)-\mathrm{U}(1)$ & $76.03(13)$ \\
\hline $\mathrm{C}(1)-\mathrm{C}(5)-\mathrm{U}(1)$ & $74.70(13)$ \\
\hline $\mathrm{C}(10)-\mathrm{C}(5)-\mathrm{U}(1)$ & $120.89(16)$ \\
\hline $\mathrm{C}(12)-\mathrm{C}(11)-\mathrm{C}(15)$ & $108.2(2)$ \\
\hline $\mathrm{C}(12)-\mathrm{C}(11)-\mathrm{C}(16)$ & $125.3(2)$ \\
\hline $\mathrm{C}(15)-\mathrm{C}(11)-\mathrm{C}(16)$ & $126.2(2)$ \\
\hline $\mathrm{C}(12)-\mathrm{C}(11)-\mathrm{U}(1)$ & $76.32(13)$ \\
\hline $\mathrm{C}(15)-\mathrm{C}(11)-\mathrm{U}(1)$ & $74.28(14)$ \\
\hline $\mathrm{C}(16)-\mathrm{C}(11)-\mathrm{U}(1)$ & $120.28(16)$ \\
\hline $\mathrm{C}(11)-\mathrm{C}(12)-\mathrm{C}(13)$ & $108.0(2)$ \\
\hline $\mathrm{C}(11)-\mathrm{C}(12)-\mathrm{C}(17)$ & $126.6(2)$ \\
\hline $\mathrm{C}(13)-\mathrm{C}(12)-\mathrm{C}(17)$ & $124.5(2)$ \\
\hline $\mathrm{C}(11)-\mathrm{C}(12)-\mathrm{U}(1)$ & $74.42(13)$ \\
\hline
\end{tabular}




\begin{tabular}{|c|c|}
\hline $\mathrm{C}(13)-\mathrm{C}(12)-\mathrm{U}(1)$ & $76.04(13)$ \\
\hline $\mathrm{C}(17)-\mathrm{C}(12)-\mathrm{U}(1)$ & $123.79(16)$ \\
\hline$C(12)-C(13)-C(14)$ & $108.4(2)$ \\
\hline$C(12)-C(13)-C(18)$ & $122.6(2)$ \\
\hline $\mathrm{C}(14)-\mathrm{C}(13)-\mathrm{C}(18)$ & $127.2(2)$ \\
\hline $\mathrm{C}(12)-\mathrm{C}(13)-\mathrm{U}(1)$ & $74.76(13)$ \\
\hline $\mathrm{C}(14)-\mathrm{C}(13)-\mathrm{U}(1)$ & $73.63(13)$ \\
\hline $\mathrm{C}(18)-\mathrm{C}(13)-\mathrm{U}(1)$ & $129.86(16)$ \\
\hline$C(13)-C(14)-C(15)$ & $107.2(2)$ \\
\hline$C(13)-C(14)-C(19)$ & $126.1(2)$ \\
\hline$C(15)-C(14)-C(19)$ & $126.3(2)$ \\
\hline $\mathrm{C}(13)-\mathrm{C}(14)-\mathrm{U}(1)$ & $76.95(13)$ \\
\hline $\mathrm{C}(15)-\mathrm{C}(14)-\mathrm{U}(1)$ & $74.26(13)$ \\
\hline $\mathrm{C}(19)-\mathrm{C}(14)-\mathrm{U}(1)$ & $120.41(16)$ \\
\hline$C(11)-C(15)-C(14)$ & $108.2(2)$ \\
\hline$C(11)-C(15)-C(20)$ & $125.9(2)$ \\
\hline$C(14)-C(15)-C(20)$ & $125.7(2)$ \\
\hline $\mathrm{C}(11)-\mathrm{C}(15)-\mathrm{U}(1)$ & $76.06(13)$ \\
\hline $\mathrm{C}(14)-\mathrm{C}(15)-\mathrm{U}(1)$ & $75.87(13)$ \\
\hline $\mathrm{C}(20)-\mathrm{C}(15)-\mathrm{U}(1)$ & $119.11(16)$ \\
\hline $\mathrm{C}(29)-\mathrm{N}(2)-\mathrm{C}(25)$ & $113.09(17)$ \\
\hline $\mathrm{C}(29)-\mathrm{N}(2)-\mathrm{C}(33)$ & $112.73(18)$ \\
\hline $\mathrm{C}(25)-\mathrm{N}(2)-\mathrm{C}(33)$ & $108.23(17)$ \\
\hline $\mathrm{C}(29)-\mathrm{N}(2)-\mathrm{C}(21)$ & $108.36(17)$ \\
\hline $\mathrm{C}(25)-\mathrm{N}(2)-\mathrm{C}(21)$ & $107.18(17)$ \\
\hline $\mathrm{C}(33)-\mathrm{N}(2)-\mathrm{C}(21)$ & 106.93(17) \\
\hline $\mathrm{C}(22)-\mathrm{C}(21)-\mathrm{N}(2)$ & $116.95(19)$ \\
\hline $\mathrm{C}(23)-\mathrm{C}(22)-\mathrm{C}(21)$ & 108.92(19) \\
\hline $\mathrm{C}(22)-\mathrm{C}(23)-\mathrm{C}(24)$ & $112.2(2)$ \\
\hline $\mathrm{C}(26)-\mathrm{C}(25)-\mathrm{N}(2)$ & $116.2(2)$ \\
\hline$C(25)-C(26)-C(27)$ & $107.8(2)$ \\
\hline $\mathrm{C}(28)-\mathrm{C}(27)-\mathrm{C}(26)$ & $112.7(3)$ \\
\hline $\mathrm{C}(30)-\mathrm{C}(29)-\mathrm{N}(2)$ & $117.68(19)$ \\
\hline $\mathrm{C}(29)-\mathrm{C}(30)-\mathrm{C}(31)$ & $109.6(2)$ \\
\hline $\mathrm{C}(32)-\mathrm{C}(31)-\mathrm{C}(30)$ & $113.3(2)$ \\
\hline $\mathrm{C}(34)-\mathrm{C}(33)-\mathrm{N}(2)$ & $118.45(19)$ \\
\hline
\end{tabular}




$\begin{array}{ll}\mathrm{C}(33)-\mathrm{C}(34)-\mathrm{C}(35) & 108.3(2) \\ \mathrm{C}(34)-\mathrm{C}(35)-\mathrm{C}(36) & 112.2(2) \\ \mathrm{C}(38)-\mathrm{C}(37)-\mathrm{C}(39) \# 1 & 120.7(3) \\ \mathrm{C}(37)-\mathrm{C}(38)-\mathrm{C}(39) & 120.7(3) \\ \mathrm{C}(38)-\mathrm{C}(39)-\mathrm{C}(37) \# 1 & 118.6(3) \\ \mathrm{C}(38)-\mathrm{C}(39)-\mathrm{C}(40) & 118.8(4) \\ \mathrm{C}(37) \# 1-\mathrm{C}(39)-\mathrm{C}(40) & 122.6(4)\end{array}$

\section{X-ray Data Collection, Structure Solution and Refinement for 2.}

An orange crystal of approximate dimensions $0.116 \times 0.198 \times 0.292 \mathrm{~mm}$ was mounted on a glass fiber and transferred to a Bruker SMART APEX II diffractometer. The APEX2 ${ }^{1}$ program package was used to determine the unit-cell parameters and for data collection (20 sec/frame scan time for a sphere of diffraction data). The raw frame data was processed using $\mathrm{SAINT}^{2}$ and $\mathrm{SADABS}^{3}$ to yield the reflection data file. Subsequent calculations were carried out using the SHELXTL ${ }^{4}$ program. There were no systematic absences nor any diffraction symmetry other than the Friedel condition. The centrosymmetric triclinic space group $P \overline{1}$ was assigned and later determined to be correct.

The structure was solved by direct methods and refined on $\mathrm{F}^{2}$ by full-matrix least-squares techniques ${ }^{5}$. The analytical scattering factors ${ }^{6}$ for neutral atoms were used throughout the analysis. Hydrogen atoms were included using a riding model. There was one-half molecule of toluene solvent present per formula-unit. The solvent was disordered about an inversion center.

At convergence, $w \mathrm{R} 2=0.0410$ and Goof $=1.032$ for 427 variables refined against 9361 data $(0.75 \AA), R 1=0.0167$ for those 8926 data with $\mathrm{I}>2.0 \sigma(\mathrm{I})$.

\section{Definitions:}

$$
\begin{aligned}
& \mathrm{wR} 2=\left[\Sigma\left[\mathrm{w}\left(\mathrm{F}_{\mathrm{o}}^{2}-\mathrm{F}_{\mathrm{c}}{ }^{2}\right)^{2}\right] / \Sigma\left[\mathrm{w}\left(\mathrm{F}_{\mathrm{o}}^{2}\right)^{2}\right]\right]^{1 / 2} \\
& \mathrm{R} 1=\Sigma|| \mathrm{F}_{\mathrm{o}}|-| \mathrm{F}_{\mathrm{c}} \| / \Sigma\left|\mathrm{F}_{\mathrm{o}}\right|
\end{aligned}
$$

Goof $=\mathrm{S}=\left[\Sigma\left[\mathrm{w}\left(\mathrm{F}_{\mathrm{o}}{ }^{2}-\mathrm{F}_{\mathrm{c}}{ }^{2}\right)^{2}\right] /(\mathrm{n}-\mathrm{p})\right]^{1 / 2}$ where $\mathrm{n}$ is the number of reflections and $\mathrm{p}$ is the total number of parameters refined. 

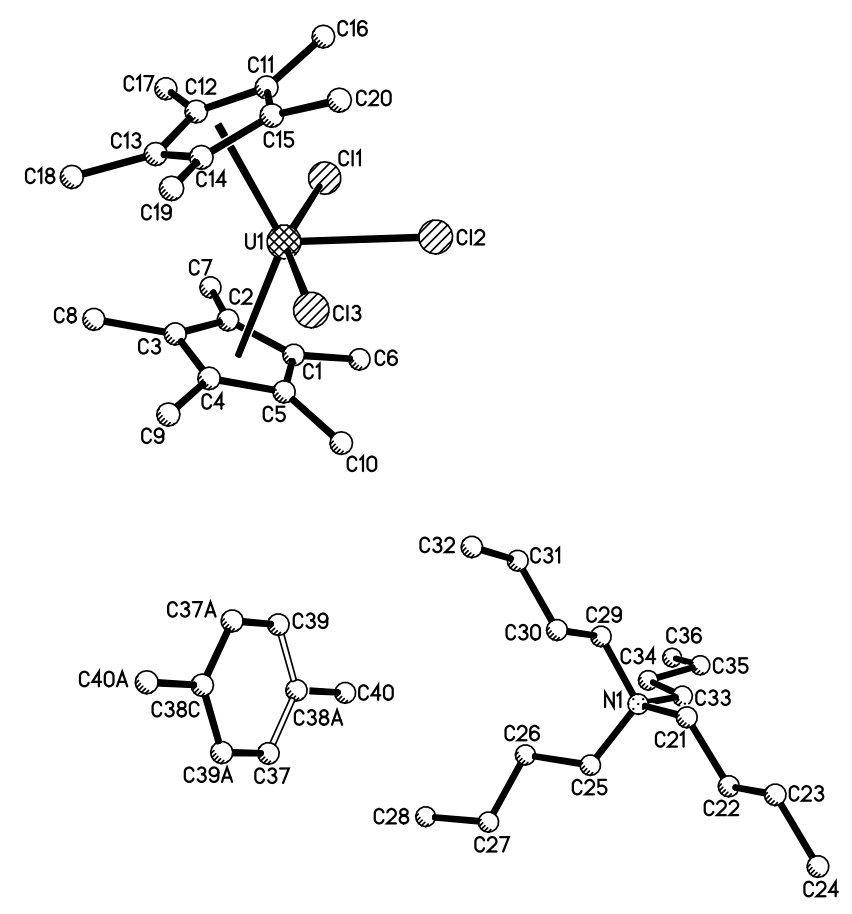

Figure S4. Ball and stick model of $\left[\mathrm{NBu}_{4}\right]\left[\left(\mathrm{C}_{5} \mathrm{Me}_{5}\right)_{2} \mathrm{UCl}_{3}\right], 2$. Hydrogen atoms have been removed for clarity.

Table S3. Crystal data and structure refinement for 2.

Identification code

Empirical formula

Formula weight

Temperature

Wavelength

Crystal system

Space group

Unit cell dimensions

Volume

$\mathrm{Z}$

Density (calculated)

Absorption coefficient clw13 (Chris Webster)

$\mathrm{C}_{36} \mathrm{H}_{66} \mathrm{Cl}_{3} \mathrm{~N} \mathrm{U} \cdot 1 / 2\left(\mathrm{C}_{7} \mathrm{H}_{8}\right)$

903.34

143(2) K

$0.71073 \AA$

Triclinic

$P \overline{1}$

$\mathrm{a}=11.3610(7) \AA \quad \square=79.0585(6)^{\circ}$.

$\mathrm{b}=11.5361(7) \AA \quad \square=89.4727(6)^{\circ}$.

$\mathrm{c}=17.3158(10) \AA \quad \square=66.6659(6)^{\circ}$.

2040.5(2) $\AA^{3}$

2

$1.470 \mathrm{Mg} / \mathrm{m}^{3}$

$4.200 \mathrm{~mm}^{-1}$ 
$\mathrm{F}(000)$

Crystal color

Crystal size

Theta range for data collection

Index ranges

Reflections collected

Independent reflections

Completeness to theta $=25.500^{\circ}$

Absorption correction

Max. and min. transmission

Refinement method

Data / restraints / parameters

Goodness-of-fit on $\mathrm{F}^{2}$

Final $\mathrm{R}$ indices $[\mathrm{I}>2 \operatorname{sigma}(\mathrm{I})=8926$ data]

$\mathrm{R}$ indices (all data, $0.75 \AA$ )

Largest diff. peak and hole
914

orange

$0.292 \times 0.198 \times 0.116 \mathrm{~mm}^{3}$

1.957 to $28.419^{\circ}$

$-14 \leq h \leq 15,-15 \leq k \leq 15,-22 \leq l \leq 23$

23718

$9361[\mathrm{R}($ int $)=0.0159]$

$99.8 \%$

Numerical

0.7188 and 0.4991

Full-matrix least-squares on $\mathrm{F}^{2}$

$9361 / 0 / 427$

1.032

$\mathrm{R} 1=0.0167, \mathrm{wR} 2=0.0403$

$\mathrm{R} 1=0.0183, \mathrm{wR} 2=0.0410$

0.871 and -0.290 e. $\AA^{-3}$

Table S4. Bond lengths $[\AA]$ and angles $\left[{ }^{\circ}\right]$ for 2 .

\begin{tabular}{ll}
\hline $\mathrm{U}(1)-\mathrm{Cnt} 1$ & 2.492 \\
$\mathrm{U}(1)-\mathrm{Cnt} 2$ & 2.501 \\
$\mathrm{U}(1)-\mathrm{Cl}(3)$ & $2.6850(5)$ \\
$\mathrm{U}(1)-\mathrm{Cl}(2)$ & $2.6912(5)$ \\
$\mathrm{U}(1)-\mathrm{Cl}(1)$ & $2.6915(5)$ \\
$\mathrm{U}(1)-\mathrm{C}(5)$ & $2.7351(18)$ \\
$\mathrm{U}(1)-\mathrm{C}(11)$ & $2.7391(19)$ \\
$\mathrm{U}(1)-\mathrm{C}(1)$ & $2.7418(19)$ \\
$\mathrm{U}(1)-\mathrm{C}(15)$ & $2.7592(19)$ \\
$\mathrm{U}(1)-\mathrm{C}(12)$ & $2.7669(19)$ \\
$\mathrm{U}(1)-\mathrm{C}(4)$ & $2.7685(18)$ \\
$\mathrm{U}(1)-\mathrm{C}(2)$ & $2.7858(19)$ \\
$\mathrm{U}(1)-\mathrm{C}(14)$ & $2.8072(19)$ \\
$\mathrm{U}(1)-\mathrm{C}(13)$ & $2.8087(18)$ \\
$\mathrm{U}(1)-\mathrm{C}(3)$ & $2.8093(18)$
\end{tabular}




\begin{tabular}{|c|c|}
\hline $\mathrm{N}(1)-\mathrm{C}(29)$ & $1.516(2)$ \\
\hline $\mathrm{N}(1)-\mathrm{C}(25)$ & $1.521(2)$ \\
\hline $\mathrm{N}(1)-\mathrm{C}(33)$ & $1.526(2)$ \\
\hline $\mathrm{N}(1)-\mathrm{C}(21)$ & $1.529(2)$ \\
\hline $\mathrm{C}(1)-\mathrm{C}(2)$ & $1.416(3)$ \\
\hline $\mathrm{C}(1)-\mathrm{C}(5)$ & $1.418(3)$ \\
\hline $\mathrm{C}(1)-\mathrm{C}(6)$ & $1.506(3)$ \\
\hline $\mathrm{C}(2)-\mathrm{C}(3)$ & $1.411(3)$ \\
\hline $\mathrm{C}(2)-\mathrm{C}(7)$ & $1.500(3)$ \\
\hline$C(3)-C(4)$ & $1.417(3)$ \\
\hline $\mathrm{C}(3)-\mathrm{C}(8)$ & $1.505(3)$ \\
\hline$C(4)-C(5)$ & $1.422(3)$ \\
\hline $\mathrm{C}(4)-\mathrm{C}(9)$ & $1.503(3)$ \\
\hline $\mathrm{C}(5)-\mathrm{C}(10)$ & $1.506(3)$ \\
\hline $\mathrm{C}(11)-\mathrm{C}(15)$ & $1.416(3)$ \\
\hline $\mathrm{C}(11)-\mathrm{C}(12)$ & $1.424(3)$ \\
\hline$C(11)-C(16)$ & $1.506(3)$ \\
\hline$C(12)-C(13)$ & $1.417(3)$ \\
\hline$C(12)-C(17)$ & $1.504(3)$ \\
\hline$C(13)-C(14)$ & $1.414(3)$ \\
\hline $\mathrm{C}(13)-\mathrm{C}(18)$ & $1.503(3)$ \\
\hline$C(14)-C(15)$ & $1.416(3)$ \\
\hline$C(14)-C(19)$ & $1.504(3)$ \\
\hline$C(15)-C(20)$ & $1.501(3)$ \\
\hline $\mathrm{C}(21)-\mathrm{C}(22)$ & $1.526(3)$ \\
\hline$C(22)-C(23)$ & $1.524(3)$ \\
\hline$C(23)-C(24)$ & $1.521(3)$ \\
\hline$C(25)-C(26)$ & $1.515(3)$ \\
\hline$C(26)-C(27)$ & $1.520(3)$ \\
\hline $\mathrm{C}(27)-\mathrm{C}(28)$ & $1.510(3)$ \\
\hline$C(29)-C(30)$ & $1.517(3)$ \\
\hline $\mathrm{C}(30)-\mathrm{C}(31)$ & $1.520(3)$ \\
\hline $\mathrm{C}(31)-\mathrm{C}(32)$ & $1.500(3)$ \\
\hline $\mathrm{C}(33)-\mathrm{C}(34)$ & $1.518(3)$ \\
\hline$C(34)-C(35)$ & $1.527(3)$ \\
\hline $\mathrm{C}(35)-\mathrm{C}(36)$ & $1.517(3)$ \\
\hline
\end{tabular}




\begin{tabular}{|c|c|}
\hline $\mathrm{C}(37)-\mathrm{C}(39) \# 1$ & $1.365(5)$ \\
\hline $\mathrm{C}(37)-\mathrm{C}(38 \mathrm{~A})$ & $1.381(5)$ \\
\hline $\mathrm{C}(39)-\mathrm{C}(37) \# 1$ & $1.365(5)$ \\
\hline $\mathrm{C}(39)-\mathrm{C}(38 \mathrm{~A})$ & $1.380(5)$ \\
\hline $\mathrm{C}(38 \mathrm{~A})-\mathrm{C}(40)$ & $1.454(7)$ \\
\hline Cnt1-U(1)-Cl(1) & 94.0 \\
\hline Cnt1-U(1)-Cl(2) & 113.5 \\
\hline Cnt1-U(1)-Cl(3) & 96.2 \\
\hline Cnt2-U(1)-Cl(1) & 95.9 \\
\hline $\mathrm{Cnt} 2-\mathrm{U}(1)-\mathrm{Cl}(2)$ & 113.1 \\
\hline $\mathrm{Cnt} 2-\mathrm{U}(1)-\mathrm{Cl}(3)$ & 94.5 \\
\hline Cnt1-U(1)-Cnt2 & 133.4 \\
\hline $\mathrm{Cl}(3)-\mathrm{U}(1)-\mathrm{Cl}(2)$ & $76.943(17)$ \\
\hline $\mathrm{Cl}(3)-\mathrm{U}(1)-\mathrm{Cl}(1)$ & $153.848(17)$ \\
\hline $\mathrm{Cl}(2)-\mathrm{U}(1)-\mathrm{Cl}(1)$ & 76.907(18) \\
\hline $\mathrm{Cl}(3)-\mathrm{U}(1)-\mathrm{C}(5)$ & $75.49(4)$ \\
\hline $\mathrm{Cl}(2)-\mathrm{U}(1)-\mathrm{C}(5)$ & $92.94(4)$ \\
\hline $\mathrm{Cl}(1)-\mathrm{U}(1)-\mathrm{C}(5)$ & $105.62(4)$ \\
\hline $\mathrm{Cl}(3)-\mathrm{U}(1)-\mathrm{C}(11)$ & $107.55(5)$ \\
\hline $\mathrm{Cl}(2)-\mathrm{U}(1)-\mathrm{C}(11)$ & $93.54(4)$ \\
\hline $\mathrm{Cl}(1)-\mathrm{U}(1)-\mathrm{C}(11)$ & $74.39(5)$ \\
\hline$C(5)-U(1)-C(11)$ & $173.34(6)$ \\
\hline $\mathrm{Cl}(3)-\mathrm{U}(1)-\mathrm{C}(1)$ & $104.13(4)$ \\
\hline $\mathrm{Cl}(2)-\mathrm{U}(1)-\mathrm{C}(1)$ & $90.85(4)$ \\
\hline $\mathrm{Cl}(1)-\mathrm{U}(1)-\mathrm{C}(1)$ & $75.99(4)$ \\
\hline $\mathrm{C}(5)-\mathrm{U}(1)-\mathrm{C}(1)$ & $30.00(6)$ \\
\hline $\mathrm{C}(11)-\mathrm{U}(1)-\mathrm{C}(1)$ & $148.19(6)$ \\
\hline $\mathrm{Cl}(3)-\mathrm{U}(1)-\mathrm{C}(15)$ & $77.86(5)$ \\
\hline $\mathrm{Cl}(2)-\mathrm{U}(1)-\mathrm{C}(15)$ & $89.77(4)$ \\
\hline $\mathrm{Cl}(1)-\mathrm{U}(1)-\mathrm{C}(15)$ & $102.31(5)$ \\
\hline $\mathrm{C}(5)-\mathrm{U}(1)-\mathrm{C}(15)$ & $151.83(6)$ \\
\hline $\mathrm{C}(11)-\mathrm{U}(1)-\mathrm{C}(15)$ & $29.85(6)$ \\
\hline$C(1)-U(1)-C(15)$ & $178.00(6)$ \\
\hline $\mathrm{Cl}(3)-\mathrm{U}(1)-\mathrm{C}(12)$ & 119.63(4) \\
\hline $\mathrm{Cl}(2)-\mathrm{U}(1)-\mathrm{C}(12)$ & $122.07(4)$ \\
\hline
\end{tabular}




\begin{tabular}{|c|c|}
\hline $\mathrm{Cl}(1)-\mathrm{U}(1)-\mathrm{C}(12)$ & $75.49(4)$ \\
\hline $\mathrm{C}(5)-\mathrm{U}(1)-\mathrm{C}(12)$ & $143.38(6)$ \\
\hline $\mathrm{C}(11)-\mathrm{U}(1)-\mathrm{C}(12)$ & $29.97(6)$ \\
\hline $\mathrm{C}(1)-\mathrm{U}(1)-\mathrm{C}(12)$ & $128.96(6)$ \\
\hline $\mathrm{C}(15)-\mathrm{U}(1)-\mathrm{C}(12)$ & $49.25(6)$ \\
\hline $\mathrm{Cl}(3)-\mathrm{U}(1)-\mathrm{C}(4)$ & $74.85(4)$ \\
\hline $\mathrm{Cl}(2)-\mathrm{U}(1)-\mathrm{C}(4)$ & $120.94(4)$ \\
\hline $\mathrm{Cl}(1)-\mathrm{U}(1)-\mathrm{C}(4)$ & $119.36(4)$ \\
\hline $\mathrm{C}(5)-\mathrm{U}(1)-\mathrm{C}(4)$ & $29.95(5)$ \\
\hline $\mathrm{C}(11)-\mathrm{U}(1)-\mathrm{C}(4)$ & $144.31(6)$ \\
\hline $\mathrm{C}(1)-\mathrm{U}(1)-\mathrm{C}(4)$ & $49.22(6)$ \\
\hline $\mathrm{C}(15)-\mathrm{U}(1)-\mathrm{C}(4)$ & $131.75(6)$ \\
\hline $\mathrm{C}(12)-\mathrm{U}(1)-\mathrm{C}(4)$ & $116.99(6)$ \\
\hline $\mathrm{Cl}(3)-\mathrm{U}(1)-\mathrm{C}(2)$ & $121.74(4)$ \\
\hline $\mathrm{Cl}(2)-\mathrm{U}(1)-\mathrm{C}(2)$ & $116.85(4)$ \\
\hline $\mathrm{Cl}(1)-\mathrm{U}(1)-\mathrm{C}(2)$ & $71.02(4)$ \\
\hline $\mathrm{C}(5)-\mathrm{U}(1)-\mathrm{C}(2)$ & $49.08(6)$ \\
\hline $\mathrm{C}(11)-\mathrm{U}(1)-\mathrm{C}(2)$ & $125.89(6)$ \\
\hline $\mathrm{C}(1)-\mathrm{U}(1)-\mathrm{C}(2)$ & $29.67(6)$ \\
\hline $\mathrm{C}(15)-\mathrm{U}(1)-\mathrm{C}(2)$ & $148.87(6)$ \\
\hline $\mathrm{C}(12)-\mathrm{U}(1)-\mathrm{C}(2)$ & $100.44(6)$ \\
\hline $\mathrm{C}(4)-\mathrm{U}(1)-\mathrm{C}(2)$ & $48.74(5)$ \\
\hline $\mathrm{Cl}(3)-\mathrm{U}(1)-\mathrm{C}(14)$ & $71.08(4)$ \\
\hline $\mathrm{Cl}(2)-\mathrm{U}(1)-\mathrm{C}(14)$ & $114.90(4)$ \\
\hline $\mathrm{Cl}(1)-\mathrm{U}(1)-\mathrm{C}(14)$ & $121.23(4)$ \\
\hline $\mathrm{C}(5)-\mathrm{U}(1)-\mathrm{C}(14)$ & $129.08(6)$ \\
\hline $\mathrm{C}(11)-\mathrm{U}(1)-\mathrm{C}(14)$ & $48.69(6)$ \\
\hline $\mathrm{C}(1)-\mathrm{U}(1)-\mathrm{C}(14)$ & $150.89(6)$ \\
\hline $\mathrm{C}(15)-\mathrm{U}(1)-\mathrm{C}(14)$ & $29.47(6)$ \\
\hline $\mathrm{C}(12)-\mathrm{U}(1)-\mathrm{C}(14)$ & $48.62(6)$ \\
\hline $\mathrm{C}(4)-\mathrm{U}(1)-\mathrm{C}(14)$ & $103.16(6)$ \\
\hline $\mathrm{C}(2)-\mathrm{U}(1)-\mathrm{C}(14)$ & $128.24(6)$ \\
\hline $\mathrm{Cl}(3)-\mathrm{U}(1)-\mathrm{C}(13)$ & $95.84(4)$ \\
\hline $\mathrm{Cl}(2)-\mathrm{U}(1)-\mathrm{C}(13)$ & $138.06(4)$ \\
\hline $\mathrm{Cl}(1)-\mathrm{U}(1)-\mathrm{C}(13)$ & $103.76(4)$ \\
\hline $\mathrm{C}(5)-\mathrm{U}(1)-\mathrm{C}(13)$ & $125.66(6)$ \\
\hline
\end{tabular}




\begin{tabular}{|c|c|}
\hline $\mathrm{C}(11)-\mathrm{U}(1)-\mathrm{C}(13)$ & $48.72(6)$ \\
\hline $\mathrm{C}(1)-\mathrm{U}(1)-\mathrm{C}(13)$ & $130.54(6)$ \\
\hline $\mathrm{C}(15)-\mathrm{U}(1)-\mathrm{C}(13)$ & $48.63(6)$ \\
\hline $\mathrm{C}(12)-\mathrm{U}(1)-\mathrm{C}(13)$ & $29.44(5)$ \\
\hline $\mathrm{C}(4)-\mathrm{U}(1)-\mathrm{C}(13)$ & $95.73(6)$ \\
\hline $\mathrm{C}(2)-\mathrm{U}(1)-\mathrm{C}(13)$ & $102.21(6)$ \\
\hline $\mathrm{C}(14)-\mathrm{U}(1)-\mathrm{C}(13)$ & $29.16(6)$ \\
\hline $\mathrm{Cl}(3)-\mathrm{U}(1)-\mathrm{C}(3)$ & $102.53(4)$ \\
\hline $\mathrm{Cl}(2)-\mathrm{U}(1)-\mathrm{C}(3)$ & 138.73(4) \\
\hline $\mathrm{Cl}(1)-\mathrm{U}(1)-\mathrm{C}(3)$ & $96.90(4)$ \\
\hline $\mathrm{C}(5)-\mathrm{U}(1)-\mathrm{C}(3)$ & $48.84(6)$ \\
\hline $\mathrm{C}(11)-\mathrm{U}(1)-\mathrm{C}(3)$ & $124.51(6)$ \\
\hline $\mathrm{C}(1)-\mathrm{U}(1)-\mathrm{C}(3)$ & $48.67(6)$ \\
\hline $\mathrm{C}(15)-\mathrm{U}(1)-\mathrm{C}(3)$ & $130.98(6)$ \\
\hline $\mathrm{C}(12)-\mathrm{U}(1)-\mathrm{C}(3)$ & $94.54(6)$ \\
\hline $\mathrm{C}(4)-\mathrm{U}(1)-\mathrm{C}(3)$ & $29.42(5)$ \\
\hline $\mathrm{C}(2)-\mathrm{U}(1)-\mathrm{C}(3)$ & $29.21(6)$ \\
\hline $\mathrm{C}(14)-\mathrm{U}(1)-\mathrm{C}(3)$ & $103.27(6)$ \\
\hline $\mathrm{C}(13)-\mathrm{U}(1)-\mathrm{C}(3)$ & $83.19(6)$ \\
\hline $\mathrm{C}(29)-\mathrm{N}(1)-\mathrm{C}(25)$ & $113.33(15)$ \\
\hline $\mathrm{C}(29)-\mathrm{N}(1)-\mathrm{C}(33)$ & $107.99(14)$ \\
\hline $\mathrm{C}(25)-\mathrm{N}(1)-\mathrm{C}(33)$ & $112.38(14)$ \\
\hline $\mathrm{C}(29)-\mathrm{N}(1)-\mathrm{C}(21)$ & $107.93(14)$ \\
\hline $\mathrm{C}(25)-\mathrm{N}(1)-\mathrm{C}(21)$ & $107.67(14)$ \\
\hline $\mathrm{C}(33)-\mathrm{N}(1)-\mathrm{C}(21)$ & $107.30(14)$ \\
\hline $\mathrm{C}(2)-\mathrm{C}(1)-\mathrm{C}(5)$ & $108.05(17)$ \\
\hline$C(2)-C(1)-C(6)$ & $126.43(18)$ \\
\hline$C(5)-C(1)-C(6)$ & $125.31(18)$ \\
\hline$C(2)-C(1)-U(1)$ & $76.88(11)$ \\
\hline $\mathrm{C}(5)-\mathrm{C}(1)-\mathrm{U}(1)$ & $74.73(10)$ \\
\hline $\mathrm{C}(6)-\mathrm{C}(1)-\mathrm{U}(1)$ & $118.76(13)$ \\
\hline $\mathrm{C}(3)-\mathrm{C}(2)-\mathrm{C}(1)$ & $108.08(17)$ \\
\hline $\mathrm{C}(3)-\mathrm{C}(2)-\mathrm{C}(7)$ & $123.98(19)$ \\
\hline $\mathrm{C}(1)-\mathrm{C}(2)-\mathrm{C}(7)$ & 127.02(19) \\
\hline $\mathrm{C}(3)-\mathrm{C}(2)-\mathrm{U}(1)$ & $76.32(11)$ \\
\hline $\mathrm{C}(1)-\mathrm{C}(2)-\mathrm{U}(1)$ & $73.44(11)$ \\
\hline
\end{tabular}




\begin{tabular}{|c|c|}
\hline$C(7)-C(2)-U(1)$ & $124.94(14)$ \\
\hline$C(2)-C(3)-C(4)$ & $108.28(17)$ \\
\hline $\mathrm{C}(2)-\mathrm{C}(3)-\mathrm{C}(8)$ & $123.22(18)$ \\
\hline $\mathrm{C}(4)-\mathrm{C}(3)-\mathrm{C}(8)$ & $127.04(18)$ \\
\hline$C(2)-C(3)-U(1)$ & $74.47(11)$ \\
\hline $\mathrm{C}(4)-\mathrm{C}(3)-\mathrm{U}(1)$ & $73.69(10)$ \\
\hline $\mathrm{C}(8)-\mathrm{C}(3)-\mathrm{U}(1)$ & $128.70(13)$ \\
\hline$C(3)-C(4)-C(5)$ & $107.76(16)$ \\
\hline$C(3)-C(4)-C(9)$ & $125.45(17)$ \\
\hline $\mathrm{C}(5)-\mathrm{C}(4)-\mathrm{C}(9)$ & $126.36(17)$ \\
\hline$C(3)-C(4)-U(1)$ & $76.89(10)$ \\
\hline $\mathrm{C}(5)-\mathrm{C}(4)-\mathrm{U}(1)$ & $73.73(10)$ \\
\hline $\mathrm{C}(9)-\mathrm{C}(4)-\mathrm{U}(1)$ & $121.29(13)$ \\
\hline$C(1)-C(5)-C(4)$ & $107.82(16)$ \\
\hline$C(1)-C(5)-C(10)$ & $125.00(18)$ \\
\hline $\mathrm{C}(4)-\mathrm{C}(5)-\mathrm{C}(10)$ & $126.95(17)$ \\
\hline$C(1)-C(5)-U(1)$ & $75.26(10)$ \\
\hline $\mathrm{C}(4)-\mathrm{C}(5)-\mathrm{U}(1)$ & $76.33(10)$ \\
\hline $\mathrm{C}(10)-\mathrm{C}(5)-\mathrm{U}(1)$ & $118.89(12)$ \\
\hline $\mathrm{C}(15)-\mathrm{C}(11)-\mathrm{C}(12)$ & $108.34(18)$ \\
\hline $\mathrm{C}(15)-\mathrm{C}(11)-\mathrm{C}(16)$ & $125.2(2)$ \\
\hline $\mathrm{C}(12)-\mathrm{C}(11)-\mathrm{C}(16)$ & $126.3(2)$ \\
\hline $\mathrm{C}(15)-\mathrm{C}(11)-\mathrm{U}(1)$ & $75.86(11)$ \\
\hline $\mathrm{C}(12)-\mathrm{C}(11)-\mathrm{U}(1)$ & $76.10(11)$ \\
\hline $\mathrm{C}(16)-\mathrm{C}(11)-\mathrm{U}(1)$ & $118.23(13)$ \\
\hline $\mathrm{C}(13)-\mathrm{C}(12)-\mathrm{C}(11)$ & $107.39(18)$ \\
\hline $\mathrm{C}(13)-\mathrm{C}(12)-\mathrm{C}(17)$ & $125.50(19)$ \\
\hline $\mathrm{C}(11)-\mathrm{C}(12)-\mathrm{C}(17)$ & $126.63(19)$ \\
\hline $\mathrm{C}(13)-\mathrm{C}(12)-\mathrm{U}(1)$ & $76.92(11)$ \\
\hline $\mathrm{C}(11)-\mathrm{C}(12)-\mathrm{U}(1)$ & 73.94(11) \\
\hline $\mathrm{C}(17)-\mathrm{C}(12)-\mathrm{U}(1)$ & $121.31(14)$ \\
\hline $\mathrm{C}(14)-\mathrm{C}(13)-\mathrm{C}(12)$ & $108.33(17)$ \\
\hline $\mathrm{C}(14)-\mathrm{C}(13)-\mathrm{C}(18)$ & $123.24(18)$ \\
\hline $\mathrm{C}(12)-\mathrm{C}(13)-\mathrm{C}(18)$ & $126.95(18)$ \\
\hline $\mathrm{C}(14)-\mathrm{C}(13)-\mathrm{U}(1)$ & $75.36(11)$ \\
\hline $\mathrm{C}(12)-\mathrm{C}(13)-\mathrm{U}(1)$ & $73.64(11)$ \\
\hline
\end{tabular}




$\begin{array}{lc}\mathrm{C}(18)-\mathrm{C}(13)-\mathrm{U}(1) & 128.04(13) \\ \mathrm{C}(13)-\mathrm{C}(14)-\mathrm{C}(15) & 108.23(17) \\ \mathrm{C}(13)-\mathrm{C}(14)-\mathrm{C}(19) & 124.21(19) \\ \mathrm{C}(15)-\mathrm{C}(14)-\mathrm{C}(19) & 126.66(19) \\ \mathrm{C}(13)-\mathrm{C}(14)-\mathrm{U}(1) & 75.48(11) \\ \mathrm{C}(15)-\mathrm{C}(14)-\mathrm{U}(1) & 73.39(11) \\ \mathrm{C}(19)-\mathrm{C}(14)-\mathrm{U}(1) & 125.74(13) \\ \mathrm{C}(11)-\mathrm{C}(15)-\mathrm{C}(14) & 107.71(18) \\ \mathrm{C}(11)-\mathrm{C}(15)-\mathrm{C}(20) & 125.7(2) \\ \mathrm{C}(14)-\mathrm{C}(15)-\mathrm{C}(20) & 126.5(2) \\ \mathrm{C}(11)-\mathrm{C}(15)-\mathrm{U}(1) & 74.29(11) \\ \mathrm{C}(14)-\mathrm{C}(15)-\mathrm{U}(1) & 77.14(11) \\ \mathrm{C}(20)-\mathrm{C}(15)-\mathrm{U}(1) & 117.13(13) \\ \mathrm{C}(22)-\mathrm{C}(21)-\mathrm{N}(1) & 116.26(15) \\ \mathrm{C}(23)-\mathrm{C}(22)-\mathrm{C}(21) & 109.34(15) \\ \mathrm{C}(24)-\mathrm{C}(23)-\mathrm{C}(22) & 112.05(17) \\ \mathrm{C}(26)-\mathrm{C}(25)-\mathrm{N}(1) & 118.22(16) \\ \mathrm{C}(25)-\mathrm{C}(26)-\mathrm{C}(27) & 108.88(16) \\ \mathrm{C}(28)-\mathrm{C}(27)-\mathrm{C}(26) & 113.05(18) \\ \mathrm{N}(1)-\mathrm{C}(29)-\mathrm{C}(30) & 116.04(16) \\ \mathrm{C}(29)-\mathrm{C}(30)-\mathrm{C}(31) & 109.00(18) \\ \mathrm{C}(32)-\mathrm{C}(31)-\mathrm{C}(30) & 112.6(2) \\ \mathrm{C}(34)-\mathrm{C}(33)-\mathrm{N}(1) & 118.02(15) \\ \mathrm{C}(33)-\mathrm{C}(34)-\mathrm{C}(35) & 108.26(16) \\ \mathrm{C}(36)-\mathrm{C}(35)-\mathrm{C}(34) & 112.20(18) \\ \mathrm{C}(39) \# 1-\mathrm{C}(37)-\mathrm{C}(38 \mathrm{~A}) & 120.6(3) \\ \mathrm{C}(37) \# 1-\mathrm{C}(39)-\mathrm{C}(38 \mathrm{~A}) & 120.1(3) \\ \mathrm{C}(39)-\mathrm{C}(38 \mathrm{~A})-\mathrm{C}(37) & 119.3(3) \\ \mathrm{C}(39)-\mathrm{C}(38 \mathrm{~A})-\mathrm{C}(40) & 120.1(5) \\ \mathrm{C}(37)-\mathrm{C}(38 \mathrm{~A})-\mathrm{C}(40) & 120.5(5) \\ & \end{array}$




\section{X-ray Data Collection, Structure Solution and Refinement for 3.}

A green crystal of approximate dimensions $0.141 \times 0.201 \times 0.256 \mathrm{~mm}$ was mounted on a glass fiber and transferred to a Bruker SMART APEX II diffractometer. The APEX2 ${ }^{7}$ program package was used to determine the unit-cell parameters and for data collection $(25 \mathrm{sec} /$ frame scan time for a sphere of diffraction data). The raw frame data was processed using SAINT $^{2}$ and SADABS ${ }^{3}$ to yield the reflection data file. Subsequent calculations were carried out using the SHELXTL ${ }^{4}$ program. The diffraction symmetry was $\mathrm{mmm}$ and the systematic absences were consistent with the orthorhombic space group Pbca that was later determined to be correct.

The structure was solved by direct methods and refined on $\mathrm{F}^{2}$ by full-matrix least-squares techniques ${ }^{8}$. The analytical scattering factors ${ }^{6}$ for neutral atoms were used throughout the analysis. Hydrogen atoms were included using a riding model. Carbon atoms C(23) and (24) were disordered and included using multiple components with partial siteoccupancy-factors.

At convergence, $\mathrm{wR} 2=0.0464$ and Goof $=1.020$ for 394 variables refined against 6972 data $(0.78 \AA ⿱ 冂 一), ~ R 1=0.0187$ for those 5861 data with $\mathrm{I}>2.0 \sigma(\mathrm{I})$.

Definitions:

$\mathrm{wR} 2=\left[\Sigma\left[\mathrm{w}\left(\mathrm{F}_{\mathrm{o}}^{2}-\mathrm{F}_{\mathrm{c}}^{2}\right)^{2}\right] / \Sigma\left[\mathrm{w}\left(\mathrm{F}_{\mathrm{o}}^{2}\right)^{2}\right]\right]^{1 / 2}$

$\mathrm{R} 1=\Sigma|| \mathrm{F}_{\mathrm{o}}|-| \mathrm{F}_{\mathrm{c}} \| / \Sigma\left|\mathrm{F}_{\mathrm{o}}\right|$

Goof $=\mathrm{S}=\left[\Sigma\left[\mathrm{w}\left(\mathrm{F}_{\mathrm{o}}^{2}-\mathrm{F}_{\mathrm{c}}\right)^{2}\right] /(\mathrm{n}-\mathrm{p})\right]^{1 / 2}$ where $\mathrm{n}$ is the number of reflections and $\mathrm{p}$ is the total number of parameters refined. 


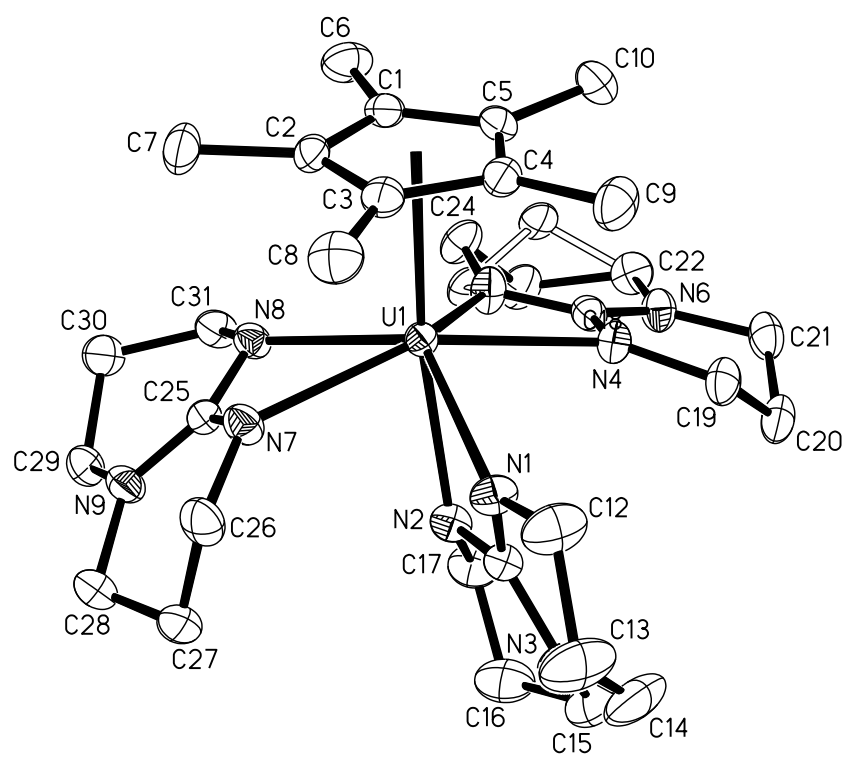

Figure S5. Thermal ellipsoid plot of $\left[\left(\mathrm{C}_{5} \mathrm{Me}_{5}\right) \mathrm{U}(\mathrm{hpp})_{3}, \mathbf{3}\right.$, shown at the $50 \%$ probability level with hydrogen atoms removed for clarity.

Table S5. Crystal data and structure refinement for $\mathbf{3}$.

Identification code

Empirical formula

Formula weight

Temperature

Wavelength

Crystal system

Space group

Unit cell dimensions

Volume

$\mathrm{Z}$

Density (calculated)

Absorption coefficient

$\mathrm{F}(000)$ clw61 (Chris Webster)

$\mathrm{C}_{31} \mathrm{H}_{51} \mathrm{~N}_{9} \mathrm{U}$

787.83

143(2) K

$0.71073 \AA$

Orthorhombic

Pbca

$$
\begin{array}{ll}
\mathrm{a}=18.9445(10) \AA & \square=90^{\circ} . \\
\mathrm{b}=16.9108(9) \AA & \square=90^{\circ} . \\
\mathrm{c}=19.7306(10) \AA & \square=90^{\circ} .
\end{array}
$$

8

$1.656 \mathrm{Mg} / \mathrm{m}^{3}$

$5.172 \mathrm{~mm}^{-1}$

3136 
Crystal color

Crystal size

Theta range for data collection

Index ranges

Reflections collected

Independent reflections

Completeness to theta $=25.242^{\circ}$

Absorption correction

Max. and min. transmission

Refinement method

Data / restraints / parameters

Goodness-of-fit on $\mathrm{F}^{2}$

Final $\mathrm{R}$ indices $[\mathrm{I}>2 \operatorname{sigma}(\mathrm{I})=5861$ data $]$

$\mathrm{R}$ indices (all data, $0.78 \AA$ )

Largest diff. peak and hole green

$0.256 \times 0.201 \times 0.141 \mathrm{~mm}^{3}$

1.916 to $27.102^{\circ}$

$-24 \leq h \leq 24,-21 \leq k \leq 21,-25 \leq l \leq 25$

68683

$6972[\mathrm{R}(\mathrm{int})=0.0296]$

$99.9 \%$

Numerical

0.6246 and 0.3916

Full-matrix least-squares on $\mathrm{F}^{2}$

6972 / 0 / 394

1.020

$\mathrm{R} 1=0.0187, \mathrm{wR} 2=0.0436$

$\mathrm{R} 1=0.0259, \mathrm{wR} 2=0.0464$

1.296 and -0.582 e. $\AA^{-3}$

Table S6. Bond lengths $[\AA]$ and angles $\left[{ }^{\circ}\right]$ for 3 .

\begin{tabular}{ll}
\hline $\mathrm{U}(1)-\mathrm{Cnt}$ & 2.491 \\
$\mathrm{U}(1)-\mathrm{N}(2)$ & $2.380(2)$ \\
$\mathrm{U}(1)-\mathrm{N}(5)$ & $2.439(2)$ \\
$\mathrm{U}(1)-\mathrm{N}(8)$ & $2.443(2)$ \\
$\mathrm{U}(1)-\mathrm{N}(7)$ & $2.448(2)$ \\
$\mathrm{U}(1)-\mathrm{N}(4)$ & $2.469(2)$ \\
$\mathrm{U}(1)-\mathrm{N}(1)$ & $2.472(2)$ \\
$\mathrm{U}(1)-\mathrm{C}(3)$ & $2.756(2)$ \\
$\mathrm{U}(1)-\mathrm{C}(4)$ & $2.759(2)$ \\
$\mathrm{U}(1)-\mathrm{C}(5)$ & $2.769(2)$ \\
$\mathrm{U}(1)-\mathrm{C}(2)$ & $2.774(2)$ \\
$\mathrm{U}(1)-\mathrm{C}(1)$ & $2.775(2)$ \\
$\mathrm{N}(1)-\mathrm{C}(11)$ & $1.334(3)$ \\
$\mathrm{N}(1)-\mathrm{C}(12)$ & $1.452(3)$
\end{tabular}




\begin{tabular}{|c|c|}
\hline $\mathrm{N}(2)-\mathrm{C}(11)$ & $1.336(3)$ \\
\hline $\mathrm{N}(2)-\mathrm{C}(17)$ & $1.445(3)$ \\
\hline $\mathrm{N}(3)-\mathrm{C}(11)$ & $1.375(3)$ \\
\hline $\mathrm{N}(3)-\mathrm{C}(15)$ & $1.456(4)$ \\
\hline $\mathrm{N}(3)-\mathrm{C}(14)$ & $1.459(4)$ \\
\hline $\mathrm{N}(4)-\mathrm{C}(18)$ & $1.334(3)$ \\
\hline $\mathrm{N}(4)-\mathrm{C}(19)$ & $1.440(3)$ \\
\hline $\mathrm{N}(5)-\mathrm{C}(18)$ & $1.343(3)$ \\
\hline $\mathrm{N}(5)-\mathrm{C}(24)$ & $1.466(6)$ \\
\hline $\mathrm{N}(5)-\mathrm{C}(24 \mathrm{~B})$ & $1.501(14)$ \\
\hline $\mathrm{N}(6)-\mathrm{C}(18)$ & $1.369(3)$ \\
\hline $\mathrm{N}(6)-\mathrm{C}(22)$ & $1.455(3)$ \\
\hline $\mathrm{N}(6)-\mathrm{C}(21)$ & $1.456(3)$ \\
\hline $\mathrm{N}(7)-\mathrm{C}(25)$ & $1.325(3)$ \\
\hline $\mathrm{N}(7)-\mathrm{C}(26)$ & $1.456(3)$ \\
\hline $\mathrm{N}(8)-\mathrm{C}(25)$ & $1.344(3)$ \\
\hline $\mathrm{N}(8)-\mathrm{C}(31)$ & $1.448(3)$ \\
\hline $\mathrm{N}(9)-\mathrm{C}(25)$ & $1.371(3)$ \\
\hline $\mathrm{N}(9)-\mathrm{C}(29)$ & $1.450(3)$ \\
\hline $\mathrm{N}(9)-\mathrm{C}(28)$ & $1.457(3)$ \\
\hline $\mathrm{C}(1)-\mathrm{C}(5)$ & $1.413(3)$ \\
\hline $\mathrm{C}(1)-\mathrm{C}(2)$ & $1.416(3)$ \\
\hline $\mathrm{C}(1)-\mathrm{C}(6)$ & $1.501(3)$ \\
\hline $\mathrm{C}(2)-\mathrm{C}(3)$ & $1.417(3)$ \\
\hline $\mathrm{C}(2)-\mathrm{C}(7)$ & $1.502(3)$ \\
\hline $\mathrm{C}(3)-\mathrm{C}(4)$ & $1.418(3)$ \\
\hline $\mathrm{C}(3)-\mathrm{C}(8)$ & $1.502(4)$ \\
\hline $\mathrm{C}(4)-\mathrm{C}(5)$ & $1.414(4)$ \\
\hline $\mathrm{C}(4)-\mathrm{C}(9)$ & $1.502(3)$ \\
\hline$C(5)-C(10)$ & $1.495(4)$ \\
\hline $\mathrm{C}(12)-\mathrm{C}(13)$ & $1.504(4)$ \\
\hline $\mathrm{C}(13)-\mathrm{C}(14)$ & $1.495(5)$ \\
\hline $\mathrm{C}(15)-\mathrm{C}(16)$ & $1.501(4)$ \\
\hline $\mathrm{C}(16)-\mathrm{C}(17)$ & $1.509(4)$ \\
\hline $\mathrm{C}(19)-\mathrm{C}(20)$ & $1.522(3)$ \\
\hline $\mathrm{C}(20)-\mathrm{C}(21)$ & $1.510(4)$ \\
\hline
\end{tabular}




\begin{tabular}{|c|c|}
\hline $\mathrm{C}(22)-\mathrm{C}(23 \mathrm{~B})$ & $1.470(10)$ \\
\hline$C(22)-C(23)$ & $1.560(5)$ \\
\hline$C(23)-C(24)$ & $1.509(8)$ \\
\hline $\mathrm{C}(23 \mathrm{~B})-\mathrm{C}(24 \mathrm{~B})$ & $1.511(18)$ \\
\hline$C(26)-C(27)$ & $1.511(4)$ \\
\hline$C(27)-C(28)$ & $1.511(4)$ \\
\hline$C(29)-C(30)$ & $1.509(4)$ \\
\hline$C(30)-C(31)$ & $1.515(4)$ \\
\hline Cnt-U(1)-N(1) & 110.0 \\
\hline Cnt-U(1)-N(2) & 164.7 \\
\hline Cnt-U(1)-N(4) & 99.8 \\
\hline Cnt-U(1)-N(5) & 103.0 \\
\hline Cnt-U(1)-N(7) & 100.1 \\
\hline Cnt-U(1)-N(8) & 103.3 \\
\hline $\mathrm{N}(2)-\mathrm{U}(1)-\mathrm{N}(5)$ & $86.95(7)$ \\
\hline $\mathrm{N}(2)-\mathrm{U}(1)-\mathrm{N}(8)$ & $89.45(7)$ \\
\hline $\mathrm{N}(5)-\mathrm{U}(1)-\mathrm{N}(8)$ & $82.15(7)$ \\
\hline $\mathrm{N}(2)-\mathrm{U}(1)-\mathrm{N}(7)$ & $80.31(7)$ \\
\hline $\mathrm{N}(5)-\mathrm{U}(1)-\mathrm{N}(7)$ & $134.47(7)$ \\
\hline $\mathrm{N}(8)-\mathrm{U}(1)-\mathrm{N}(7)$ & $54.43(7)$ \\
\hline $\mathrm{N}(2)-\mathrm{U}(1)-\mathrm{N}(4)$ & $76.34(7)$ \\
\hline $\mathrm{N}(5)-\mathrm{U}(1)-\mathrm{N}(4)$ & $54.43(7)$ \\
\hline $\mathrm{N}(8)-\mathrm{U}(1)-\mathrm{N}(4)$ & $134.40(7)$ \\
\hline $\mathrm{N}(7)-\mathrm{U}(1)-\mathrm{N}(4)$ & $154.55(7)$ \\
\hline $\mathrm{N}(2)-\mathrm{U}(1)-\mathrm{N}(1)$ & $54.93(7)$ \\
\hline $\mathrm{N}(5)-\mathrm{U}(1)-\mathrm{N}(1)$ & 127.51(7) \\
\hline $\mathrm{N}(8)-\mathrm{U}(1)-\mathrm{N}(1)$ & $125.92(7)$ \\
\hline $\mathrm{N}(7)-\mathrm{U}(1)-\mathrm{N}(1)$ & $78.27(7)$ \\
\hline $\mathrm{N}(4)-\mathrm{U}(1)-\mathrm{N}(1)$ & $80.10(7)$ \\
\hline $\mathrm{N}(2)-\mathrm{U}(1)-\mathrm{C}(3)$ & $142.12(7)$ \\
\hline $\mathrm{N}(5)-\mathrm{U}(1)-\mathrm{C}(3)$ & $128.85(8)$ \\
\hline $\mathrm{N}(8)-\mathrm{U}(1)-\mathrm{C}(3)$ & $105.57(7)$ \\
\hline $\mathrm{N}(7)-\mathrm{U}(1)-\mathrm{C}(3)$ & $80.86(7)$ \\
\hline $\mathrm{N}(4)-\mathrm{U}(1)-\mathrm{C}(3)$ & $112.13(7)$ \\
\hline $\mathrm{N}(1)-\mathrm{U}(1)-\mathrm{C}(3)$ & $89.14(7)$ \\
\hline
\end{tabular}




\begin{tabular}{|c|c|}
\hline $\mathrm{N}(2)-\mathrm{U}(1)-\mathrm{C}(4)$ & $139.76(7)$ \\
\hline $\mathrm{N}(5)-\mathrm{U}(1)-\mathrm{C}(4)$ & $108.05(8)$ \\
\hline $\mathrm{N}(8)-\mathrm{U}(1)-\mathrm{C}(4)$ & $128.72(7)$ \\
\hline $\mathrm{N}(7)-\mathrm{U}(1)-\mathrm{C}(4)$ & $109.75(7)$ \\
\hline $\mathrm{N}(4)-\mathrm{U}(1)-\mathrm{C}(4)$ & $82.65(7)$ \\
\hline $\mathrm{N}(1)-\mathrm{U}(1)-\mathrm{C}(4)$ & $88.09(7)$ \\
\hline $\mathrm{C}(3)-\mathrm{U}(1)-\mathrm{C}(4)$ & $29.79(7)$ \\
\hline $\mathrm{N}(2)-\mathrm{U}(1)-\mathrm{C}(5)$ & $151.92(7)$ \\
\hline $\mathrm{N}(5)-\mathrm{U}(1)-\mathrm{C}(5)$ & $81.15(8)$ \\
\hline $\mathrm{N}(8)-\mathrm{U}(1)-\mathrm{C}(5)$ & $113.75(7)$ \\
\hline $\mathrm{N}(7)-\mathrm{U}(1)-\mathrm{C}(5)$ & $125.60(7)$ \\
\hline $\mathrm{N}(4)-\mathrm{U}(1)-\mathrm{C}(5)$ & $76.04(7)$ \\
\hline $\mathrm{N}(1)-\mathrm{U}(1)-\mathrm{C}(5)$ & $114.75(7)$ \\
\hline $\mathrm{C}(3)-\mathrm{U}(1)-\mathrm{C}(5)$ & $48.98(7)$ \\
\hline $\mathrm{C}(4)-\mathrm{U}(1)-\mathrm{C}(5)$ & $29.64(7)$ \\
\hline $\mathrm{N}(2)-\mathrm{U}(1)-\mathrm{C}(2)$ & $157.63(7)$ \\
\hline $\mathrm{N}(5)-\mathrm{U}(1)-\mathrm{C}(2)$ & $110.83(8)$ \\
\hline $\mathrm{N}(8)-\mathrm{U}(1)-\mathrm{C}(2)$ & $80.08(7)$ \\
\hline $\mathrm{N}(7)-\mathrm{U}(1)-\mathrm{C}(2)$ & $77.51(7)$ \\
\hline $\mathrm{N}(4)-\mathrm{U}(1)-\mathrm{C}(2)$ & $124.79(7)$ \\
\hline $\mathrm{N}(1)-\mathrm{U}(1)-\mathrm{C}(2)$ & $116.72(7)$ \\
\hline $\mathrm{C}(3)-\mathrm{U}(1)-\mathrm{C}(2)$ & $29.69(7)$ \\
\hline $\mathrm{C}(4)-\mathrm{U}(1)-\mathrm{C}(2)$ & $48.97(7)$ \\
\hline $\mathrm{C}(5)-\mathrm{U}(1)-\mathrm{C}(2)$ & $48.83(7)$ \\
\hline $\mathrm{N}(2)-\mathrm{U}(1)-\mathrm{C}(1)$ & $168.95(7)$ \\
\hline $\mathrm{N}(5)-\mathrm{U}(1)-\mathrm{C}(1)$ & $82.84(7)$ \\
\hline $\mathrm{N}(8)-\mathrm{U}(1)-\mathrm{C}(1)$ & $84.97(7)$ \\
\hline $\mathrm{N}(7)-\mathrm{U}(1)-\mathrm{C}(1)$ & $103.92(7)$ \\
\hline $\mathrm{N}(4)-\mathrm{U}(1)-\mathrm{C}(1)$ & $100.89(7)$ \\
\hline $\mathrm{N}(1)-\mathrm{U}(1)-\mathrm{C}(1)$ & $135.63(7)$ \\
\hline $\mathrm{C}(3)-\mathrm{U}(1)-\mathrm{C}(1)$ & $48.89(7)$ \\
\hline $\mathrm{C}(4)-\mathrm{U}(1)-\mathrm{C}(1)$ & $48.84(7)$ \\
\hline $\mathrm{C}(5)-\mathrm{U}(1)-\mathrm{C}(1)$ & $29.53(7)$ \\
\hline $\mathrm{C}(2)-\mathrm{U}(1)-\mathrm{C}(1)$ & $29.56(7)$ \\
\hline $\mathrm{C}(11)-\mathrm{N}(1)-\mathrm{C}(12)$ & $119.5(2)$ \\
\hline $\mathrm{C}(11)-\mathrm{N}(1)-\mathrm{U}(1)$ & $92.48(15)$ \\
\hline
\end{tabular}




\begin{tabular}{|c|c|}
\hline $\mathrm{C}(12)-\mathrm{N}(1)-\mathrm{U}(1)$ & $145.17(18)$ \\
\hline $\mathrm{C}(11)-\mathrm{N}(2)-\mathrm{C}(17)$ & $120.5(2)$ \\
\hline $\mathrm{C}(11)-\mathrm{N}(2)-\mathrm{U}(1)$ & $96.55(15)$ \\
\hline $\mathrm{C}(17)-\mathrm{N}(2)-\mathrm{U}(1)$ & $134.01(17)$ \\
\hline $\mathrm{C}(11)-\mathrm{N}(3)-\mathrm{C}(15)$ & $118.6(2)$ \\
\hline $\mathrm{C}(11)-\mathrm{N}(3)-\mathrm{C}(14)$ & $118.8(2)$ \\
\hline $\mathrm{C}(15)-\mathrm{N}(3)-\mathrm{C}(14)$ & $117.5(2)$ \\
\hline $\mathrm{C}(18)-\mathrm{N}(4)-\mathrm{C}(19)$ & $120.6(2)$ \\
\hline $\mathrm{C}(18)-\mathrm{N}(4)-\mathrm{U}(1)$ & $95.10(15)$ \\
\hline $\mathrm{C}(19)-\mathrm{N}(4)-\mathrm{U}(1)$ & $142.83(17)$ \\
\hline $\mathrm{C}(18)-\mathrm{N}(5)-\mathrm{C}(24)$ & $119.0(3)$ \\
\hline $\mathrm{C}(18)-\mathrm{N}(5)-\mathrm{C}(24 \mathrm{~B})$ & $112.5(6)$ \\
\hline $\mathrm{C}(18)-\mathrm{N}(5)-\mathrm{U}(1)$ & $96.22(15)$ \\
\hline $\mathrm{C}(24)-\mathrm{N}(5)-\mathrm{U}(1)$ & 144.1(3) \\
\hline $\mathrm{C}(24 \mathrm{~B})-\mathrm{N}(5)-\mathrm{U}(1)$ & $145.8(6)$ \\
\hline $\mathrm{C}(18)-\mathrm{N}(6)-\mathrm{C}(22)$ & $122.1(2)$ \\
\hline $\mathrm{C}(18)-\mathrm{N}(6)-\mathrm{C}(21)$ & $119.9(2)$ \\
\hline $\mathrm{C}(22)-\mathrm{N}(6)-\mathrm{C}(21)$ & $117.6(2)$ \\
\hline $\mathrm{C}(25)-\mathrm{N}(7)-\mathrm{C}(26)$ & $117.6(2)$ \\
\hline $\mathrm{C}(25)-\mathrm{N}(7)-\mathrm{U}(1)$ & $93.06(15)$ \\
\hline $\mathrm{C}(26)-\mathrm{N}(7)-\mathrm{U}(1)$ & $137.66(17)$ \\
\hline $\mathrm{C}(25)-\mathrm{N}(8)-\mathrm{C}(31)$ & $118.3(2)$ \\
\hline $\mathrm{C}(25)-\mathrm{N}(8)-\mathrm{U}(1)$ & $92.81(15)$ \\
\hline $\mathrm{C}(31)-\mathrm{N}(8)-\mathrm{U}(1)$ & $142.08(16)$ \\
\hline $\mathrm{C}(25)-\mathrm{N}(9)-\mathrm{C}(29)$ & $121.2(2)$ \\
\hline $\mathrm{C}(25)-\mathrm{N}(9)-\mathrm{C}(28)$ & $121.3(2)$ \\
\hline $\mathrm{C}(29)-\mathrm{N}(9)-\mathrm{C}(28)$ & $116.6(2)$ \\
\hline$C(5)-C(1)-C(2)$ & $108.2(2)$ \\
\hline$C(5)-C(1)-C(6)$ & $126.7(2)$ \\
\hline$C(2)-C(1)-C(6)$ & $125.1(2)$ \\
\hline$C(5)-C(1)-U(1)$ & $75.00(14)$ \\
\hline $\mathrm{C}(2)-\mathrm{C}(1)-\mathrm{U}(1)$ & $75.20(14)$ \\
\hline $\mathrm{C}(6)-\mathrm{C}(1)-\mathrm{U}(1)$ & $116.47(16)$ \\
\hline $\mathrm{C}(1)-\mathrm{C}(2)-\mathrm{C}(3)$ & $107.8(2)$ \\
\hline$C(1)-C(2)-C(7)$ & $125.2(2)$ \\
\hline $\mathrm{C}(3)-\mathrm{C}(2)-\mathrm{C}(7)$ & $126.9(2)$ \\
\hline
\end{tabular}




\begin{tabular}{|c|c|}
\hline $\mathrm{C}(1)-\mathrm{C}(2)-\mathrm{U}(1)$ & $75.24(14)$ \\
\hline $\mathrm{C}(3)-\mathrm{C}(2)-\mathrm{U}(1)$ & $74.45(13)$ \\
\hline $\mathrm{C}(7)-\mathrm{C}(2)-\mathrm{U}(1)$ & 119.07(16) \\
\hline $\mathrm{C}(2)-\mathrm{C}(3)-\mathrm{C}(4)$ & $108.0(2)$ \\
\hline $\mathrm{C}(2)-\mathrm{C}(3)-\mathrm{C}(8)$ & $125.0(2)$ \\
\hline $\mathrm{C}(4)-\mathrm{C}(3)-\mathrm{C}(8)$ & $127.0(2)$ \\
\hline $\mathrm{C}(2)-\mathrm{C}(3)-\mathrm{U}(1)$ & $75.86(14)$ \\
\hline $\mathrm{C}(4)-\mathrm{C}(3)-\mathrm{U}(1)$ & $75.20(14)$ \\
\hline $\mathrm{C}(8)-\mathrm{C}(3)-\mathrm{U}(1)$ & $115.74(16)$ \\
\hline$C(5)-C(4)-C(3)$ & $108.0(2)$ \\
\hline $\mathrm{C}(5)-\mathrm{C}(4)-\mathrm{C}(9)$ & $125.2(2)$ \\
\hline $\mathrm{C}(3)-\mathrm{C}(4)-\mathrm{C}(9)$ & $126.8(2)$ \\
\hline $\mathrm{C}(5)-\mathrm{C}(4)-\mathrm{U}(1)$ & $75.57(13)$ \\
\hline$C(3)-C(4)-U(1)$ & $75.01(13)$ \\
\hline $\mathrm{C}(9)-\mathrm{C}(4)-\mathrm{U}(1)$ & $118.13(16)$ \\
\hline$C(1)-C(5)-C(4)$ & $108.1(2)$ \\
\hline $\mathrm{C}(1)-\mathrm{C}(5)-\mathrm{C}(10)$ & $126.3(2)$ \\
\hline $\mathrm{C}(4)-\mathrm{C}(5)-\mathrm{C}(10)$ & $125.4(2)$ \\
\hline $\mathrm{C}(1)-\mathrm{C}(5)-\mathrm{U}(1)$ & $75.48(14)$ \\
\hline$C(4)-C(5)-U(1)$ & $74.79(13)$ \\
\hline $\mathrm{C}(10)-\mathrm{C}(5)-\mathrm{U}(1)$ & 119.97(17) \\
\hline $\mathrm{N}(1)-\mathrm{C}(11)-\mathrm{N}(2)$ & $114.0(2)$ \\
\hline $\mathrm{N}(1)-\mathrm{C}(11)-\mathrm{N}(3)$ & $123.5(2)$ \\
\hline $\mathrm{N}(2)-\mathrm{C}(11)-\mathrm{N}(3)$ & $122.5(2)$ \\
\hline $\mathrm{N}(1)-\mathrm{C}(12)-\mathrm{C}(13)$ & $112.8(2)$ \\
\hline$C(14)-C(13)-C(12)$ & 109.1(3) \\
\hline $\mathrm{N}(3)-\mathrm{C}(14)-\mathrm{C}(13)$ & $109.8(3)$ \\
\hline $\mathrm{N}(3)-\mathrm{C}(15)-\mathrm{C}(16)$ & $110.9(2)$ \\
\hline$C(15)-C(16)-C(17)$ & $110.4(2)$ \\
\hline $\mathrm{N}(2)-\mathrm{C}(17)-\mathrm{C}(16)$ & $112.4(2)$ \\
\hline $\mathrm{N}(4)-\mathrm{C}(18)-\mathrm{N}(5)$ & $114.0(2)$ \\
\hline $\mathrm{N}(4)-\mathrm{C}(18)-\mathrm{N}(6)$ & $123.1(2)$ \\
\hline $\mathrm{N}(5)-\mathrm{C}(18)-\mathrm{N}(6)$ & $122.9(2)$ \\
\hline $\mathrm{N}(4)-\mathrm{C}(19)-\mathrm{C}(20)$ & $112.6(2)$ \\
\hline $\mathrm{C}(21)-\mathrm{C}(20)-\mathrm{C}(19)$ & 109.2(2) \\
\hline $\mathrm{N}(6)-\mathrm{C}(21)-\mathrm{C}(20)$ & $109.8(2)$ \\
\hline
\end{tabular}




$\begin{array}{ll}\mathrm{N}(6)-\mathrm{C}(22)-\mathrm{C}(23 \mathrm{~B}) & 111.5(4) \\ \mathrm{N}(6)-\mathrm{C}(22)-\mathrm{C}(23) & 108.8(2) \\ \mathrm{C}(24)-\mathrm{C}(23)-\mathrm{C}(22) & 109.6(4) \\ \mathrm{N}(5)-\mathrm{C}(24)-\mathrm{C}(23) & 109.3(4) \\ \mathrm{C}(22)-\mathrm{C}(23 \mathrm{~B})-\mathrm{C}(24 \mathrm{~B}) & 105.9(10) \\ \mathrm{N}(5)-\mathrm{C}(24 \mathrm{~B})-\mathrm{C}(23 \mathrm{~B}) & 108.2(11) \\ \mathrm{N}(7)-\mathrm{C}(25)-\mathrm{N}(8) & 113.9(2) \\ \mathrm{N}(7)-\mathrm{C}(25)-\mathrm{N}(9) & 123.1(2) \\ \mathrm{N}(8)-\mathrm{C}(25)-\mathrm{N}(9) & 123.1(2) \\ \mathrm{N}(7)-\mathrm{C}(26)-\mathrm{C}(27) & 111.5(2) \\ \mathrm{C}(28)-\mathrm{C}(27)-\mathrm{C}(26) & 108.9(2) \\ \mathrm{N}(9)-\mathrm{C}(28)-\mathrm{C}(27) & 111.0(2) \\ \mathrm{N}(9)-\mathrm{C}(29)-\mathrm{C}(30) & 110.0(2) \\ \mathrm{C}(29)-\mathrm{C}(30)-\mathrm{C}(31) & 108.8(2) \\ \mathrm{N}(8)-\mathrm{C}(31)-\mathrm{C}(30) & 111.3(2)\end{array}$

\section{X-ray Data Collection, Structure Solution and Refinement for 5.}

An orange crystal of approximate dimensions 0.047 x 0.053 x $0.198 \mathrm{~mm}$ was mounted on a glass fiber and transferred to a Bruker SMART APEX II diffractometer. The APEX2 ${ }^{1}$ program package was used to determine the unit-cell parameters and for data collection (45 sec/frame scan time for a sphere of diffraction data). The raw frame data was processed using $\mathrm{SAINT}^{2}$ and $\mathrm{SADABS}^{3}$ to yield the reflection data file. Subsequent calculations were carried out using the SHELXTL ${ }^{4}$ program. There were no systematic absences nor any diffraction symmetry other than the Friedel condition. The centrosymmetric triclinic space group $P \overline{1}$ was assigned and later determined to be correct.

The structure was solved by direct methods and refined on $\mathrm{F}^{2}$ by full-matrix least-squares techniques ${ }^{5}$. The analytical scattering factors ${ }^{6}$ for neutral atoms were used throughout the analysis. Hydrogen atoms were included using a riding model.

At convergence, $w R 2=0.0836$ and Goof $=1.005$ for 321 variables refined against 6574 data $(0.75 \AA), \mathrm{R} 1=0.0331$ for those 5844 data with $\mathrm{I}>2.0 \sigma(\mathrm{I})$.

Definitions:

$$
\begin{aligned}
& \mathrm{wR} 2=\left[\Sigma\left[\mathrm{w}\left(\mathrm{F}_{\mathrm{o}}^{2}-\mathrm{F}_{\mathrm{c}}{ }^{2}\right)^{2}\right] / \Sigma\left[\mathrm{w}\left(\mathrm{F}_{\mathrm{o}}{ }^{2}\right)^{2}\right]\right]^{1 / 2} \\
& \mathrm{R} 1=\Sigma\left\|\mathrm{F}_{\mathrm{o}}|-| \mathrm{F}_{\mathrm{c}}\right\| / \Sigma\left|\mathrm{F}_{\mathrm{o}}\right|
\end{aligned}
$$


Goof $=\mathrm{S}=\left[\Sigma\left[\mathrm{w}\left(\mathrm{F}_{\mathrm{o}}^{2}-\mathrm{F}_{\mathrm{c}}{ }^{2}\right)^{2}\right] /(\mathrm{n}-\mathrm{p})\right]^{1 / 2}$ where $\mathrm{n}$ is the number of reflections and $\mathrm{p}$ is the total number of parameters refined.

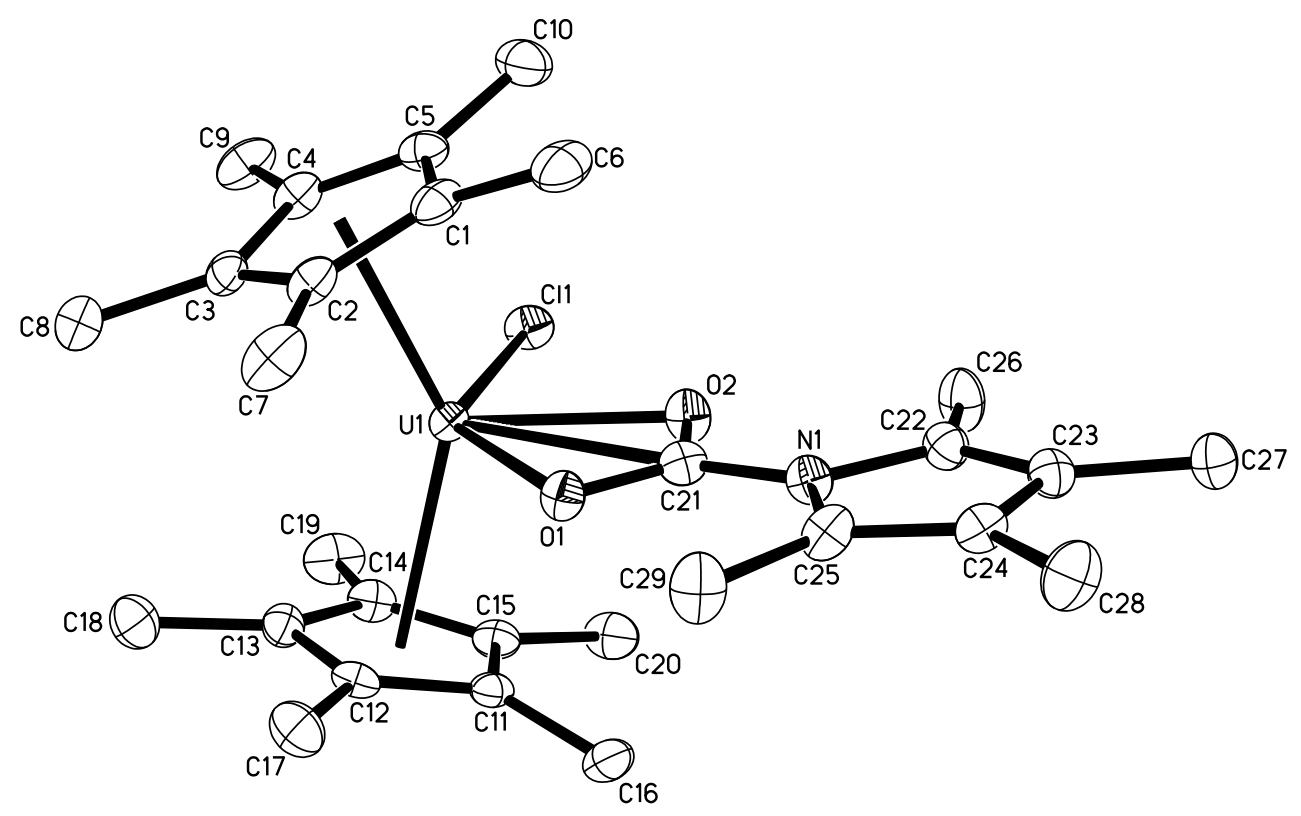

Figure S6. Thermal ellipsoid plot of $\left(\mathrm{C}_{5} \mathrm{Me}_{5}\right)_{2} \mathrm{U}\left(\kappa^{2}-O, O^{\prime}-\mathrm{O}_{2} \mathrm{CNC}_{4} \mathrm{Me}_{4}\right) \mathrm{Cl}, \mathbf{5}$, shown at the $50 \%$ probability level with hydrogen atoms removed for clarity.

Table S7. Crystal data and structure refinement for 5.

Identification code

clw23 (Chris Webster)

Empirical formula

$\mathrm{C}_{29} \mathrm{H}_{42} \mathrm{Cl} \mathrm{N} \mathrm{O} \mathrm{U}_{2}$

Formula weight

710.11

Temperature

88(2) K

Wavelength

$0.71073 \AA$

Crystal system

Space group

Triclinic

Unit cell dimensions

$P \overline{1}$

\section{Unit cell dimensions}

$\mathrm{a}=8.4285(13) \AA$

$\square=94.9062(18)^{\circ}$.

$\mathrm{b}=10.3929(16) \AA$

$\square=95.2116(18)^{\circ}$.

$\mathrm{c}=17.363(3) \AA$

$\square=111.1593(17)^{\circ}$.

Volume

1401.0(4) $\AA^{3}$

$\mathrm{Z}$

2

Density (calculated)

$1.683 \mathrm{Mg} / \mathrm{m}^{3}$ 


$\begin{array}{ll}\text { Absorption coefficient } & 5.913 \mathrm{~mm}^{-1} \\ \mathrm{~F}(000) & 696 \\ \text { Crystal color } & \text { orange } \\ \text { Crystal size } & 0.198 \times 0.053 \times 0.047 \mathrm{~mm}^{3} \\ \text { Theta range for data collection } & 2.118 \text { to } 28.284^{\circ} \\ \text { Index ranges } & -11 \leq h \leq 11,-13 \leq k \leq 13,-22 \leq l \leq 22 \\ \text { Reflections collected } & 16363 \\ \text { Independent reflections } & 6574[\mathrm{R}(\mathrm{int})=0.0343] \\ \text { Completeness to theta }=25.242^{\circ} & 99.8 \% \\ \text { Absorption correction } & \mathrm{Numerical} \\ \text { Refinement method } & \text { Full-matrix least-squares on } \mathrm{F}^{2} \\ \text { Data / restraints / parameters } & 6574 / 0 / 321 \\ \text { Goodness-of-fit on } \mathrm{F}^{2} & 1.005 \\ \text { Final R indices [I } 2 \text { sigma(I) }=5844 \text { data] } & \mathrm{R} 1=0.0331, \text { wR2 }=0.0807 \\ \text { R indices (all data, } 0.75 \AA \text { ) } & \mathrm{R} 1=0.0403, \text { wR2 }=0.0836 \\ \text { Largest diff. peak and hole } & 3.148 \text { and }-1.658 \text { e. } \AA^{-3}\end{array}$

Table S8. Bond lengths $[\AA ̊]$ and angles $\left[{ }^{\circ}\right]$ for $\mathbf{5}$.

\begin{tabular}{ll}
\hline $\mathrm{U}(1)-\mathrm{Cnt} 1$ & 2.443 \\
$\mathrm{U}(1)-\mathrm{Cnt} 2$ & 2.452 \\
$\mathrm{U}(1)-\mathrm{O}(2)$ & $2.404(3)$ \\
$\mathrm{U}(1)-\mathrm{O}(1)$ & $2.457(3)$ \\
$\mathrm{U}(1)-\mathrm{Cl}(1)$ & $2.6222(11)$ \\
$\mathrm{U}(1)-\mathrm{C}(15)$ & $2.715(5)$ \\
$\mathrm{U}(1)-\mathrm{C}(4)$ & $2.716(5)$ \\
$\mathrm{U}(1)-\mathrm{C}(11)$ & $2.717(4)$ \\
$\mathrm{U}(1)-\mathrm{C}(5)$ & $2.720(5)$ \\
$\mathrm{U}(1)-\mathrm{C}(1)$ & $2.722(5)$ \\
$\mathrm{U}(1)-\mathrm{C}(12)$ & $2.727(4)$ \\
$\mathrm{U}(1)-\mathrm{C}(2)$ & $2.729(5)$ \\
$\mathrm{U}(1)-\mathrm{C}(3)$ & $2.739(4)$ \\
$\mathrm{U}(1)-\mathrm{C}(14)$ & $2.745(5)$ \\
$\mathrm{U}(1)-\mathrm{C}(13)$ & $2.761(5)$
\end{tabular}




\begin{tabular}{|c|c|}
\hline $\mathrm{O}(1)-\mathrm{C}(21)$ & $1.274(5)$ \\
\hline $\mathrm{O}(2)-\mathrm{C}(21)$ & $1.262(5)$ \\
\hline $\mathrm{N}(1)-\mathrm{C}(21)$ & $1.383(6)$ \\
\hline $\mathrm{N}(1)-\mathrm{C}(22)$ & $1.421(6)$ \\
\hline $\mathrm{N}(1)-\mathrm{C}(25)$ & $1.422(6)$ \\
\hline $\mathrm{C}(1)-\mathrm{C}(2)$ & $1.411(7)$ \\
\hline$C(1)-C(5)$ & $1.413(7)$ \\
\hline $\mathrm{C}(1)-\mathrm{C}(6)$ & $1.508(7)$ \\
\hline $\mathrm{C}(2)-\mathrm{C}(3)$ & $1.417(7)$ \\
\hline $\mathrm{C}(2)-\mathrm{C}(7)$ & $1.515(7)$ \\
\hline $\mathrm{C}(3)-\mathrm{C}(4)$ & $1.428(6)$ \\
\hline $\mathrm{C}(3)-\mathrm{C}(8)$ & $1.507(7)$ \\
\hline $\mathrm{C}(4)-\mathrm{C}(5)$ & $1.429(7)$ \\
\hline $\mathrm{C}(4)-\mathrm{C}(9)$ & $1.503(6)$ \\
\hline$C(5)-C(10)$ & $1.504(7)$ \\
\hline $\mathrm{C}(11)-\mathrm{C}(15)$ & $1.414(6)$ \\
\hline $\mathrm{C}(11)-\mathrm{C}(12)$ & $1.418(6)$ \\
\hline$C(11)-C(16)$ & $1.505(7)$ \\
\hline $\mathrm{C}(12)-\mathrm{C}(13)$ & $1.413(6)$ \\
\hline $\mathrm{C}(12)-\mathrm{C}(17)$ & $1.503(6)$ \\
\hline $\mathrm{C}(13)-\mathrm{C}(14)$ & $1.424(7)$ \\
\hline $\mathrm{C}(13)-\mathrm{C}(18)$ & $1.511(7)$ \\
\hline $\mathrm{C}(14)-\mathrm{C}(15)$ & $1.422(7)$ \\
\hline $\mathrm{C}(14)-\mathrm{C}(19)$ & $1.505(7)$ \\
\hline$C(15)-C(20)$ & $1.511(6)$ \\
\hline $\mathrm{C}(22)-\mathrm{C}(23)$ & $1.355(7)$ \\
\hline$C(22)-C(26)$ & $1.498(7)$ \\
\hline $\mathrm{C}(23)-\mathrm{C}(24)$ & $1.444(6)$ \\
\hline$C(23)-C(27)$ & $1.489(6)$ \\
\hline$C(24)-C(25)$ & $1.366(7)$ \\
\hline $\mathrm{C}(24)-\mathrm{C}(28)$ & $1.499(6)$ \\
\hline$C(25)-C(29)$ & $1.483(7)$ \\
\hline Cnt1-U(1)-O(1) & 93.0 \\
\hline Cnt1-U(1)-O(2) & 108.7 \\
\hline Cnt1-U(1)-C(21) & 101.9 \\
\hline
\end{tabular}




\begin{tabular}{|c|c|}
\hline Cnt1-U(1)-Cl(1) & 101.3 \\
\hline Cnt1-U(1)-O(1) & 94.4 \\
\hline Cnt1-U(1)-O(2) & 106.3 \\
\hline Cnt1-U(1)-C(21) & 101.8 \\
\hline Cnt1-U(1)-Cl(1) & 100.0 \\
\hline Cnt1-U(1)-Cnt2 & 141.3 \\
\hline $\mathrm{O}(2)-\mathrm{U}(1)-\mathrm{O}(1)$ & $53.80(10)$ \\
\hline $\mathrm{O}(2)-\mathrm{U}(1)-\mathrm{Cl}(1)$ & $81.25(8)$ \\
\hline $\mathrm{O}(1)-\mathrm{U}(1)-\mathrm{Cl}(1)$ & $135.03(8)$ \\
\hline $\mathrm{O}(2)-\mathrm{U}(1)-\mathrm{C}(15)$ & $87.02(13)$ \\
\hline $\mathrm{O}(1)-\mathrm{U}(1)-\mathrm{C}(15)$ & $97.51(13)$ \\
\hline $\mathrm{Cl}(1)-\mathrm{U}(1)-\mathrm{C}(15)$ & $79.41(10)$ \\
\hline $\mathrm{O}(2)-\mathrm{U}(1)-\mathrm{C}(4)$ & $121.85(13)$ \\
\hline $\mathrm{O}(1)-\mathrm{U}(1)-\mathrm{C}(4)$ & $119.55(12)$ \\
\hline $\mathrm{Cl}(1)-\mathrm{U}(1)-\mathrm{C}(4)$ & $80.78(10)$ \\
\hline $\mathrm{C}(15)-\mathrm{U}(1)-\mathrm{C}(4)$ & $141.62(15)$ \\
\hline $\mathrm{O}(2)-\mathrm{U}(1)-\mathrm{C}(11)$ & $82.76(13)$ \\
\hline $\mathrm{O}(1)-\mathrm{U}(1)-\mathrm{C}(11)$ & $70.86(12)$ \\
\hline $\mathrm{Cl}(1)-\mathrm{U}(1)-\mathrm{C}(11)$ & $108.19(10)$ \\
\hline $\mathrm{C}(15)-\mathrm{U}(1)-\mathrm{C}(11)$ & $30.19(13)$ \\
\hline $\mathrm{C}(4)-\mathrm{U}(1)-\mathrm{C}(11)$ & $155.21(15)$ \\
\hline $\mathrm{O}(2)-\mathrm{U}(1)-\mathrm{C}(5)$ & $91.73(13)$ \\
\hline $\mathrm{O}(1)-\mathrm{U}(1)-\mathrm{C}(5)$ & $99.35(13)$ \\
\hline $\mathrm{Cl}(1)-\mathrm{U}(1)-\mathrm{C}(5)$ & $78.80(10)$ \\
\hline $\mathrm{C}(15)-\mathrm{U}(1)-\mathrm{C}(5)$ & $158.10(15)$ \\
\hline $\mathrm{C}(4)-\mathrm{U}(1)-\mathrm{C}(5)$ & $30.49(15)$ \\
\hline $\mathrm{C}(11)-\mathrm{U}(1)-\mathrm{C}(5)$ & $170.20(14)$ \\
\hline $\mathrm{O}(2)-\mathrm{U}(1)-\mathrm{C}(1)$ & $83.83(13)$ \\
\hline $\mathrm{O}(1)-\mathrm{U}(1)-\mathrm{C}(1)$ & $71.25(13)$ \\
\hline $\mathrm{Cl}(1)-\mathrm{U}(1)-\mathrm{C}(1)$ & $106.18(11)$ \\
\hline $\mathrm{C}(15)-\mathrm{U}(1)-\mathrm{C}(1)$ & $168.36(14)$ \\
\hline $\mathrm{C}(4)-\mathrm{U}(1)-\mathrm{C}(1)$ & $50.03(14)$ \\
\hline $\mathrm{C}(11)-\mathrm{U}(1)-\mathrm{C}(1)$ & $140.52(14)$ \\
\hline $\mathrm{C}(5)-\mathrm{U}(1)-\mathrm{C}(1)$ & $30.09(14)$ \\
\hline $\mathrm{O}(2)-\mathrm{U}(1)-\mathrm{C}(12)$ & 108.76(13) \\
\hline $\mathrm{O}(1)-\mathrm{U}(1)-\mathrm{C}(12)$ & $76.25(12)$ \\
\hline
\end{tabular}




\begin{tabular}{|c|c|}
\hline $\mathrm{Cl}(1)-\mathrm{U}(1)-\mathrm{C}(12)$ & $126.16(10)$ \\
\hline $\mathrm{C}(15)-\mathrm{U}(1)-\mathrm{C}(12)$ & $49.83(13)$ \\
\hline $\mathrm{C}(4)-\mathrm{U}(1)-\mathrm{C}(12)$ & $126.31(14)$ \\
\hline $\mathrm{C}(11)-\mathrm{U}(1)-\mathrm{C}(12)$ & $30.19(13)$ \\
\hline $\mathrm{C}(5)-\mathrm{U}(1)-\mathrm{C}(12)$ & $148.96(14)$ \\
\hline $\mathrm{C}(1)-\mathrm{U}(1)-\mathrm{C}(12)$ & $127.15(14)$ \\
\hline $\mathrm{O}(2)-\mathrm{U}(1)-\mathrm{C}(2)$ & $107.14(13)$ \\
\hline $\mathrm{O}(1)-\mathrm{U}(1)-\mathrm{C}(2)$ & $72.58(12)$ \\
\hline $\mathrm{Cl}(1)-\mathrm{U}(1)-\mathrm{C}(2)$ & $127.43(10)$ \\
\hline $\mathrm{C}(15)-\mathrm{U}(1)-\mathrm{C}(2)$ & $150.54(14)$ \\
\hline $\mathrm{C}(4)-\mathrm{U}(1)-\mathrm{C}(2)$ & $50.10(13)$ \\
\hline $\mathrm{C}(11)-\mathrm{U}(1)-\mathrm{C}(2)$ & $124.24(14)$ \\
\hline $\mathrm{C}(5)-\mathrm{U}(1)-\mathrm{C}(2)$ & $49.79(14)$ \\
\hline $\mathrm{C}(1)-\mathrm{U}(1)-\mathrm{C}(2)$ & $30.01(14)$ \\
\hline $\mathrm{C}(12)-\mathrm{U}(1)-\mathrm{C}(2)$ & $100.73(14)$ \\
\hline $\mathrm{O}(2)-\mathrm{U}(1)-\mathrm{C}(3)$ & $133.32(13)$ \\
\hline $\mathrm{O}(1)-\mathrm{U}(1)-\mathrm{C}(3)$ & $101.52(12)$ \\
\hline $\mathrm{Cl}(1)-\mathrm{U}(1)-\mathrm{C}(3)$ & $109.93(10)$ \\
\hline $\mathrm{C}(15)-\mathrm{U}(1)-\mathrm{C}(3)$ & $138.89(14)$ \\
\hline $\mathrm{C}(4)-\mathrm{U}(1)-\mathrm{C}(3)$ & $30.35(13)$ \\
\hline $\mathrm{C}(11)-\mathrm{U}(1)-\mathrm{C}(3)$ & $130.37(14)$ \\
\hline $\mathrm{C}(5)-\mathrm{U}(1)-\mathrm{C}(3)$ & $49.82(14)$ \\
\hline $\mathrm{C}(1)-\mathrm{U}(1)-\mathrm{C}(3)$ & $49.52(14)$ \\
\hline $\mathrm{C}(12)-\mathrm{U}(1)-\mathrm{C}(3)$ & $100.32(14)$ \\
\hline $\mathrm{C}(2)-\mathrm{U}(1)-\mathrm{C}(3)$ & $30.04(14)$ \\
\hline $\mathrm{O}(2)-\mathrm{U}(1)-\mathrm{C}(14)$ & $116.20(13)$ \\
\hline $\mathrm{O}(1)-\mathrm{U}(1)-\mathrm{C}(14)$ & $120.18(13)$ \\
\hline $\mathrm{Cl}(1)-\mathrm{U}(1)-\mathrm{C}(14)$ & $77.86(10)$ \\
\hline $\mathrm{C}(15)-\mathrm{U}(1)-\mathrm{C}(14)$ & $30.19(14)$ \\
\hline $\mathrm{C}(4)-\mathrm{U}(1)-\mathrm{C}(14)$ & $113.09(14)$ \\
\hline $\mathrm{C}(11)-\mathrm{U}(1)-\mathrm{C}(14)$ & $49.76(14)$ \\
\hline $\mathrm{C}(5)-\mathrm{U}(1)-\mathrm{C}(14)$ & $139.86(15)$ \\
\hline $\mathrm{C}(1)-\mathrm{U}(1)-\mathrm{C}(14)$ & $159.96(15)$ \\
\hline $\mathrm{C}(12)-\mathrm{U}(1)-\mathrm{C}(14)$ & 49.71(14) \\
\hline $\mathrm{C}(2)-\mathrm{U}(1)-\mathrm{C}(14)$ & $133.13(15)$ \\
\hline $\mathrm{C}(3)-\mathrm{U}(1)-\mathrm{C}(14)$ & $110.47(14)$ \\
\hline
\end{tabular}




\begin{tabular}{|c|c|}
\hline $\mathrm{O}(2)-\mathrm{U}(1)-\mathrm{C}(13)$ & $131.78(13)$ \\
\hline $\mathrm{O}(1)-\mathrm{U}(1)-\mathrm{C}(13)$ & $105.74(12)$ \\
\hline $\mathrm{Cl}(1)-\mathrm{U}(1)-\mathrm{C}(13)$ & $105.51(10)$ \\
\hline $\mathrm{C}(15)-\mathrm{U}(1)-\mathrm{C}(13)$ & $49.51(14)$ \\
\hline $\mathrm{C}(4)-\mathrm{U}(1)-\mathrm{C}(13)$ & $106.29(14)$ \\
\hline $\mathrm{C}(11)-\mathrm{U}(1)-\mathrm{C}(13)$ & $49.41(14)$ \\
\hline $\mathrm{C}(5)-\mathrm{U}(1)-\mathrm{C}(13)$ & $136.47(14)$ \\
\hline $\mathrm{C}(1)-\mathrm{U}(1)-\mathrm{C}(13)$ & $135.27(14)$ \\
\hline $\mathrm{C}(12)-\mathrm{U}(1)-\mathrm{C}(13)$ & $29.83(13)$ \\
\hline $\mathrm{C}(2)-\mathrm{U}(1)-\mathrm{C}(13)$ & $105.39(14)$ \\
\hline $\mathrm{C}(3)-\mathrm{U}(1)-\mathrm{C}(13)$ & $90.10(14)$ \\
\hline $\mathrm{C}(14)-\mathrm{U}(1)-\mathrm{C}(13)$ & $29.98(14)$ \\
\hline $\mathrm{C}(21)-\mathrm{O}(1)-\mathrm{U}(1)$ & $91.5(3)$ \\
\hline $\mathrm{C}(21)-\mathrm{O}(2)-\mathrm{U}(1)$ & $94.3(3)$ \\
\hline $\mathrm{C}(21)-\mathrm{N}(1)-\mathrm{C}(22)$ & $125.3(4)$ \\
\hline $\mathrm{C}(21)-\mathrm{N}(1)-\mathrm{C}(25)$ & $126.0(4)$ \\
\hline $\mathrm{C}(22)-\mathrm{N}(1)-\mathrm{C}(25)$ & 108.7(4) \\
\hline$C(2)-C(1)-C(5)$ & $108.6(4)$ \\
\hline$C(2)-C(1)-C(6)$ & $126.9(5)$ \\
\hline $\mathrm{C}(5)-\mathrm{C}(1)-\mathrm{C}(6)$ & $124.2(5)$ \\
\hline $\mathrm{C}(2)-\mathrm{C}(1)-\mathrm{U}(1)$ & $75.3(3)$ \\
\hline $\mathrm{C}(5)-\mathrm{C}(1)-\mathrm{U}(1)$ & $74.9(3)$ \\
\hline $\mathrm{C}(6)-\mathrm{C}(1)-\mathrm{U}(1)$ & $120.6(3)$ \\
\hline $\mathrm{C}(1)-\mathrm{C}(2)-\mathrm{C}(3)$ & $107.9(4)$ \\
\hline $\mathrm{C}(1)-\mathrm{C}(2)-\mathrm{C}(7)$ & $125.3(5)$ \\
\hline $\mathrm{C}(3)-\mathrm{C}(2)-\mathrm{C}(7)$ & $126.7(5)$ \\
\hline $\mathrm{C}(1)-\mathrm{C}(2)-\mathrm{U}(1)$ & $74.7(3)$ \\
\hline $\mathrm{C}(3)-\mathrm{C}(2)-\mathrm{U}(1)$ & $75.4(3)$ \\
\hline$C(7)-C(2)-U(1)$ & 119.1(3) \\
\hline $\mathrm{C}(2)-\mathrm{C}(3)-\mathrm{C}(4)$ & $108.3(4)$ \\
\hline $\mathrm{C}(2)-\mathrm{C}(3)-\mathrm{C}(8)$ & $126.6(4)$ \\
\hline $\mathrm{C}(4)-\mathrm{C}(3)-\mathrm{C}(8)$ & $124.7(4)$ \\
\hline $\mathrm{C}(2)-\mathrm{C}(3)-\mathrm{U}(1)$ & $74.6(3)$ \\
\hline $\mathrm{C}(4)-\mathrm{C}(3)-\mathrm{U}(1)$ & $73.9(2)$ \\
\hline $\mathrm{C}(8)-\mathrm{C}(3)-\mathrm{U}(1)$ & $123.6(3)$ \\
\hline$C(3)-C(4)-C(5)$ & $107.1(4)$ \\
\hline
\end{tabular}




\begin{tabular}{|c|c|}
\hline$C(3)-C(4)-C(9)$ & $125.5(4)$ \\
\hline$C(5)-C(4)-C(9)$ & $127.3(4)$ \\
\hline$C(3)-C(4)-U(1)$ & $75.7(3)$ \\
\hline $\mathrm{C}(5)-\mathrm{C}(4)-\mathrm{U}(1)$ & $74.9(3)$ \\
\hline $\mathrm{C}(9)-\mathrm{C}(4)-\mathrm{U}(1)$ & $118.3(3)$ \\
\hline$C(1)-C(5)-C(4)$ & $108.0(4)$ \\
\hline$C(1)-C(5)-C(10)$ & $124.7(5)$ \\
\hline$C(4)-C(5)-C(10)$ & $127.2(5)$ \\
\hline$C(1)-C(5)-U(1)$ & $75.0(3)$ \\
\hline $\mathrm{C}(4)-\mathrm{C}(5)-\mathrm{U}(1)$ & $74.6(3)$ \\
\hline $\mathrm{C}(10)-\mathrm{C}(5)-\mathrm{U}(1)$ & $118.7(3)$ \\
\hline $\mathrm{C}(15)-\mathrm{C}(11)-\mathrm{C}(12)$ & $108.1(4)$ \\
\hline$C(15)-C(11)-C(16)$ & $125.2(4)$ \\
\hline $\mathrm{C}(12)-\mathrm{C}(11)-\mathrm{C}(16)$ & $126.3(4)$ \\
\hline $\mathrm{C}(15)-\mathrm{C}(11)-\mathrm{U}(1)$ & $74.8(3)$ \\
\hline $\mathrm{C}(12)-\mathrm{C}(11)-\mathrm{U}(1)$ & $75.3(3)$ \\
\hline $\mathrm{C}(16)-\mathrm{C}(11)-\mathrm{U}(1)$ & $121.5(3)$ \\
\hline $\mathrm{C}(13)-\mathrm{C}(12)-\mathrm{C}(11)$ & $108.0(4)$ \\
\hline $\mathrm{C}(13)-\mathrm{C}(12)-\mathrm{C}(17)$ & $126.5(4)$ \\
\hline $\mathrm{C}(11)-\mathrm{C}(12)-\mathrm{C}(17)$ & $125.5(4)$ \\
\hline $\mathrm{C}(13)-\mathrm{C}(12)-\mathrm{U}(1)$ & $76.4(3)$ \\
\hline $\mathrm{C}(11)-\mathrm{C}(12)-\mathrm{U}(1)$ & $74.5(2)$ \\
\hline $\mathrm{C}(17)-\mathrm{C}(12)-\mathrm{U}(1)$ & $117.4(3)$ \\
\hline$C(12)-C(13)-C(14)$ & $108.3(4)$ \\
\hline $\mathrm{C}(12)-\mathrm{C}(13)-\mathrm{C}(18)$ & $126.1(4)$ \\
\hline $\mathrm{C}(14)-\mathrm{C}(13)-\mathrm{C}(18)$ & $124.5(4)$ \\
\hline $\mathrm{C}(12)-\mathrm{C}(13)-\mathrm{U}(1)$ & $73.8(3)$ \\
\hline $\mathrm{C}(14)-\mathrm{C}(13)-\mathrm{U}(1)$ & $74.4(3)$ \\
\hline $\mathrm{C}(18)-\mathrm{C}(13)-\mathrm{U}(1)$ & 127.1(3) \\
\hline$C(15)-C(14)-C(13)$ & $107.4(4)$ \\
\hline$C(15)-C(14)-C(19)$ & $127.4(5)$ \\
\hline $\mathrm{C}(13)-\mathrm{C}(14)-\mathrm{C}(19)$ & $124.9(5)$ \\
\hline $\mathrm{C}(15)-\mathrm{C}(14)-\mathrm{U}(1)$ & $73.7(3)$ \\
\hline $\mathrm{C}(13)-\mathrm{C}(14)-\mathrm{U}(1)$ & $75.6(3)$ \\
\hline $\mathrm{C}(19)-\mathrm{C}(14)-\mathrm{U}(1)$ & $121.5(3)$ \\
\hline$C(11)-C(15)-C(14)$ & $108.2(4)$ \\
\hline
\end{tabular}




$\begin{array}{lr}\mathrm{C}(11)-\mathrm{C}(15)-\mathrm{C}(20) & 125.1(4) \\ \mathrm{C}(14)-\mathrm{C}(15)-\mathrm{C}(20) & 126.6(4) \\ \mathrm{C}(11)-\mathrm{C}(15)-\mathrm{U}(1) & 75.0(3) \\ \mathrm{C}(14)-\mathrm{C}(15)-\mathrm{U}(1) & 76.1(3) \\ \mathrm{C}(20)-\mathrm{C}(15)-\mathrm{U}(1) & 117.2(3) \\ \mathrm{O}(2)-\mathrm{C}(21)-\mathrm{O}(1) & 120.3(4) \\ \mathrm{O}(2)-\mathrm{C}(21)-\mathrm{N}(1) & 119.2(4) \\ \mathrm{O}(1)-\mathrm{C}(21)-\mathrm{N}(1) & 120.5(4) \\ \mathrm{C}(23)-\mathrm{C}(22)-\mathrm{N}(1) & 107.4(4) \\ \mathrm{C}(23)-\mathrm{C}(22)-\mathrm{C}(26) & 129.2(4) \\ \mathrm{N}(1)-\mathrm{C}(22)-\mathrm{C}(26) & 123.3(4) \\ \mathrm{C}(22)-\mathrm{C}(23)-\mathrm{C}(24) & 108.5(4) \\ \mathrm{C}(22)-\mathrm{C}(23)-\mathrm{C}(27) & 127.7(4) \\ \mathrm{C}(24)-\mathrm{C}(23)-\mathrm{C}(27) & 123.8(4) \\ \mathrm{C}(25)-\mathrm{C}(24)-\mathrm{C}(23) & 108.7(4) \\ \mathrm{C}(25)-\mathrm{C}(24)-\mathrm{C}(28) & 127.3(4) \\ \mathrm{C}(23)-\mathrm{C}(24)-\mathrm{C}(28) & 124.1(4) \\ \mathrm{C}(24)-\mathrm{C}(25)-\mathrm{N}(1) & 106.7(4) \\ \mathrm{C}(24)-\mathrm{C}(25)-\mathrm{C}(29) & 128.9(4) \\ \mathrm{N}(1)-\mathrm{C}(25)-\mathrm{C}(29) & 124.3(4) \\ & \end{array}$

\section{X-ray Data Collection, Structure Solution and Refinement for 8.}

A green crystal of approximate dimensions $0.089 \times 0.102 \times 0.706 \mathrm{~mm}$ was mounted on a glass fiber and transferred to a Bruker SMART APEX II diffractometer. The APEX2 ${ }^{7}$ program package was used to determine the unit-cell parameters and for data collection (30 sec/frame scan time for a sphere of diffraction data). The raw frame data was processed using $\mathrm{SAINT}^{2}$ and $\mathrm{SADABS}^{3}$ to yield the reflection data file. Subsequent calculations were carried out using the SHELXTL ${ }^{4}$ program. The diffraction symmetry was $2 / m$ and the systematic absences were consistent with the monoclinic space group $P 2_{1} / n$ that was later determined to be correct.

The structure was solved by direct methods and refined on $\mathrm{F}^{2}$ by full-matrix least-squares techniques ${ }^{8}$. The analytical scattering factors ${ }^{6}$ for neutral atoms were used throughout the analysis. Hydrogen atoms were included using a riding model.

At convergence, $w R 2=0.0552$ and Goof $=1.007$ for 709 variables refined against 16640 data $(0.76 \AA), \mathrm{R} 1=0.0244$ for those 13994 data with $\mathrm{I}>2.0 \sigma(\mathrm{I})$. 


\section{Definitions:}

$\mathrm{wR} 2=\left[\Sigma\left[\mathrm{w}\left(\mathrm{F}_{\mathrm{o}}^{2}-\mathrm{F}_{\mathrm{c}}^{2}\right)^{2}\right] / \Sigma\left[\mathrm{w}\left(\mathrm{F}_{\mathrm{o}}^{2}\right)^{2}\right]\right]^{1 / 2}$

$\mathrm{R} 1=\Sigma|| \mathrm{F}_{\mathrm{o}}|-| \mathrm{F}_{\mathrm{c}} \| / \Sigma\left|\mathrm{F}_{\mathrm{o}}\right|$

Goof $=\mathrm{S}=\left[\Sigma\left[\mathrm{w}\left(\mathrm{F}_{\mathrm{o}}{ }^{2}-\mathrm{F}_{\mathrm{c}}{ }^{2}\right)^{2}\right] /(\mathrm{n}-\mathrm{p})\right]^{1 / 2}$ where $\mathrm{n}$ is the number of reflections and $\mathrm{p}$ is the total number of parameters refined.

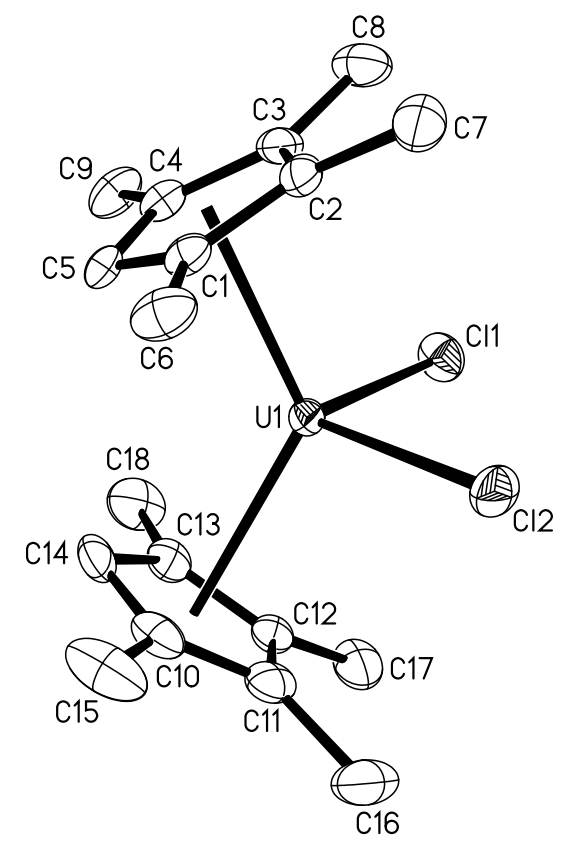

Figure S7. Thermal ellipsoid plot of $\left[\mathrm{NBu}_{4}\right]\left[\left(\mathrm{C}_{5} \mathrm{Me}_{4} \mathrm{H}\right)_{2} \mathrm{UCl}_{2}\right], \mathbf{8}$, shown at the $50 \%$ probability level with hydrogen atoms removed for clarity.

Table S9. Crystal data and structure refinement for $\mathbf{8}$.

Identification code

Empirical formula

Formula weight

Temperature

Wavelength

Crystal system

Space group

Unit cell dimensions clw58 (Chris Webster)

$\mathrm{C}_{34} \mathrm{H}_{62} \mathrm{Cl}_{2} \mathrm{~N} \mathrm{U}$

793.77

143(2) K

$0.71073 \AA$

Monoclinic

$P 2{ }_{1} / n$

$\mathrm{a}=22.7263(18) \AA \quad \square=90^{\circ}$. 
Volume

$\mathrm{Z}$

Density (calculated)

Absorption coefficient

$\mathrm{F}(000)$

Crystal color

Crystal size

Theta range for data collection

Index ranges

Reflections collected

Independent reflections

Completeness to theta $=25.242^{\circ}$

Absorption correction

Max. and min. transmission

Refinement method

Data / restraints / parameters

Goodness-of-fit on $\mathrm{F}^{2}$

$$
\begin{array}{ll}
\mathrm{b}=12.3259(10) \AA & \square=97.0365(10)^{\circ} . \\
\mathrm{c}=25.706(2) \AA & \square=90^{\circ} .
\end{array}
$$$$
\text { 7146.6(10) } \AA^{3}
$$$$
8
$$

$1.475 \mathrm{Mg} / \mathrm{m}^{3}$

$4.713 \mathrm{~mm}^{-1}$

3192

green

$0.706 \times 0.102 \times 0.089 \mathrm{~mm}^{3}$

1.276 to $27.874^{\circ}$

$-29 \leq h \leq 29,-16 \leq k \leq 16,-33 \leq l \leq 33$

79947

$16640[\mathrm{R}(\mathrm{int})=0.0365]$

$100.0 \%$

Numerical

0.7888 and 0.2203

Full-matrix least-squares on $\mathrm{F}^{2}$

16640 / 0 / 709

1.007

Final $\mathrm{R}$ indices $[\mathrm{I}>2 \operatorname{sigma}(\mathrm{I})=13994$ data] $\mathrm{R} 1=0.0244, \mathrm{wR} 2=0.0517$

$\mathrm{R}$ indices (all data, $0.76 \AA$ )

$\mathrm{R} 1=0.0360, \mathrm{wR} 2=0.0552$

Largest diff. peak and hole

Table S10. Bond lengths $[\AA]$ and angles $\left[{ }^{\circ}\right]$ for $\mathbf{8}$.

\begin{tabular}{ll}
\hline $\mathrm{U}(1)-\mathrm{Cnt} 1$ & 2.505 \\
$\mathrm{U}(1)-\mathrm{Cnt} 2$ & 2.497 \\
$\mathrm{U}(2)-\mathrm{Cnt} 3$ & 2.487 \\
$\mathrm{U}(2)-\mathrm{Cnt} 4$ & 2.491 \\
$\mathrm{U}(1)-\mathrm{Cl}(2)$ & $2.6966(7)$ \\
$\mathrm{U}(1)-\mathrm{C}(5)$ & $2.702(3)$ \\
$\mathrm{U}(1)-\mathrm{Cl}(1)$ & $2.7168(7)$ \\
$\mathrm{U}(1)-\mathrm{C}(14)$ & $2.720(3)$ \\
$\mathrm{U}(1)-\mathrm{C}(4)$ & $2.730(3)$ \\
$\mathrm{U}(1)-\mathrm{C}(10)$ & $2.744(3)$ \\
$\mathrm{U}(1)-\mathrm{C}(13)$ & $2.769(3)$
\end{tabular}




\begin{tabular}{|c|c|}
\hline $\mathrm{U}(1)-\mathrm{C}(1)$ & $2.779(3)$ \\
\hline $\mathrm{U}(1)-\mathrm{C}(11)$ & $2.798(3)$ \\
\hline $\mathrm{U}(1)-\mathrm{C}(12)$ & $2.816(3)$ \\
\hline $\mathrm{U}(1)-\mathrm{C}(3)$ & $2.823(3)$ \\
\hline $\mathrm{U}(1)-\mathrm{C}(2)$ & $2.856(3)$ \\
\hline$C(1)-C(5)$ & $1.411(4)$ \\
\hline$C(1)-C(2)$ & $1.416(4)$ \\
\hline $\mathrm{C}(1)-\mathrm{C}(6)$ & $1.501(4)$ \\
\hline $\mathrm{C}(2)-\mathrm{C}(3)$ & $1.415(4)$ \\
\hline $\mathrm{C}(2)-\mathrm{C}(7)$ & $1.504(4)$ \\
\hline $\mathrm{C}(3)-\mathrm{C}(4)$ & $1.409(4)$ \\
\hline $\mathrm{C}(3)-\mathrm{C}(8)$ & $1.509(4)$ \\
\hline$C(4)-C(5)$ & $1.420(4)$ \\
\hline $\mathrm{C}(4)-\mathrm{C}(9)$ & $1.506(4)$ \\
\hline $\mathrm{C}(10)-\mathrm{C}(11)$ & $1.410(4)$ \\
\hline $\mathrm{C}(10)-\mathrm{C}(14)$ & $1.414(5)$ \\
\hline$C(10)-C(15)$ & $1.506(4)$ \\
\hline $\mathrm{C}(11)-\mathrm{C}(12)$ & $1.406(4)$ \\
\hline$C(11)-C(16)$ & $1.509(4)$ \\
\hline $\mathrm{C}(12)-\mathrm{C}(13)$ & $1.410(4)$ \\
\hline $\mathrm{C}(12)-\mathrm{C}(17)$ & $1.501(4)$ \\
\hline $\mathrm{C}(13)-\mathrm{C}(14)$ & $1.407(4)$ \\
\hline $\mathrm{C}(13)-\mathrm{C}(18)$ & $1.509(4)$ \\
\hline $\mathrm{U}(2)-\mathrm{Cl}(4)$ & $2.7106(7)$ \\
\hline $\mathrm{U}(2)-\mathrm{C}(23)$ & $2.726(3)$ \\
\hline $\mathrm{U}(2)-\mathrm{Cl}(3)$ & $2.7282(7)$ \\
\hline $\mathrm{U}(2)-\mathrm{C}(32)$ & $2.729(3)$ \\
\hline $\mathrm{U}(2)-\mathrm{C}(19)$ & $2.749(3)$ \\
\hline $\mathrm{U}(2)-\mathrm{C}(28)$ & $2.751(3)$ \\
\hline $\mathrm{U}(2)-\mathrm{C}(31)$ & $2.767(3)$ \\
\hline $\mathrm{U}(2)-\mathrm{C}(21)$ & $2.773(3)$ \\
\hline $\mathrm{U}(2)-\mathrm{C}(22)$ & $2.775(3)$ \\
\hline $\mathrm{U}(2)-\mathrm{C}(20)$ & $2.786(3)$ \\
\hline $\mathrm{U}(2)-\mathrm{C}(30)$ & $2.792(3)$ \\
\hline $\mathrm{U}(2)-\mathrm{C}(29)$ & $2.792(3)$ \\
\hline$C(19)-C(20)$ & $1.411(4)$ \\
\hline
\end{tabular}




\begin{tabular}{|c|c|}
\hline$C(19)-C(23)$ & $1.416(4)$ \\
\hline $\mathrm{C}(19)-\mathrm{C}(24)$ & $1.497(4)$ \\
\hline$C(20)-C(21)$ & $1.419(4)$ \\
\hline$C(20)-C(25)$ & $1.508(4)$ \\
\hline $\mathrm{C}(21)-\mathrm{C}(22)$ & $1.408(4)$ \\
\hline$C(21)-C(26)$ & $1.505(4)$ \\
\hline$C(22)-C(23)$ & $1.411(4)$ \\
\hline$C(22)-C(27)$ & $1.508(4)$ \\
\hline $\mathrm{C}(28)-\mathrm{C}(29)$ & $1.408(4)$ \\
\hline $\mathrm{C}(28)-\mathrm{C}(32)$ & $1.409(4)$ \\
\hline $\mathrm{C}(28)-\mathrm{C}(33)$ & $1.507(4)$ \\
\hline $\mathrm{C}(29)-\mathrm{C}(30)$ & $1.420(4)$ \\
\hline $\mathrm{C}(29)-\mathrm{C}(34)$ & $1.503(4)$ \\
\hline $\mathrm{C}(30)-\mathrm{C}(31)$ & $1.416(4)$ \\
\hline$C(30)-C(35)$ & $1.505(4)$ \\
\hline $\mathrm{C}(31)-\mathrm{C}(32)$ & $1.414(4)$ \\
\hline$C(31)-C(36)$ & $1.502(4)$ \\
\hline $\mathrm{N}(1)-\mathrm{C}(49)$ & $1.519(3)$ \\
\hline $\mathrm{N}(1)-\mathrm{C}(37)$ & $1.526(3)$ \\
\hline $\mathrm{N}(1)-\mathrm{C}(41)$ & $1.526(4)$ \\
\hline $\mathrm{N}(1)-\mathrm{C}(45)$ & $1.526(3)$ \\
\hline $\mathrm{C}(37)-\mathrm{C}(38)$ & $1.523(4)$ \\
\hline $\mathrm{C}(38)-\mathrm{C}(39)$ & $1.534(4)$ \\
\hline $\mathrm{C}(39)-\mathrm{C}(40)$ & $1.524(4)$ \\
\hline $\mathrm{C}(41)-\mathrm{C}(42)$ & $1.515(4)$ \\
\hline$C(42)-C(43)$ & $1.521(4)$ \\
\hline $\mathrm{C}(43)-\mathrm{C}(44)$ & $1.527(5)$ \\
\hline $\mathrm{C}(45)-\mathrm{C}(46)$ & $1.519(4)$ \\
\hline$C(46)-C(47)$ & $1.497(4)$ \\
\hline $\mathrm{C}(47)-\mathrm{C}(48)$ & $1.508(4)$ \\
\hline $\mathrm{C}(49)-\mathrm{C}(50)$ & $1.523(4)$ \\
\hline$C(50)-C(51)$ & $1.528(4)$ \\
\hline $\mathrm{C}(51)-\mathrm{C}(52)$ & $1.532(5)$ \\
\hline $\mathrm{N}(2)-\mathrm{C}(57)$ & $1.516(3)$ \\
\hline $\mathrm{N}(2)-\mathrm{C}(53)$ & $1.519(4)$ \\
\hline $\mathrm{N}(2)-\mathrm{C}(65)$ & $1.523(3)$ \\
\hline
\end{tabular}




\begin{tabular}{|c|c|}
\hline $\mathrm{N}(2)-\mathrm{C}(61)$ & $1.526(3)$ \\
\hline $\mathrm{C}(53)-\mathrm{C}(54)$ & $1.528(4)$ \\
\hline$C(54)-C(55)$ & $1.522(4)$ \\
\hline $\mathrm{C}(55)-\mathrm{C}(56)$ & $1.520(4)$ \\
\hline $\mathrm{C}(57)-\mathrm{C}(58)$ & $1.528(4)$ \\
\hline C(58)-C(59) & $1.528(4)$ \\
\hline $\mathrm{C}(59)-\mathrm{C}(60)$ & $1.511(5)$ \\
\hline $\mathrm{C}(61)-\mathrm{C}(62)$ & $1.518(4)$ \\
\hline$C(62)-C(63)$ & $1.525(4)$ \\
\hline $\mathrm{C}(63)-\mathrm{C}(64)$ & $1.516(4)$ \\
\hline $\mathrm{C}(65)-\mathrm{C}(66)$ & $1.518(4)$ \\
\hline $\mathrm{C}(66)-\mathrm{C}(67)$ & $1.527(4)$ \\
\hline $\mathrm{C}(67)-\mathrm{C}(68)$ & $1.519(4)$ \\
\hline Cnt1-U(1)-Cl(1) & 107.7 \\
\hline Cnt1-U(1)-Cl(2) & 104.4 \\
\hline Cnt2-U(1)-Cl(1) & 105.5 \\
\hline $\mathrm{Cnt} 2-\mathrm{U}(1)-\mathrm{Cl}(2)$ & 106.4 \\
\hline Cnt1-U(1)-Cnt2 & 127.0 \\
\hline $\mathrm{Cnt} 3-\mathrm{U}(2)-\mathrm{Cl}(3)$ & 106.9 \\
\hline Cnt3-U(2)-Cl(4) & 105.1 \\
\hline $\mathrm{Cnt} 4-\mathrm{U}(2)-\mathrm{Cl}(3)$ & 107.7 \\
\hline Cnt4-U(2)-Cl(4) & 105.0 \\
\hline Cnt3-U(2)-Cnt4 & 128.4 \\
\hline $\mathrm{Cl}(2)-\mathrm{U}(1)-\mathrm{C}(5)$ & $115.88(6)$ \\
\hline $\mathrm{Cl}(2)-\mathrm{U}(1)-\mathrm{Cl}(1)$ & $103.67(2)$ \\
\hline $\mathrm{C}(5)-\mathrm{U}(1)-\mathrm{Cl}(1)$ & $123.05(6)$ \\
\hline $\mathrm{Cl}(2)-\mathrm{U}(1)-\mathrm{C}(14)$ & $121.78(7)$ \\
\hline $\mathrm{C}(5)-\mathrm{U}(1)-\mathrm{C}(14)$ & $75.18(9)$ \\
\hline $\mathrm{Cl}(1)-\mathrm{U}(1)-\mathrm{C}(14)$ & $116.73(7)$ \\
\hline $\mathrm{Cl}(2)-\mathrm{U}(1)-\mathrm{C}(4)$ & $129.88(6)$ \\
\hline $\mathrm{C}(5)-\mathrm{U}(1)-\mathrm{C}(4)$ & $30.31(8)$ \\
\hline $\mathrm{Cl}(1)-\mathrm{U}(1)-\mathrm{C}(4)$ & $92.78(6)$ \\
\hline $\mathrm{C}(14)-\mathrm{U}(1)-\mathrm{C}(4)$ & $89.56(9)$ \\
\hline $\mathrm{Cl}(2)-\mathrm{U}(1)-\mathrm{C}(10)$ & $91.80(7)$ \\
\hline $\mathrm{C}(5)-\mathrm{U}(1)-\mathrm{C}(10)$ & $88.42(9)$ \\
\hline
\end{tabular}




\begin{tabular}{|c|c|}
\hline $\mathrm{Cl}(1)-\mathrm{U}(1)-\mathrm{C}(10)$ & $130.91(7)$ \\
\hline $\mathrm{C}(14)-\mathrm{U}(1)-\mathrm{C}(10)$ & $29.99(10)$ \\
\hline $\mathrm{C}(4)-\mathrm{U}(1)-\mathrm{C}(10)$ & $112.33(9)$ \\
\hline $\mathrm{Cl}(2)-\mathrm{U}(1)-\mathrm{C}(13)$ & $129.74(7)$ \\
\hline $\mathrm{C}(5)-\mathrm{U}(1)-\mathrm{C}(13)$ & $95.95(9)$ \\
\hline $\mathrm{Cl}(1)-\mathrm{U}(1)-\mathrm{C}(13)$ & $87.68(7)$ \\
\hline $\mathrm{C}(14)-\mathrm{U}(1)-\mathrm{C}(13)$ & $29.70(9)$ \\
\hline $\mathrm{C}(4)-\mathrm{U}(1)-\mathrm{C}(13)$ & $97.40(9)$ \\
\hline $\mathrm{C}(10)-\mathrm{U}(1)-\mathrm{C}(13)$ & 49.18(9) \\
\hline $\mathrm{Cl}(2)-\mathrm{U}(1)-\mathrm{C}(1)$ & $86.73(6)$ \\
\hline $\mathrm{C}(5)-\mathrm{U}(1)-\mathrm{C}(1)$ & $29.79(8)$ \\
\hline $\mathrm{Cl}(1)-\mathrm{U}(1)-\mathrm{C}(1)$ & $131.08(6)$ \\
\hline $\mathrm{C}(14)-\mathrm{U}(1)-\mathrm{C}(1)$ & $95.45(9)$ \\
\hline $\mathrm{C}(4)-\mathrm{U}(1)-\mathrm{C}(1)$ & $49.31(8)$ \\
\hline $\mathrm{C}(10)-\mathrm{U}(1)-\mathrm{C}(1)$ & $95.53(9)$ \\
\hline $\mathrm{C}(13)-\mathrm{U}(1)-\mathrm{C}(1)$ & $121.94(9)$ \\
\hline $\mathrm{Cl}(2)-\mathrm{U}(1)-\mathrm{C}(11)$ & $81.87(6)$ \\
\hline $\mathrm{C}(5)-\mathrm{U}(1)-\mathrm{C}(11)$ & 117.71(9) \\
\hline $\mathrm{Cl}(1)-\mathrm{U}(1)-\mathrm{C}(11)$ & $106.59(7)$ \\
\hline $\mathrm{C}(14)-\mathrm{U}(1)-\mathrm{C}(11)$ & $48.51(9)$ \\
\hline $\mathrm{C}(4)-\mathrm{U}(1)-\mathrm{C}(11)$ & $138.04(9)$ \\
\hline $\mathrm{C}(10)-\mathrm{U}(1)-\mathrm{C}(11)$ & $29.45(9)$ \\
\hline $\mathrm{C}(13)-\mathrm{U}(1)-\mathrm{C}(11)$ & $48.27(9)$ \\
\hline $\mathrm{C}(1)-\mathrm{U}(1)-\mathrm{C}(11)$ & $122.25(9)$ \\
\hline $\mathrm{Cl}(2)-\mathrm{U}(1)-\mathrm{C}(12)$ & $102.99(6)$ \\
\hline $\mathrm{C}(5)-\mathrm{U}(1)-\mathrm{C}(12)$ & $122.85(9)$ \\
\hline $\mathrm{Cl}(1)-\mathrm{U}(1)-\mathrm{C}(12)$ & $82.37(6)$ \\
\hline $\mathrm{C}(14)-\mathrm{U}(1)-\mathrm{C}(12)$ & $48.46(9)$ \\
\hline $\mathrm{C}(4)-\mathrm{U}(1)-\mathrm{C}(12)$ & $126.20(9)$ \\
\hline $\mathrm{C}(10)-\mathrm{U}(1)-\mathrm{C}(12)$ & $48.62(9)$ \\
\hline $\mathrm{C}(13)-\mathrm{U}(1)-\mathrm{C}(12)$ & $29.22(9)$ \\
\hline $\mathrm{C}(1)-\mathrm{U}(1)-\mathrm{C}(12)$ & $142.41(9)$ \\
\hline $\mathrm{C}(11)-\mathrm{U}(1)-\mathrm{C}(12)$ & 29.01(9) \\
\hline $\mathrm{Cl}(2)-\mathrm{U}(1)-\mathrm{C}(3)$ & $105.60(6)$ \\
\hline$C(5)-U(1)-C(3)$ & $48.70(8)$ \\
\hline $\mathrm{Cl}(1)-\mathrm{U}(1)-\mathrm{C}(3)$ & $83.22(6)$ \\
\hline
\end{tabular}




\begin{tabular}{|c|c|}
\hline $\mathrm{C}(14)-\mathrm{U}(1)-\mathrm{C}(3)$ & $118.62(9)$ \\
\hline $\mathrm{C}(4)-\mathrm{U}(1)-\mathrm{C}(3)$ & $29.34(8)$ \\
\hline $\mathrm{C}(10)-\mathrm{U}(1)-\mathrm{C}(3)$ & 137.11(9) \\
\hline $\mathrm{C}(13)-\mathrm{U}(1)-\mathrm{C}(3)$ & $124.45(9)$ \\
\hline $\mathrm{C}(1)-\mathrm{U}(1)-\mathrm{C}(3)$ & $48.26(8)$ \\
\hline $\mathrm{C}(11)-\mathrm{U}(1)-\mathrm{C}(3)$ & $166.21(9)$ \\
\hline $\mathrm{C}(12)-\mathrm{U}(1)-\mathrm{C}(3)$ & $150.29(9)$ \\
\hline $\mathrm{Cl}(2)-\mathrm{U}(1)-\mathrm{C}(2)$ & $81.60(6)$ \\
\hline $\mathrm{C}(5)-\mathrm{U}(1)-\mathrm{C}(2)$ & $48.36(8)$ \\
\hline $\mathrm{Cl}(1)-\mathrm{U}(1)-\mathrm{C}(2)$ & $104.33(6)$ \\
\hline $\mathrm{C}(14)-\mathrm{U}(1)-\mathrm{C}(2)$ & $122.47(9)$ \\
\hline $\mathrm{C}(4)-\mathrm{U}(1)-\mathrm{C}(2)$ & $48.34(8)$ \\
\hline $\mathrm{C}(10)-\mathrm{U}(1)-\mathrm{C}(2)$ & $124.09(9)$ \\
\hline $\mathrm{C}(13)-\mathrm{U}(1)-\mathrm{C}(2)$ & $143.32(9)$ \\
\hline $\mathrm{C}(1)-\mathrm{U}(1)-\mathrm{C}(2)$ & $29.06(8)$ \\
\hline $\mathrm{C}(11)-\mathrm{U}(1)-\mathrm{C}(2)$ & 147.57(9) \\
\hline $\mathrm{C}(12)-\mathrm{U}(1)-\mathrm{C}(2)$ & $170.92(8)$ \\
\hline $\mathrm{C}(3)-\mathrm{U}(1)-\mathrm{C}(2)$ & $28.84(8)$ \\
\hline $\mathrm{C}(5)-\mathrm{C}(1)-\mathrm{C}(2)$ & $107.6(2)$ \\
\hline $\mathrm{C}(5)-\mathrm{C}(1)-\mathrm{C}(6)$ & $127.7(3)$ \\
\hline$C(2)-C(1)-C(6)$ & $124.7(3)$ \\
\hline $\mathrm{C}(5)-\mathrm{C}(1)-\mathrm{U}(1)$ & $72.09(15)$ \\
\hline$C(2)-C(1)-U(1)$ & $78.52(16)$ \\
\hline $\mathrm{C}(6)-\mathrm{C}(1)-\mathrm{U}(1)$ & $117.00(18)$ \\
\hline$C(3)-C(2)-C(1)$ & $108.0(2)$ \\
\hline $\mathrm{C}(3)-\mathrm{C}(2)-\mathrm{C}(7)$ & $126.9(3)$ \\
\hline $\mathrm{C}(1)-\mathrm{C}(2)-\mathrm{C}(7)$ & $124.8(3)$ \\
\hline $\mathrm{C}(3)-\mathrm{C}(2)-\mathrm{U}(1)$ & $74.26(16)$ \\
\hline$C(1)-C(2)-U(1)$ & $72.42(16)$ \\
\hline $\mathrm{C}(7)-\mathrm{C}(2)-\mathrm{U}(1)$ & $123.25(19)$ \\
\hline $\mathrm{C}(4)-\mathrm{C}(3)-\mathrm{C}(2)$ & $108.4(2)$ \\
\hline $\mathrm{C}(4)-\mathrm{C}(3)-\mathrm{C}(8)$ & $124.7(3)$ \\
\hline $\mathrm{C}(2)-\mathrm{C}(3)-\mathrm{C}(8)$ & $126.8(3)$ \\
\hline $\mathrm{C}(4)-\mathrm{C}(3)-\mathrm{U}(1)$ & $71.66(16)$ \\
\hline$C(2)-C(3)-U(1)$ & $76.90(16)$ \\
\hline $\mathrm{C}(8)-\mathrm{C}(3)-\mathrm{U}(1)$ & $120.57(19)$ \\
\hline
\end{tabular}




\begin{tabular}{|c|c|}
\hline$C(3)-C(4)-C(5)$ & $107.4(2)$ \\
\hline$C(3)-C(4)-C(9)$ & $125.3(3)$ \\
\hline $\mathrm{C}(5)-\mathrm{C}(4)-\mathrm{C}(9)$ & $127.3(3)$ \\
\hline $\mathrm{C}(3)-\mathrm{C}(4)-\mathrm{U}(1)$ & $79.00(16)$ \\
\hline $\mathrm{C}(5)-\mathrm{C}(4)-\mathrm{U}(1)$ & $73.77(15)$ \\
\hline $\mathrm{C}(9)-\mathrm{C}(4)-\mathrm{U}(1)$ & $112.83(19)$ \\
\hline$C(1)-C(5)-C(4)$ & $108.5(3)$ \\
\hline$C(1)-C(5)-U(1)$ & $78.12(16)$ \\
\hline$C(4)-C(5)-U(1)$ & $75.92(16)$ \\
\hline $\mathrm{C}(11)-\mathrm{C}(10)-\mathrm{C}(14)$ & $106.8(3)$ \\
\hline $\mathrm{C}(11)-\mathrm{C}(10)-\mathrm{C}(15)$ & $126.6(3)$ \\
\hline $\mathrm{C}(14)-\mathrm{C}(10)-\mathrm{C}(15)$ & $126.5(3)$ \\
\hline $\mathrm{C}(11)-\mathrm{C}(10)-\mathrm{U}(1)$ & $77.38(17)$ \\
\hline $\mathrm{C}(14)-\mathrm{C}(10)-\mathrm{U}(1)$ & $74.05(17)$ \\
\hline $\mathrm{C}(15)-\mathrm{C}(10)-\mathrm{U}(1)$ & $116.9(2)$ \\
\hline $\mathrm{C}(12)-\mathrm{C}(11)-\mathrm{C}(10)$ & $108.9(3)$ \\
\hline $\mathrm{C}(12)-\mathrm{C}(11)-\mathrm{C}(16)$ & $125.5(3)$ \\
\hline $\mathrm{C}(10)-\mathrm{C}(11)-\mathrm{C}(16)$ & $125.3(3)$ \\
\hline $\mathrm{C}(12)-\mathrm{C}(11)-\mathrm{U}(1)$ & $76.23(17)$ \\
\hline $\mathrm{C}(10)-\mathrm{C}(11)-\mathrm{U}(1)$ & $73.17(17)$ \\
\hline $\mathrm{C}(16)-\mathrm{C}(11)-\mathrm{U}(1)$ & $121.6(2)$ \\
\hline $\mathrm{C}(11)-\mathrm{C}(12)-\mathrm{C}(13)$ & $107.9(3)$ \\
\hline $\mathrm{C}(11)-\mathrm{C}(12)-\mathrm{C}(17)$ & $127.5(3)$ \\
\hline $\mathrm{C}(13)-\mathrm{C}(12)-\mathrm{C}(17)$ & $124.4(3)$ \\
\hline $\mathrm{C}(11)-\mathrm{C}(12)-\mathrm{U}(1)$ & $74.76(17)$ \\
\hline $\mathrm{C}(13)-\mathrm{C}(12)-\mathrm{U}(1)$ & $73.52(16)$ \\
\hline $\mathrm{C}(17)-\mathrm{C}(12)-\mathrm{U}(1)$ & $121.92(19)$ \\
\hline $\mathrm{C}(14)-\mathrm{C}(13)-\mathrm{C}(12)$ & $107.6(3)$ \\
\hline $\mathrm{C}(14)-\mathrm{C}(13)-\mathrm{C}(18)$ & $126.0(3)$ \\
\hline $\mathrm{C}(12)-\mathrm{C}(13)-\mathrm{C}(18)$ & $126.3(3)$ \\
\hline $\mathrm{C}(14)-\mathrm{C}(13)-\mathrm{U}(1)$ & $73.22(17)$ \\
\hline $\mathrm{C}(12)-\mathrm{C}(13)-\mathrm{U}(1)$ & $77.25(16)$ \\
\hline $\mathrm{C}(18)-\mathrm{C}(13)-\mathrm{U}(1)$ & $118.6(2)$ \\
\hline$C(13)-C(14)-C(10)$ & $108.8(3)$ \\
\hline $\mathrm{C}(13)-\mathrm{C}(14)-\mathrm{U}(1)$ & $77.08(17)$ \\
\hline $\mathrm{C}(10)-\mathrm{C}(14)-\mathrm{U}(1)$ & $75.95(17)$ \\
\hline
\end{tabular}




\begin{tabular}{|c|c|}
\hline $\mathrm{Cl}(4)-\mathrm{U}(2)-\mathrm{C}(23)$ & $105.99(6)$ \\
\hline $\mathrm{Cl}(4)-\mathrm{U}(2)-\mathrm{Cl}(3)$ & $100.31(2)$ \\
\hline $\mathrm{C}(23)-\mathrm{U}(2)-\mathrm{Cl}(3)$ & $130.56(7)$ \\
\hline $\mathrm{Cl}(4)-\mathrm{U}(2)-\mathrm{C}(32)$ & $119.74(6)$ \\
\hline $\mathrm{C}(23)-\mathrm{U}(2)-\mathrm{C}(32)$ & $80.06(9)$ \\
\hline $\mathrm{Cl}(3)-\mathrm{U}(2)-\mathrm{C}(32)$ & $120.86(6)$ \\
\hline $\mathrm{Cl}(4)-\mathrm{U}(2)-\mathrm{C}(19)$ & $130.45(6)$ \\
\hline$C(23)-U(2)-C(19)$ & $29.98(9)$ \\
\hline $\mathrm{Cl}(3)-\mathrm{U}(2)-\mathrm{C}(19)$ & $103.41(6)$ \\
\hline $\mathrm{C}(32)-\mathrm{U}(2)-\mathrm{C}(19)$ & $82.94(9)$ \\
\hline $\mathrm{Cl}(4)-\mathrm{U}(2)-\mathrm{C}(28)$ & $89.99(6)$ \\
\hline $\mathrm{C}(23)-\mathrm{U}(2)-\mathrm{C}(28)$ & $89.20(8)$ \\
\hline $\mathrm{Cl}(3)-\mathrm{U}(2)-\mathrm{C}(28)$ & $132.29(6)$ \\
\hline $\mathrm{C}(32)-\mathrm{U}(2)-\mathrm{C}(28)$ & $29.79(8)$ \\
\hline $\mathrm{C}(19)-\mathrm{U}(2)-\mathrm{C}(28)$ & $104.47(8)$ \\
\hline $\mathrm{Cl}(4)-\mathrm{U}(2)-\mathrm{C}(31)$ & $128.88(6)$ \\
\hline $\mathrm{C}(23)-\mathrm{U}(2)-\mathrm{C}(31)$ & $103.01(9)$ \\
\hline $\mathrm{Cl}(3)-\mathrm{U}(2)-\mathrm{C}(31)$ & $91.31(6)$ \\
\hline $\mathrm{C}(32)-\mathrm{U}(2)-\mathrm{C}(31)$ & $29.81(8)$ \\
\hline $\mathrm{C}(19)-\mathrm{U}(2)-\mathrm{C}(31)$ & $93.46(8)$ \\
\hline $\mathrm{C}(28)-\mathrm{U}(2)-\mathrm{C}(31)$ & $49.24(8)$ \\
\hline $\mathrm{Cl}(4)-\mathrm{U}(2)-\mathrm{C}(21)$ & $87.41(6)$ \\
\hline $\mathrm{C}(23)-\mathrm{U}(2)-\mathrm{C}(21)$ & $48.84(9)$ \\
\hline $\mathrm{Cl}(3)-\mathrm{U}(2)-\mathrm{C}(21)$ & $92.41(7)$ \\
\hline $\mathrm{C}(32)-\mathrm{U}(2)-\mathrm{C}(21)$ & $128.07(8)$ \\
\hline$C(19)-U(2)-C(21)$ & $49.04(8)$ \\
\hline $\mathrm{C}(28)-\mathrm{U}(2)-\mathrm{C}(21)$ & $134.81(9)$ \\
\hline $\mathrm{C}(31)-\mathrm{U}(2)-\mathrm{C}(21)$ & $142.06(8)$ \\
\hline $\mathrm{Cl}(4)-\mathrm{U}(2)-\mathrm{C}(22)$ & $81.35(6)$ \\
\hline$C(23)-U(2)-C(22)$ & $29.71(8)$ \\
\hline $\mathrm{Cl}(3)-\mathrm{U}(2)-\mathrm{C}(22)$ & $121.78(7)$ \\
\hline $\mathrm{C}(32)-\mathrm{U}(2)-\mathrm{C}(22)$ & $106.66(9)$ \\
\hline$C(19)-U(2)-C(22)$ & $49.18(8)$ \\
\hline $\mathrm{C}(28)-\mathrm{U}(2)-\mathrm{C}(22)$ & $105.75(9)$ \\
\hline$C(31)-U(2)-C(22)$ & $132.41(9)$ \\
\hline $\mathrm{C}(21)-\mathrm{U}(2)-\mathrm{C}(22)$ & $29.41(9)$ \\
\hline
\end{tabular}




\begin{tabular}{|c|c|}
\hline $\mathrm{Cl}(4)-\mathrm{U}(2)-\mathrm{C}(20)$ & $116.46(6)$ \\
\hline $\mathrm{C}(23)-\mathrm{U}(2)-\mathrm{C}(20)$ & $48.78(9)$ \\
\hline $\mathrm{Cl}(3)-\mathrm{U}(2)-\mathrm{C}(20)$ & $82.09(6)$ \\
\hline $\mathrm{C}(32)-\mathrm{U}(2)-\mathrm{C}(20)$ & $111.44(8)$ \\
\hline $\mathrm{C}(19)-\mathrm{U}(2)-\mathrm{C}(20)$ & $29.52(8)$ \\
\hline $\mathrm{C}(28)-\mathrm{U}(2)-\mathrm{C}(20)$ & $133.80(8)$ \\
\hline $\mathrm{C}(31)-\mathrm{U}(2)-\mathrm{C}(20)$ & $114.38(8)$ \\
\hline $\mathrm{C}(21)-\mathrm{U}(2)-\mathrm{C}(20)$ & $29.58(8)$ \\
\hline $\mathrm{C}(22)-\mathrm{U}(2)-\mathrm{C}(20)$ & $48.64(9)$ \\
\hline $\mathrm{Cl}(4)-\mathrm{U}(2)-\mathrm{C}(30)$ & $102.37(6)$ \\
\hline $\mathrm{C}(23)-\mathrm{U}(2)-\mathrm{C}(30)$ & $128.68(8)$ \\
\hline $\mathrm{Cl}(3)-\mathrm{U}(2)-\mathrm{C}(30)$ & $83.52(6)$ \\
\hline $\mathrm{C}(32)-\mathrm{U}(2)-\mathrm{C}(30)$ & $48.68(8)$ \\
\hline $\mathrm{C}(19)-\mathrm{U}(2)-\mathrm{C}(30)$ & $122.96(8)$ \\
\hline $\mathrm{C}(28)-\mathrm{U}(2)-\mathrm{C}(30)$ & $48.80(8)$ \\
\hline $\mathrm{C}(31)-\mathrm{U}(2)-\mathrm{C}(30)$ & $29.51(8)$ \\
\hline $\mathrm{C}(21)-\mathrm{U}(2)-\mathrm{C}(30)$ & $169.93(8)$ \\
\hline $\mathrm{C}(22)-\mathrm{U}(2)-\mathrm{C}(30)$ & 153.72(9) \\
\hline $\mathrm{C}(20)-\mathrm{U}(2)-\mathrm{C}(30)$ & $140.36(8)$ \\
\hline $\mathrm{Cl}(4)-\mathrm{U}(2)-\mathrm{C}(29)$ & $80.31(6)$ \\
\hline $\mathrm{C}(23)-\mathrm{U}(2)-\mathrm{C}(29)$ & $118.53(8)$ \\
\hline $\mathrm{Cl}(3)-\mathrm{U}(2)-\mathrm{C}(29)$ & $106.56(6)$ \\
\hline $\mathrm{C}(32)-\mathrm{U}(2)-\mathrm{C}(29)$ & $48.62(8)$ \\
\hline $\mathrm{C}(19)-\mathrm{U}(2)-\mathrm{C}(29)$ & $131.18(8)$ \\
\hline $\mathrm{C}(28)-\mathrm{U}(2)-\mathrm{C}(29)$ & $29.41(8)$ \\
\hline $\mathrm{C}(31)-\mathrm{U}(2)-\mathrm{C}(29)$ & $48.81(8)$ \\
\hline $\mathrm{C}(21)-\mathrm{U}(2)-\mathrm{C}(29)$ & $158.90(9)$ \\
\hline $\mathrm{C}(22)-\mathrm{U}(2)-\mathrm{C}(29)$ & $130.53(9)$ \\
\hline $\mathrm{C}(20)-\mathrm{U}(2)-\mathrm{C}(29)$ & $160.03(8)$ \\
\hline $\mathrm{C}(30)-\mathrm{U}(2)-\mathrm{C}(29)$ & $29.48(8)$ \\
\hline$C(20)-C(19)-C(23)$ & $107.3(2)$ \\
\hline $\mathrm{C}(20)-\mathrm{C}(19)-\mathrm{C}(24)$ & $126.3(3)$ \\
\hline$C(23)-C(19)-C(24)$ & $126.1(3)$ \\
\hline $\mathrm{C}(20)-\mathrm{C}(19)-\mathrm{U}(2)$ & $76.70(16)$ \\
\hline $\mathrm{C}(23)-\mathrm{C}(19)-\mathrm{U}(2)$ & $74.10(16)$ \\
\hline $\mathrm{C}(24)-\mathrm{C}(19)-\mathrm{U}(2)$ & $119.52(18)$ \\
\hline
\end{tabular}




\begin{tabular}{|c|c|}
\hline$C(19)-C(20)-C(21)$ & $108.1(3)$ \\
\hline$C(19)-C(20)-C(25)$ & $125.8(3)$ \\
\hline$C(21)-C(20)-C(25)$ & $125.9(3)$ \\
\hline $\mathrm{C}(19)-\mathrm{C}(20)-\mathrm{U}(2)$ & $73.78(16)$ \\
\hline $\mathrm{C}(21)-\mathrm{C}(20)-\mathrm{U}(2)$ & $74.70(16)$ \\
\hline $\mathrm{C}(25)-\mathrm{C}(20)-\mathrm{U}(2)$ & $121.36(19)$ \\
\hline$C(22)-C(21)-C(20)$ & $108.2(3)$ \\
\hline$C(22)-C(21)-C(26)$ & $126.2(3)$ \\
\hline$C(20)-C(21)-C(26)$ & $125.5(3)$ \\
\hline $\mathrm{C}(22)-\mathrm{C}(21)-\mathrm{U}(2)$ & $75.38(16)$ \\
\hline $\mathrm{C}(20)-\mathrm{C}(21)-\mathrm{U}(2)$ & $75.72(16)$ \\
\hline $\mathrm{C}(26)-\mathrm{C}(21)-\mathrm{U}(2)$ & $118.09(19)$ \\
\hline $\mathrm{C}(21)-\mathrm{C}(22)-\mathrm{C}(23)$ & $107.5(3)$ \\
\hline$C(21)-C(22)-C(27)$ & $126.8(3)$ \\
\hline$C(23)-C(22)-C(27)$ & $125.5(3)$ \\
\hline $\mathrm{C}(21)-\mathrm{C}(22)-\mathrm{U}(2)$ & $75.22(16)$ \\
\hline $\mathrm{C}(23)-\mathrm{C}(22)-\mathrm{U}(2)$ & $73.20(16)$ \\
\hline $\mathrm{C}(27)-\mathrm{C}(22)-\mathrm{U}(2)$ & $121.0(2)$ \\
\hline$C(22)-C(23)-C(19)$ & $108.8(3)$ \\
\hline $\mathrm{C}(22)-\mathrm{C}(23)-\mathrm{U}(2)$ & $77.08(16)$ \\
\hline $\mathrm{C}(19)-\mathrm{C}(23)-\mathrm{U}(2)$ & $75.92(16)$ \\
\hline $\mathrm{C}(29)-\mathrm{C}(28)-\mathrm{C}(32)$ & $107.6(2)$ \\
\hline $\mathrm{C}(29)-\mathrm{C}(28)-\mathrm{C}(33)$ & $125.1(3)$ \\
\hline $\mathrm{C}(32)-\mathrm{C}(28)-\mathrm{C}(33)$ & $127.3(3)$ \\
\hline $\mathrm{C}(29)-\mathrm{C}(28)-\mathrm{U}(2)$ & $76.91(15)$ \\
\hline $\mathrm{C}(32)-\mathrm{C}(28)-\mathrm{U}(2)$ & $74.24(15)$ \\
\hline $\mathrm{C}(33)-\mathrm{C}(28)-\mathrm{U}(2)$ & $114.91(18)$ \\
\hline $\mathrm{C}(28)-\mathrm{C}(29)-\mathrm{C}(30)$ & $108.1(2)$ \\
\hline $\mathrm{C}(28)-\mathrm{C}(29)-\mathrm{C}(34)$ & $125.0(3)$ \\
\hline$C(30)-C(29)-C(34)$ & $126.7(3)$ \\
\hline $\mathrm{C}(28)-\mathrm{C}(29)-\mathrm{U}(2)$ & $73.67(15)$ \\
\hline $\mathrm{C}(30)-\mathrm{C}(29)-\mathrm{U}(2)$ & $75.25(15)$ \\
\hline $\mathrm{C}(34)-\mathrm{C}(29)-\mathrm{U}(2)$ & $120.27(18)$ \\
\hline $\mathrm{C}(31)-\mathrm{C}(30)-\mathrm{C}(29)$ & $108.1(2)$ \\
\hline $\mathrm{C}(31)-\mathrm{C}(30)-\mathrm{C}(35)$ & 125.1(3) \\
\hline$C(29)-C(30)-C(35)$ & $126.8(3)$ \\
\hline
\end{tabular}




\begin{tabular}{|c|c|}
\hline $\mathrm{C}(31)-\mathrm{C}(30)-\mathrm{U}(2)$ & $74.27(15)$ \\
\hline $\mathrm{C}(29)-\mathrm{C}(30)-\mathrm{U}(2)$ & $75.28(15)$ \\
\hline $\mathrm{C}(35)-\mathrm{C}(30)-\mathrm{U}(2)$ & $117.70(18)$ \\
\hline $\mathrm{C}(32)-\mathrm{C}(31)-\mathrm{C}(30)$ & $107.1(2)$ \\
\hline $\mathrm{C}(32)-\mathrm{C}(31)-\mathrm{C}(36)$ & $127.3(3)$ \\
\hline$C(30)-C(31)-C(36)$ & $125.6(3)$ \\
\hline $\mathrm{C}(32)-\mathrm{C}(31)-\mathrm{U}(2)$ & $73.62(15)$ \\
\hline $\mathrm{C}(30)-\mathrm{C}(31)-\mathrm{U}(2)$ & $76.22(15)$ \\
\hline $\mathrm{C}(36)-\mathrm{C}(31)-\mathrm{U}(2)$ & $118.57(19)$ \\
\hline $\mathrm{C}(28)-\mathrm{C}(32)-\mathrm{C}(31)$ & $109.0(2)$ \\
\hline $\mathrm{C}(28)-\mathrm{C}(32)-\mathrm{U}(2)$ & $75.97(15)$ \\
\hline $\mathrm{C}(31)-\mathrm{C}(32)-\mathrm{U}(2)$ & $76.57(15)$ \\
\hline $\mathrm{C}(49)-\mathrm{N}(1)-\mathrm{C}(37)$ & $108.1(2)$ \\
\hline $\mathrm{C}(49)-\mathrm{N}(1)-\mathrm{C}(41)$ & $108.8(2)$ \\
\hline $\mathrm{C}(37)-\mathrm{N}(1)-\mathrm{C}(41)$ & $111.6(2)$ \\
\hline $\mathrm{C}(49)-\mathrm{N}(1)-\mathrm{C}(45)$ & $111.5(2)$ \\
\hline $\mathrm{C}(37)-\mathrm{N}(1)-\mathrm{C}(45)$ & $108.4(2)$ \\
\hline $\mathrm{C}(41)-\mathrm{N}(1)-\mathrm{C}(45)$ & $108.4(2)$ \\
\hline $\mathrm{C}(38)-\mathrm{C}(37)-\mathrm{N}(1)$ & $114.4(2)$ \\
\hline $\mathrm{C}(37)-\mathrm{C}(38)-\mathrm{C}(39)$ & $112.2(2)$ \\
\hline $\mathrm{C}(40)-\mathrm{C}(39)-\mathrm{C}(38)$ & $114.2(2)$ \\
\hline $\mathrm{C}(42)-\mathrm{C}(41)-\mathrm{N}(1)$ & $115.3(2)$ \\
\hline $\mathrm{C}(41)-\mathrm{C}(42)-\mathrm{C}(43)$ & $109.8(3)$ \\
\hline $\mathrm{C}(42)-\mathrm{C}(43)-\mathrm{C}(44)$ & $112.2(3)$ \\
\hline $\mathrm{C}(46)-\mathrm{C}(45)-\mathrm{N}(1)$ & $114.7(2)$ \\
\hline $\mathrm{C}(47)-\mathrm{C}(46)-\mathrm{C}(45)$ & $112.2(3)$ \\
\hline $\mathrm{C}(46)-\mathrm{C}(47)-\mathrm{C}(48)$ & $113.4(3)$ \\
\hline $\mathrm{N}(1)-\mathrm{C}(49)-\mathrm{C}(50)$ & $115.0(2)$ \\
\hline$C(49)-C(50)-C(51)$ & $109.8(2)$ \\
\hline$C(50)-C(51)-C(52)$ & $113.9(3)$ \\
\hline $\mathrm{C}(57)-\mathrm{N}(2)-\mathrm{C}(53)$ & $108.7(2)$ \\
\hline $\mathrm{C}(57)-\mathrm{N}(2)-\mathrm{C}(65)$ & $111.2(2)$ \\
\hline $\mathrm{C}(53)-\mathrm{N}(2)-\mathrm{C}(65)$ & $108.5(2)$ \\
\hline $\mathrm{C}(57)-\mathrm{N}(2)-\mathrm{C}(61)$ & $108.5(2)$ \\
\hline $\mathrm{C}(53)-\mathrm{N}(2)-\mathrm{C}(61)$ & $111.6(2)$ \\
\hline $\mathrm{C}(65)-\mathrm{N}(2)-\mathrm{C}(61)$ & $108.3(2)$ \\
\hline
\end{tabular}




$\begin{array}{ll}\mathrm{N}(2)-\mathrm{C}(53)-\mathrm{C}(54) & 115.7(2) \\ \mathrm{C}(55)-\mathrm{C}(54)-\mathrm{C}(53) & 110.1(2) \\ \mathrm{C}(56)-\mathrm{C}(55)-\mathrm{C}(54) & 112.2(3) \\ \mathrm{N}(2)-\mathrm{C}(57)-\mathrm{C}(58) & 115.4(2) \\ \mathrm{C}(59)-\mathrm{C}(58)-\mathrm{C}(57) & 110.9(2) \\ \mathrm{C}(60)-\mathrm{C}(59)-\mathrm{C}(58) & 113.7(3) \\ \mathrm{C}(62)-\mathrm{C}(61)-\mathrm{N}(2) & 114.8(2) \\ \mathrm{C}(61)-\mathrm{C}(62)-\mathrm{C}(63) & 110.5(2) \\ \mathrm{C}(64)-\mathrm{C}(63)-\mathrm{C}(62) & 113.7(2) \\ \mathrm{C}(66)-\mathrm{C}(65)-\mathrm{N}(2) & 115.7(2) \\ \mathrm{C}(65)-\mathrm{C}(66)-\mathrm{C}(67) & 110.3(2) \\ \mathrm{C}(68)-\mathrm{C}(67)-\mathrm{C}(66) & 111.8(3)\end{array}$

\section{X-ray Data Collection, Structure Solution and Refinement for 9.}

A green crystal of approximate dimensions $0.070 \times 0.153 \times 0.218 \mathrm{~mm}$ was mounted on a glass fiber and transferred to a Bruker SMART APEX II diffractometer. The APEX2 ${ }^{7}$ program package was used to determine the unit-cell parameters and for data collection (20 sec/frame scan time for a sphere of diffraction data). The raw frame data was processed using SAINT ${ }^{2}$ and $\mathrm{SADABS}^{3}$ to yield the reflection data file. Subsequent calculations were carried out using the SHELXTL ${ }^{4}$ program. The diffraction symmetry was $2 / m$ and the systematic absences were consistent with the monoclinic space groups $C c$ and $C 2 / c$. It was later determined that space group $C 2 / c$ was correct.

The structure was solved by direct methods and refined on $\mathrm{F}^{2}$ by full-matrix least-squares techniques. The analytical scattering factors ${ }^{8}$ for neutral atoms were used throughout the analysis. The molecule was located on a two-fold rotation axis. Hydrogen atoms were included using a riding model. Carbon atoms C(19)-C(22) were disordered and included using multiple components with partial site-occupancy-factors.

At convergence, $\mathrm{wR} 2=0.0695$ and Goof $=1.052$ for 322 variables refined against 6166 data $(0.80 \AA)$, R $1=0.0284$ for those 4995 data with $\mathrm{I}>2.0 \sigma(\mathrm{I})$. . 


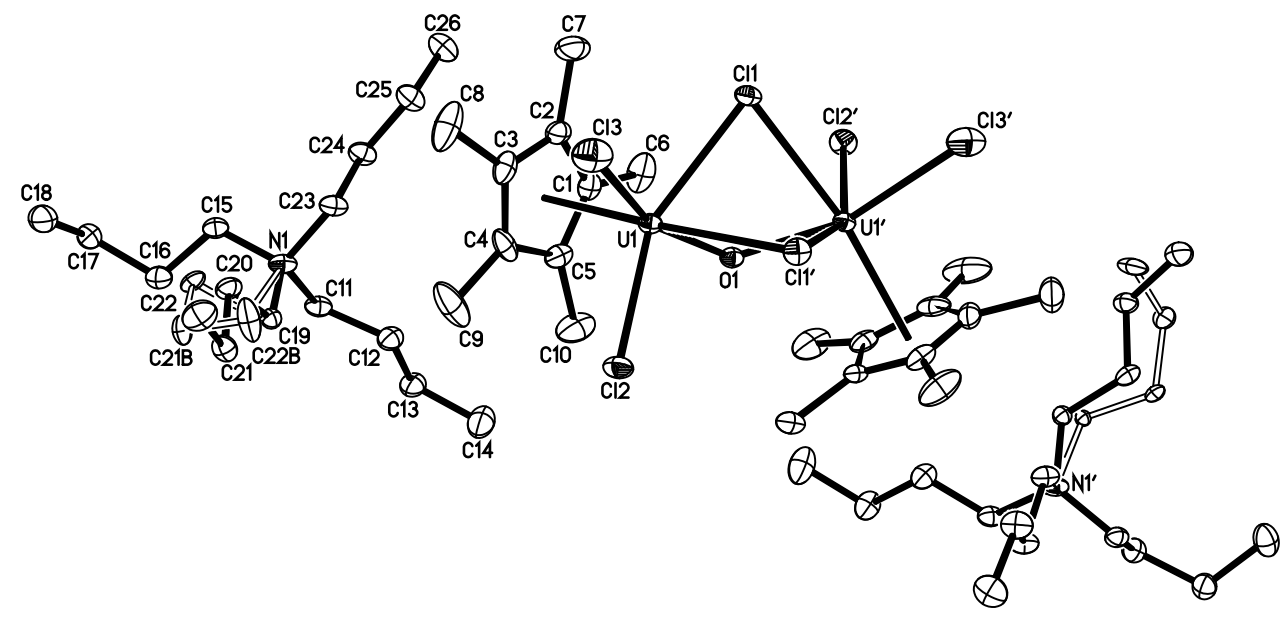

Figure S8. Thermal ellipsoid plot of $\left[\mathrm{NBu}_{4}\right]_{2}\left\{\left[\left(\mathrm{C}_{5} \mathrm{Me}_{5}\right) \mathrm{UCl}_{2}\right]_{2}(\mu-\mathrm{Cl})_{2}(\mu-\mathrm{O})\right\}, \mathbf{9}$, shown at the $50 \%$ probability level with hydrogen atoms removed for clarity.

Table S11. Crystal data and structure refinement for 9.

Identification code

clw28 (Chris Webster)

Empirical formula

$\mathrm{C}_{52} \mathrm{H}_{102} \mathrm{Cl}_{6} \mathrm{~N}_{2} \mathrm{O} \mathrm{U}_{2}$

Formula weight

1460.11

Temperature

143(2) K

Wavelength

$0.71073 \AA$

Crystal system

Monoclinic

Space group

Unit cell dimensions

$C 2 / c$

$\begin{array}{lll} & b=16.6868(10) \AA \quad \AA & \square=103.9622(7)^{\circ} . \\ & c=17.6872(10) \AA \quad & \square=90^{\circ} . \\ \text { Volume } & 6023.6(6) \AA^{3} & \\ Z & 4 \\ \text { Density (calculated) } & 1.610 \mathrm{Mg} / \mathrm{m}^{3} \\ \text { Absorption coefficient } & 5.671 \mathrm{~mm}^{-1} \\ \text { F(000) } & 2888 \\ \text { Crystal color } & \text { green } \\ \text { Crystal size } & 0.218 \times 0.153 \times 0.070 \mathrm{~mm}^{3}\end{array}$


Theta range for data collection

Index ranges

Reflections collected

Independent reflections

Completeness to theta $=25.242^{\circ}$

Absorption correction

Max. and min. transmission

Refinement method

Data / restraints / parameters

Goodness-of-fit on $\mathrm{F}^{2}$

Final R indices [I $>2 \operatorname{sigma}(\mathrm{I})=4995$ data]

$\mathrm{R}$ indices (all data, $0.80 \AA$ )

Largest diff. peak and hole
1.576 to $26.371^{\circ}$

$-26 \leq h \leq 26,-20 \leq k \leq 20,-22 \leq l \leq 22$

31937

$6166[\mathrm{R}(\mathrm{int})=0.0361]$

$100.0 \%$

Numerical

0.6814 and 0.3815

Full-matrix least-squares on $\mathrm{F}^{2}$

6166 / 0 / 322

1.052

$\mathrm{R} 1=0.0284, \mathrm{wR} 2=0.0644$

$\mathrm{R} 1=0.0417, \mathrm{wR} 2=0.0695$

2.513 and -1.095 e. $\AA^{-3}$

Table S12. Bond lengths $[\AA]$ and angles $\left[{ }^{\circ}\right]$ for 9.

\begin{tabular}{ll}
\hline $\mathrm{U}(1)-\mathrm{Cnt}$ & 2.481 \\
$\mathrm{U}(1)-\mathrm{O}(1)$ & $2.087(2)$ \\
$\mathrm{U}(1)-\mathrm{Cl}(2)$ & $2.6744(11)$ \\
$\mathrm{U}(1)-\mathrm{Cl}(3)$ & $2.6782(17)$ \\
$\mathrm{U}(1)-\mathrm{C}(5)$ & $2.713(5)$ \\
$\mathrm{U}(1)-\mathrm{C}(1)$ & $2.720(4)$ \\
$\mathrm{U}(1)-\mathrm{C}(2)$ & $2.760(5)$ \\
$\mathrm{U}(1)-\mathrm{C}(4)$ & $2.768(5)$ \\
$\mathrm{U}(1)-\mathrm{C}(3)$ & $2.799(5)$ \\
$\mathrm{U}(1)-\mathrm{Cl}(1)$ & $2.8121(11)$ \\
$\mathrm{U}(1)-\mathrm{Cl}(1) \# 1$ & $2.9017(12)$ \\
$\mathrm{U}(1)-\mathrm{U}(1) \# 1$ & $3.6033(4)$ \\
$\mathrm{Cl}(1)-\mathrm{U}(1) \# 1$ & $2.9017(12)$ \\
$\mathrm{O}(1)-\mathrm{U}(1) \# 1$ & $2.087(2)$ \\
$\mathrm{C}(1)-\mathrm{C}(2)$ & $1.390(7)$ \\
$\mathrm{C}(1)-\mathrm{C}(5)$ & $1.404(7)$ \\
$\mathrm{C}(1)-\mathrm{C}(6)$ & $1.502(7)$ \\
$\mathrm{C}(2)-\mathrm{C}(3)$ & $1.398(8)$ \\
$\mathrm{C}(2)-\mathrm{C}(7)$ & $1.516(7)$ \\
\end{tabular}




\begin{tabular}{|c|c|}
\hline $\mathrm{C}(3)-\mathrm{C}(4)$ & $1.392(8)$ \\
\hline $\mathrm{C}(3)-\mathrm{C}(8)$ & $1.513(8)$ \\
\hline $\mathrm{C}(4)-\mathrm{C}(5)$ & $1.422(8)$ \\
\hline $\mathrm{C}(4)-\mathrm{C}(9)$ & $1.504(8)$ \\
\hline$C(5)-C(10)$ & $1.497(7)$ \\
\hline $\mathrm{N}(1)-\mathrm{C}(19)$ & $1.504(9)$ \\
\hline $\mathrm{N}(1)-\mathrm{C}(23)$ & $1.515(6)$ \\
\hline $\mathrm{N}(1)-\mathrm{C}(15)$ & $1.516(6)$ \\
\hline $\mathrm{N}(1)-\mathrm{C}(11)$ & $1.518(6)$ \\
\hline $\mathrm{N}(1)-\mathrm{C}(19 \mathrm{~B})$ & $1.592(13)$ \\
\hline$C(11)-C(12)$ & $1.512(7)$ \\
\hline$C(12)-C(13)$ & $1.527(7)$ \\
\hline$C(13)-C(14)$ & $1.510(8)$ \\
\hline$C(15)-C(16)$ & $1.516(7)$ \\
\hline$C(16)-C(17)$ & $1.523(7)$ \\
\hline$C(17)-C(18)$ & $1.507(8)$ \\
\hline$C(19)-C(20)$ & $1.521(14)$ \\
\hline$C(20)-C(21)$ & $1.519(13)$ \\
\hline$C(21)-C(22)$ & $1.491(16)$ \\
\hline$C(19 B)-C(20 B)$ & $1.47(2)$ \\
\hline $\mathrm{C}(20 \mathrm{~B})-\mathrm{C}(21 \mathrm{~B})$ & $1.53(2)$ \\
\hline $\mathrm{C}(21 \mathrm{~B})-\mathrm{C}(22 \mathrm{~B})$ & $1.49(2)$ \\
\hline$C(23)-C(24)$ & $1.511(6)$ \\
\hline$C(24)-C(25)$ & $1.508(7)$ \\
\hline$C(25)-C(26)$ & $1.515(7)$ \\
\hline Cnt-U(1)-Cl(1) & 104.0 \\
\hline Cnt-U(1)-Cl(2) & 103.5 \\
\hline Cnt-U(1)-Cl(3) & 99.7 \\
\hline Cnt-U(1)-Cl(1)\#1 & 171.6 \\
\hline Cnt-U(1)-O(1) & 99.9 \\
\hline $\mathrm{O}(1)-\mathrm{U}(1)-\mathrm{Cl}(2)$ & $96.42(5)$ \\
\hline $\mathrm{O}(1)-\mathrm{U}(1)-\mathrm{Cl}(3)$ & $156.85(11)$ \\
\hline $\mathrm{Cl}(2)-\mathrm{U}(1)-\mathrm{Cl}(3)$ & $90.88(4)$ \\
\hline $\mathrm{O}(1)-\mathrm{U}(1)-\mathrm{C}(5)$ & $81.46(15)$ \\
\hline $\mathrm{Cl}(2)-\mathrm{U}(1)-\mathrm{C}(5)$ & $87.27(11)$ \\
\hline
\end{tabular}




\begin{tabular}{|c|c|}
\hline $\mathrm{Cl}(3)-\mathrm{U}(1)-\mathrm{C}(5)$ & $120.93(12)$ \\
\hline $\mathrm{O}(1)-\mathrm{U}(1)-\mathrm{C}(1)$ & $76.56(12)$ \\
\hline $\mathrm{Cl}(2)-\mathrm{U}(1)-\mathrm{C}(1)$ & $117.08(11)$ \\
\hline $\mathrm{Cl}(3)-\mathrm{U}(1)-\mathrm{C}(1)$ & $119.27(11)$ \\
\hline $\mathrm{C}(5)-\mathrm{U}(1)-\mathrm{C}(1)$ & $29.94(15)$ \\
\hline $\mathrm{O}(1)-\mathrm{U}(1)-\mathrm{C}(2)$ & $102.21(13)$ \\
\hline $\mathrm{Cl}(2)-\mathrm{U}(1)-\mathrm{C}(2)$ & $127.69(11)$ \\
\hline $\mathrm{Cl}(3)-\mathrm{U}(1)-\mathrm{C}(2)$ & $90.39(12)$ \\
\hline $\mathrm{C}(5)-\mathrm{U}(1)-\mathrm{C}(2)$ & $48.92(15)$ \\
\hline $\mathrm{C}(1)-\mathrm{U}(1)-\mathrm{C}(2)$ & $29.39(15)$ \\
\hline $\mathrm{O}(1)-\mathrm{U}(1)-\mathrm{C}(4)$ & $111.09(16)$ \\
\hline $\mathrm{Cl}(2)-\mathrm{U}(1)-\mathrm{C}(4)$ & $79.40(11)$ \\
\hline $\mathrm{Cl}(3)-\mathrm{U}(1)-\mathrm{C}(4)$ & $91.82(13)$ \\
\hline $\mathrm{C}(5)-\mathrm{U}(1)-\mathrm{C}(4)$ & $30.06(16)$ \\
\hline C(1)-U(1)-C(4) & $48.93(15)$ \\
\hline $\mathrm{C}(2)-\mathrm{U}(1)-\mathrm{C}(4)$ & $48.29(15)$ \\
\hline $\mathrm{O}(1)-\mathrm{U}(1)-\mathrm{C}(3)$ & $124.55(13)$ \\
\hline $\mathrm{Cl}(2)-\mathrm{U}(1)-\mathrm{C}(3)$ & $102.71(13)$ \\
\hline $\mathrm{Cl}(3)-\mathrm{U}(1)-\mathrm{C}(3)$ & $74.58(11)$ \\
\hline $\mathrm{C}(5)-\mathrm{U}(1)-\mathrm{C}(3)$ & $48.71(15)$ \\
\hline $\mathrm{C}(1)-\mathrm{U}(1)-\mathrm{C}(3)$ & $48.35(15)$ \\
\hline $\mathrm{C}(2)-\mathrm{U}(1)-\mathrm{C}(3)$ & $29.12(16)$ \\
\hline $\mathrm{C}(4)-\mathrm{U}(1)-\mathrm{C}(3)$ & $28.96(17)$ \\
\hline $\mathrm{O}(1)-\mathrm{U}(1)-\mathrm{Cl}(1)$ & $74.50(8)$ \\
\hline $\mathrm{Cl}(2)-\mathrm{U}(1)-\mathrm{Cl}(1)$ & $152.13(4)$ \\
\hline $\mathrm{Cl}(3)-\mathrm{U}(1)-\mathrm{Cl}(1)$ & $88.87(4)$ \\
\hline $\mathrm{C}(5)-\mathrm{U}(1)-\mathrm{Cl}(1)$ & $116.47(12)$ \\
\hline $\mathrm{C}(1)-\mathrm{U}(1)-\mathrm{Cl}(1)$ & $86.91(11)$ \\
\hline $\mathrm{C}(2)-\mathrm{U}(1)-\mathrm{Cl}(1)$ & $80.18(11)$ \\
\hline $\mathrm{C}(4)-\mathrm{U}(1)-\mathrm{Cl}(1)$ & $128.47(11)$ \\
\hline $\mathrm{C}(3)-\mathrm{U}(1)-\mathrm{Cl}(1)$ & $104.07(13)$ \\
\hline $\mathrm{O}(1)-\mathrm{U}(1)-\mathrm{Cl}(1) \# 1$ & $72.46(8)$ \\
\hline $\mathrm{Cl}(2)-\mathrm{U}(1)-\mathrm{Cl}(1) \# 1$ & $81.12(4)$ \\
\hline $\mathrm{Cl}(3)-\mathrm{U}(1)-\mathrm{Cl}(1) \# 1$ & $87.10(4)$ \\
\hline $\mathrm{C}(5)-\mathrm{U}(1)-\mathrm{Cl}(1) \# 1$ & 149.91(11) \\
\hline $\mathrm{C}(1)-\mathrm{U}(1)-\mathrm{Cl}(1) \# 1$ & $145.69(10)$ \\
\hline
\end{tabular}




\begin{tabular}{|c|c|}
\hline $\mathrm{C}(2)-\mathrm{U}(1)-\mathrm{Cl}(1) \# 1$ & $151.14(11)$ \\
\hline $\mathrm{C}(4)-\mathrm{U}(1)-\mathrm{Cl}(1) \# 1$ & $160.46(11)$ \\
\hline $\mathrm{C}(3)-\mathrm{U}(1)-\mathrm{Cl}(1) \# 1$ & $161.26(11)$ \\
\hline $\mathrm{Cl}(1)-\mathrm{U}(1)-\mathrm{Cl}(1) \# 1$ & $71.04(4)$ \\
\hline $\mathrm{O}(1)-\mathrm{U}(1)-\mathrm{U}(1) \# 1$ & $30.32(10)$ \\
\hline $\mathrm{Cl}(2)-\mathrm{U}(1)-\mathrm{U}(1) \# 1$ & $108.15(3)$ \\
\hline $\mathrm{Cl}(3)-\mathrm{U}(1)-\mathrm{U}(1) \# 1$ & $126.66(4)$ \\
\hline $\mathrm{C}(5)-\mathrm{U}(1)-\mathrm{U}(1) \# 1$ & $109.63(12)$ \\
\hline $\mathrm{C}(1)-\mathrm{U}(1)-\mathrm{U}(1) \# 1$ & $95.93(10)$ \\
\hline $\mathrm{C}(2)-\mathrm{U}(1)-\mathrm{U}(1) \# 1$ & $112.43(12)$ \\
\hline $\mathrm{C}(4)-\mathrm{U}(1)-\mathrm{U}(1) \# 1$ & $139.67(12)$ \\
\hline $\mathrm{C}(3)-\mathrm{U}(1)-\mathrm{U}(1) \# 1$ & $141.29(12)$ \\
\hline $\mathrm{Cl}(1)-\mathrm{U}(1)-\mathrm{U}(1) \# 1$ & $52.02(2)$ \\
\hline $\mathrm{Cl}(1) \# 1-\mathrm{U}(1)-\mathrm{U}(1) \# 1$ & $49.80(2)$ \\
\hline $\mathrm{U}(1)-\mathrm{Cl}(1)-\mathrm{U}(1) \# 1$ & $78.18(3)$ \\
\hline $\mathrm{U}(1)-\mathrm{O}(1)-\mathrm{U}(1) \# 1$ & $119.4(2)$ \\
\hline$C(2)-C(1)-C(5)$ & $108.4(4)$ \\
\hline$C(2)-C(1)-C(6)$ & $126.3(5)$ \\
\hline $\mathrm{C}(5)-\mathrm{C}(1)-\mathrm{C}(6)$ & $125.2(5)$ \\
\hline $\mathrm{C}(2)-\mathrm{C}(1)-\mathrm{U}(1)$ & $76.9(3)$ \\
\hline $\mathrm{C}(5)-\mathrm{C}(1)-\mathrm{U}(1)$ & $74.7(3)$ \\
\hline $\mathrm{C}(6)-\mathrm{C}(1)-\mathrm{U}(1)$ & 118.1(3) \\
\hline $\mathrm{C}(1)-\mathrm{C}(2)-\mathrm{C}(3)$ & $108.4(5)$ \\
\hline $\mathrm{C}(1)-\mathrm{C}(2)-\mathrm{C}(7)$ & $125.6(6)$ \\
\hline $\mathrm{C}(3)-\mathrm{C}(2)-\mathrm{C}(7)$ & $125.8(6)$ \\
\hline $\mathrm{C}(1)-\mathrm{C}(2)-\mathrm{U}(1)$ & $73.7(3)$ \\
\hline $\mathrm{C}(3)-\mathrm{C}(2)-\mathrm{U}(1)$ & $77.0(3)$ \\
\hline $\mathrm{C}(7)-\mathrm{C}(2)-\mathrm{U}(1)$ & $120.1(3)$ \\
\hline $\mathrm{C}(4)-\mathrm{C}(3)-\mathrm{C}(2)$ & $108.3(5)$ \\
\hline $\mathrm{C}(4)-\mathrm{C}(3)-\mathrm{C}(8)$ & $125.7(6)$ \\
\hline $\mathrm{C}(2)-\mathrm{C}(3)-\mathrm{C}(8)$ & $125.5(6)$ \\
\hline $\mathrm{C}(4)-\mathrm{C}(3)-\mathrm{U}(1)$ & 74.3(3) \\
\hline $\mathrm{C}(2)-\mathrm{C}(3)-\mathrm{U}(1)$ & $73.9(3)$ \\
\hline $\mathrm{C}(8)-\mathrm{C}(3)-\mathrm{U}(1)$ & $124.3(4)$ \\
\hline$C(3)-C(4)-C(5)$ & $107.8(4)$ \\
\hline$C(3)-C(4)-C(9)$ & $125.0(6)$ \\
\hline
\end{tabular}




\begin{tabular}{|c|c|}
\hline $\mathrm{C}(5)-\mathrm{C}(4)-\mathrm{C}(9)$ & $127.0(6)$ \\
\hline $\mathrm{C}(3)-\mathrm{C}(4)-\mathrm{U}(1)$ & $76.8(3)$ \\
\hline $\mathrm{C}(5)-\mathrm{C}(4)-\mathrm{U}(1)$ & $72.8(3)$ \\
\hline $\mathrm{C}(9)-\mathrm{C}(4)-\mathrm{U}(1)$ & $119.4(4)$ \\
\hline $\mathrm{C}(1)-\mathrm{C}(5)-\mathrm{C}(4)$ & $107.1(4)$ \\
\hline$C(1)-C(5)-C(10)$ & $127.4(6)$ \\
\hline$C(4)-C(5)-C(10)$ & $125.5(6)$ \\
\hline $\mathrm{C}(1)-\mathrm{C}(5)-\mathrm{U}(1)$ & $75.3(3)$ \\
\hline $\mathrm{C}(4)-\mathrm{C}(5)-\mathrm{U}(1)$ & $77.1(3)$ \\
\hline$C(10)-C(5)-U(1)$ & $114.3(3)$ \\
\hline $\mathrm{C}(19)-\mathrm{N}(1)-\mathrm{C}(23)$ & $106.6(5)$ \\
\hline $\mathrm{C}(19)-\mathrm{N}(1)-\mathrm{C}(15)$ & $116.9(5)$ \\
\hline $\mathrm{C}(23)-\mathrm{N}(1)-\mathrm{C}(15)$ & $108.6(3)$ \\
\hline $\mathrm{C}(19)-\mathrm{N}(1)-\mathrm{C}(11)$ & $104.5(5)$ \\
\hline $\mathrm{C}(23)-\mathrm{N}(1)-\mathrm{C}(11)$ & $111.5(4)$ \\
\hline $\mathrm{C}(15)-\mathrm{N}(1)-\mathrm{C}(11)$ & $108.8(3)$ \\
\hline $\mathrm{C}(23)-\mathrm{N}(1)-\mathrm{C}(19 \mathrm{~B})$ & $111.7(6)$ \\
\hline $\mathrm{C}(15)-\mathrm{N}(1)-\mathrm{C}(19 \mathrm{~B})$ & $102.0(7)$ \\
\hline $\mathrm{C}(11)-\mathrm{N}(1)-\mathrm{C}(19 \mathrm{~B})$ & $113.8(6)$ \\
\hline $\mathrm{C}(12)-\mathrm{C}(11)-\mathrm{N}(1)$ & $115.0(4)$ \\
\hline $\mathrm{C}(11)-\mathrm{C}(12)-\mathrm{C}(13)$ & $109.6(4)$ \\
\hline$C(14)-C(13)-C(12)$ & $112.4(5)$ \\
\hline $\mathrm{N}(1)-\mathrm{C}(15)-\mathrm{C}(16)$ & $116.0(4)$ \\
\hline $\mathrm{C}(15)-\mathrm{C}(16)-\mathrm{C}(17)$ & $109.8(4)$ \\
\hline $\mathrm{C}(18)-\mathrm{C}(17)-\mathrm{C}(16)$ & $114.1(5)$ \\
\hline $\mathrm{N}(1)-\mathrm{C}(19)-\mathrm{C}(20)$ & $114.5(7)$ \\
\hline $\mathrm{C}(21)-\mathrm{C}(20)-\mathrm{C}(19)$ & $110.8(8)$ \\
\hline $\mathrm{C}(22)-\mathrm{C}(21)-\mathrm{C}(20)$ & $112.9(8)$ \\
\hline $\mathrm{C}(20 \mathrm{~B})-\mathrm{C}(19 \mathrm{~B})-\mathrm{N}(1)$ & $119.8(11)$ \\
\hline$C(19 B)-C(20 B)-C(21 B)$ & $112.4(12)$ \\
\hline $\mathrm{C}(22 \mathrm{~B})-\mathrm{C}(21 \mathrm{~B})-\mathrm{C}(20 \mathrm{~B})$ & $112.0(13)$ \\
\hline $\mathrm{C}(24)-\mathrm{C}(23)-\mathrm{N}(1)$ & $116.8(4)$ \\
\hline $\mathrm{C}(25)-\mathrm{C}(24)-\mathrm{C}(23)$ & $110.1(4)$ \\
\hline$C(24)-C(25)-C(26)$ & $114.0(5)$ \\
\hline
\end{tabular}




\section{References}

1. APEX2 Version 2012.4-0, Bruker AXS, Inc.; Madison, WI 2012.

2. SAINT Version 7.68a, Bruker AXS, Inc.; Madison, WI 2009.

3. Sheldrick, G. M. SADABS, Version 2008/1, Bruker AXS, Inc.; Madison, WI 2008.

4. Sheldrick, G. M. SHELXTL, Version 2008/4, Bruker AXS, Inc.; Madison, WI 2008.

5. Sheldrick, G. M. SHELXL 2013/2, 2013

6. International Tables for X-Ray Crystallography 1992, Vol. C., Dordrecht: Kluwer Academic Publishers.

7. APEX2 Version 2011.4-1, Bruker AXS, Inc.; Madison, WI 2011.

8. Sheldrick, G. M. SHELXTL, Version 2013/3, Bruker AXS, Inc.; Madison, WI 2013. 